\title{
Efeito da tração no sinal de inversão temporal de ondas acústicas guiadas
}

\author{
Alan Conci Kubrusly
}

Dissertação (Mestrado em Engenharia Elétrica). Pontifícia Universidade Católica do Rio de Janeiro. Rio de Janeiro, 2012. 


\section{Alan Conci Kubrusly}

\section{Efeito da tração no sinal de inversão temporal de ondas acústicas guiadas}

Dissertação apresentada como requisito parcial para obtenção do grau de Mestre pelo Programa de Pós-graduação em Engenharia Elétrica do Departamento de Engenharia Elétrica da PUC-Rio

Orientador: Prof. Jean Pierre von der Weid 


\section{Alan Conci Kubrusly}

\section{Efeito da tração no sinal de inversão temporal de ondas acústicas guiadas}

Dissertação de Mestrado apresentada como requisito parcial para obtenção do grau de Mestre pelo Programa de Pósgraduação em Engenharia Elétrica do Departamento de Engenharia Elétrica do Centro Técnico Científico da PUC-Rio. Aprovada pela comissão examinadora abaixo assinada.

Prof. Jean Pierre von der Weid Centro de Estudos em Telecomunicações - PUC-Rio

Prof. Arthur Martins Barbosa Braga Departamento de Engenharia Mecânica - PUC-Rio

Prof. Nicolás Leonardo Pérez Alvarez Universidad de La Republica - Uruguai

Prof. Marcelo Roberto Baptista Pereira Luis Jimenez Centro de Estudos em Telecomunicações - PUC-Rio

Prof. José Eugenio Leal Coordenador Setorial do Centro Técnico Científico - PUC-Rio 
Todos os direitos reservados. Proibida a reprodução total ou parcial do trabalho sem autorização da universidade, do autor e do orientador.

\section{Alan Conci Kubrusly}

Kubrusly, Alan Conci

Efeito da tração no sinal de inversão temporal de ondas acústicas guiadas / Alan Conci Kubrusly; orientador: Jean Pierre von der Weid. - Rio de Janeiro : PUC-Rio, Departamento de Engenharia Elétrica, 2012.

v., प1] f: il. ; $29,7 \mathrm{~cm}$

1. Dissertação (Mestrado em Engenharia Elétrica) - Pontifícia Universidade Católica do Rio de Janeiro, Departamento de Engenharia Elétrica.

Inclui referências bibliográficas.

1. Engenharia Elétrica - Tese. 2. Inversão Temporal. 3. Ondas Guiadas. 4. Influência da Tensão Mecânica. I. von der Weid, Jean Pierre. II. Pontifícia Universidade Católica do Rio de Janeiro. Departamento de Engenharia Elétrica. III. Título. 


\section{Agradecimentos}

Esse trabalho não teria sido possível sem a orientação do professor Jean Pierre von der Weid, conselhos e sugestões de Arthur Braga, Julio Cezar Adamowski, Marcelo Roberto Jimenez, Miguel Freitas, Nicolás Pérez e Nilson Souza. Além da ajuda direta dos colegas, Adriana Nazário Raphael, Caíque Albuquerque da Silva, David Henrique de Lima, Edgard Vieira da Silva, Felipe dos Santos Bezerra, Guttemberg Coelho, José Eugênio Marins, Luiz Carlos Domingos, Rafael Honório, Ramon Bernardo, Rodrigo de Oliveira e Sérgio Paes.

À minha mulher, Anna, por seus diversos olhares. 


\section{Resumo}

Kubrusly, Alan Conci; von der Weid, Jean Pierre. Efeito da tração no sinal de inversão temporal de ondas acústicas guiadas. Rio de Janeiro, 2012. Ш - Departamento de Engenharia Elétrica, Pontifícia Universidade Católica do Rio de Janeiro.

A inversão temporal é um método bem conhecido de se obter focalização de ondas. Quando usado em ondas dispersivas, como ondas acústicas de Lamb, a técnica compensa a dispersão de cada modo fornecendo um sinal focalizado no tempo. O operador de inversão temporal em um meio fechado é dependente da geometria e características físicas do meio. A capacidade de focalização da técnica pode ser usada para detectar variações na condição de contorno de meio. A variação da função de transferência do meio, especialmente na fase de cada componente em freqüência, causa perda da qualidade de focalização, degradando o sinal de inversão temporal recebido. Nesse trabalho propõe-se o uso da técnica da inversão temporal para detectar a variação na tração externa aplicada à uma placa metálica. Foram feitos experimentos com dois transdutores de ultra-som espaçados sobre uma placa de alumínio utilizados no modo transmissão-recepção a fim de excitar ondas de Lamb por um pulso de banda larga. Uma tração londitudinal é aplicada à placa e o sinal de inversão temporal é observado. Como o sinal recebido na condição de tração inicial possui forma bem definida, a análise da sensibilidade é facilitada. O sinal transmitido é filtrado a fim de fornecer um sinal de inversão temporal com espectro mais amplo melhorando a qualidade de foco e sensibilidade à tração.

A sensibilidade à tração é comprovada e medida experimentalmente. A fase do espectro do sinal observada indica a variação no percurso da onda guiada devido ao tracionamento imposto. O valor e instante de pico sofrem variação em função da variação de tração. Mostra-se que a sensibilidade do sinal de inversão temporal pode ser usado como um indicador de variação do estado de tensão do meio.

\section{Palavras-chave}

Inversão Temporal. Ondas Guiadas. Influência da Tensão Mecânica. 
Kubrusly, Alan Conci; von der Weid, Jean Pierre. Traction effect on the time reversal signal of acoustic guided waves. Rio de Janeiro, 2012. ㅁ. p. MsC Thesis — Departament of Telecommunications, Pontifícia Universidade Católica do Rio de Janeiro.

The time reversal process is a well-known method of obtaining focused waves. When used at Lamb guided acoustic waves it permits compensating the dispersion of each propagation mode providing a time recompressed focused signal. The time reversal operator in a closed medium is very dependent on the geometry and physical characteristics of the medium. The good focusing capability of the process can be used to detect changes in medium boundary conditions. The mismatch of the impulse response transfer function of the medium, especially in the phase of its frequency components, causes loss in the focusing quality, and so degrades the received signal shape. In this work it is proposed the use of the time reversal technique to detect the variation on the external applied traction in a plate structure.

Experiments were performed in transmission-reception mode for two fixed ultrasonic transducers spaced in an aluminum plate where Lamb waves have been excited by a wideband pulse. A variable longitudinal traction is applied to the plate and the received time reversal signal is observed. As the received signal with no traction difference has a well-defined shape, the analysis of the process traction sensitivity is simplified. Digital filtering in the frequency domain was used at the transmitted time reversed signal in order to receive a broader spectrum signal, enhancing the process focus quality and stress sensitivity.

The external traction sensitivity was verified. The observed phase spectrum variation indicated a wave path change, caused by the deformation of the plate. The peak value has been decreased for the applied traction and returned to it maximum value as the traction difference was removed. Also, the group delay has changed during the traction process. A model for the peak position has been proposed and compared with the measured experiments. The results show that the high sensibility of the time reversal signal technique due to changes of the geometry of the closed medium can be used as strain variation pointer.

\section{Keywords}

Time Reversal. Guided Waves. Stress Influence. 


\section{Sumário}

Sumário das notaçōes 12

1 Introduçad 13

\begin{tabular}{lll}
\hline 1.1 & Organização da Dissertação & 15
\end{tabular}

\begin{tabular}{ll}
\hline Ondas Gllladas em Placas & 17
\end{tabular}

\begin{tabular}{lll}
\hline 2.1 & Equação de movimento para ondas elástıcas & 18
\end{tabular}

2.2 Ondas elásticas em placas de faces paralelas 21

2.2 .1 Ondas primárias e secundárias vertıcaıs 24

D2) Ondas secundárias horizontars 29

2.3 Modos Propagantes em Placas em Meios Anisotrópicos 33

2.3 .1 Equação de Dispersão 33

2.3.2 Rotına Computacional para Obtenção da Curva de Dispersãa 36

B Acustoelasticidade 39

BI lensor de Flasticidade em Mein sob Lstado de lensao Inicial 40

3.2 Curva de Dispersão para ondas Guladas em Placas para Meio sob Detormação Inıcial 43

$4 \quad$ Inversão lemporal $\quad 45$

4.1 Etapas do Processo de Inversão lemporal 48

4.2 Inversão Temporal de Ondas Guladas em Placas 49

4.3 Análıse do Processo de Inversão lemporal no Domínı de trequêncıa 50

4.3 .1 Focalização lemporal 54

4.3 .2 Focalızação Espacial 58

4.3 .3 Recuperaçáo do Sınal Inıcial 58

434 Filtro lnverso 59

4.4 Varıação da Função de Transterêncla do Meid 61

4.4.1 Intluência da Traçäo Aplicada 63

4.4.1.1 Modelo Proposto para Fase do Sinal de Inversão Temporal dada a Variaçao da Traça Aplicada 64

5 Parte Experimental $\quad 70$

5.1 Experımento Inıcial: Excitaçäo de Amplo Espectro 73

5.1.1 Influêncıa da Iraçáo - traçáo Inıcıal nula 77

5.II Valor de Pica 78

5.12 lnstante de Pica 79

5.1.2 Intluência da Traçäo - sistema Inıcialmente tracionado 80

5I T Valor de Picd 81

$5.2 \%$ Instantede Pica 82

5.2 Análıse da Funçäo de Transterêncla Frente à Varıação da Tração 83

5.3 Equalização de Faixas de Frequência 86

5.3.1 Influência da Tração - tração inıcial nula 89 


\begin{tabular}{|c|c|}
\hline \multicolumn{2}{|l|}{ Valor de Pico } \\
\hline 5.3 .12 Instante de Pico & 90 \\
\hline 5.3.2 Influência da Iração - sistema inıcialmente tracionado & 91 \\
\hline 5.321 Valor de Pica & 1 \\
\hline $5: 322$ Instante de Pica & 92 \\
\hline 24 Filtro Inverso & 93 \\
\hline 5.4.1 Influência da Iração - tração inıcial nula & \\
\hline 541 I Valor de Pica & 96 \\
\hline 5.4 .12 Instante de Pico & 97 \\
\hline 5.4.2 Influência da Iração - sistema inıcialmente tracionado & \\
\hline 5421 Valor de Pica & \\
\hline 5422 Instante de Pica & 99 \\
\hline 0.5 Resumo dos Resultados Experimentais & 100 \\
\hline 5 Conclusöes & 1 \\
\hline eferêncıas Bibliográtıcas & 1 \\
\hline
\end{tabular}




\section{Lista de figuras}

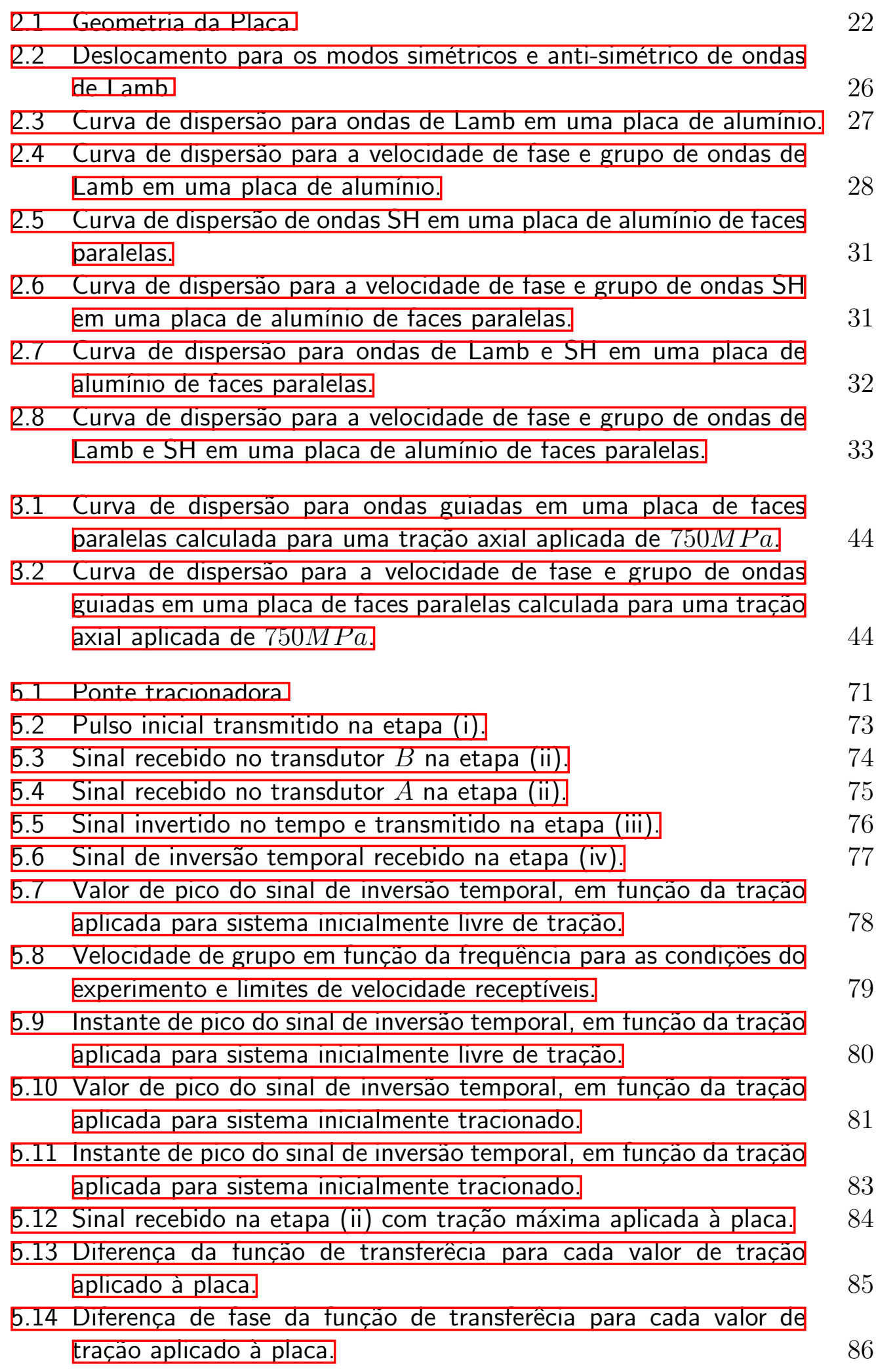


5.15 Sinal recebido na etapa (ii) e filtrado com filtro equalizador de trequências

5.16 Sinal de inversão temporal recebido na etapa (iv) usando filtro equalizador.

5.17 Valor de pico do sinal de inversäo temporal utilizando o filtro equalizador em função da tração para sistema inıcialmente livre de tração.

5.18 Instante de pico do sinal de inversäo temporal utilizando o filtro equalızador em funçáo da traçao para sıstema inıcialmente livre de traçao.

5.19 Valor de pico do sinal de inversäo temporal utilizando o filtro equalızador em função da tração para sistema inıcialmente tracionado. 92

5.20 Instante de pico do sinal de inversäo temporal utilizando o filtro equalizador em função da tração para sistema inicialmente tracionado. 93

5.21 Sinal recebido na etapa (ii) e filtrado pelo filtro inverso. 94

5.22 Sinal de inversão temporal recebido na etapa (iv) usando o filtro inverso

5.23 Detalhe do sinal de inversäo temporal recebido usando o filtro inverso para o instante de tocalização temporal.

5.24 Sinal de inversão temporal recebido utilizando filtro inverso para a condiçáo de traçáo máxıma aplıcada.

96

5.25 Valor de pico do sinal de inversäo temporal utilizando o filtro inverso, em função da tração aplicada para sistema inicialmente Ivre de tração.

5.26 Instante de pico do sinal de inversão temporal utilizando o filtro inverso, em função da tração aplicada para sistema inıcialmente IVre de traçao.

5.27 Valor de pico do sinal de inversão temporal utilizando o filtro nverso, em função da tração aplicada para sistema inıcialmente tracionado

5.28 Instante de pico do sinal de inversäo temporal utilizando o filtro nverso, em função da tração aplicada para sistema inıcialmente 


\section{Lista de tabelas}

D] Parämetros elásticos do aluminio 27

B] Constantes de terceira ordem do aluminio 43

5.1 Caracteristıcas da tocalızaçao temporal em cada experièncıa. $\quad 100$

5.2 Valores da sensibilidade para tração crescente. 101

5.3 Valores da sensibilidade para tração decrescente. 102

5.4 Erro do modelo proposto em tração crescente. 102

5.5 Erro do modelo proposto em tração decrescente. 102 


\section{Sumário das notações}

E Módulo de Young. Unidade: $\mathrm{Pa}$

$\mu$ Módulo de cisalhamento. Unidade: $\mathrm{Pa}$

$\lambda$ Constante de Lamé. Unidade: Pa

$\nu$ Coeficiente de Poisson. Unidade: adimensional

$l, m, n$ Constantes elásticas de terceira ordem (Murnaghan). Unid: Pa

$\rho$ Densidade de massa. Unidade: $\mathrm{kg} / \mathrm{m}^{3}$

$\varepsilon$ Deformação (strain) infinitesimal (tensor). Unidade: adimensional

$\boldsymbol{\sigma}$ Tensão mecânica (tensor). Unidade: Pa

$\boldsymbol{u}$ Deslocamento infinitesimal (vetor). Unidade: $\mathrm{m}$

$\boldsymbol{C}$ Tensor de elasticidade (tensor). Unidade: $\mathrm{Pa}$

$x_{1}, x_{2}, x_{2}$ Coordenadas espaciais do sistema cartesiano. Unidade: $\mathrm{m}$

$t$ Tempo. Unidade: $\mathrm{s}$

$f$ Frequência. Unidade: $\mathrm{Hz}$

$\omega$ Frequência angular. Unidade: $\mathrm{rad} / \mathrm{s}$

$\lambda$ Comprimento de onda. Unidade: $\mathrm{m}$

$k$ Número de onda. Unidade: $\mathrm{m}^{-1}$

$h$ Semi-espessura da placa. Unidade: $\mathrm{m}$

$c$ Velocidade de fase. Unidade: $\mathrm{m} / \mathrm{s}$

$c_{g}$ Velocidade de grupo. Unidade: $\mathrm{m} / \mathrm{s}$

$c_{L}$ Velocidade de onda de corpo longitudinal. Unidade: $\mathrm{m} / \mathrm{s}$

$c_{T}$ Velocidade de onda de corpo transversal. Unidade: $\mathrm{m} / \mathrm{s}$

$T$ Tamanho da janela temporal de recepção. Unidade: $\mathrm{s}$

$t_{0}$ Tempo inicial de recepção. Unidade: $\mathrm{s}$

$\tau$ Tração longitudinal. Unidade: $\mathrm{Pa}$

$\varepsilon$ Deformação (strain) principal. Unidade: adimensional

j Unidade dos números imaginários. Unidade: adimensional 


\section{Introdução}

Ultra-som é o termo utilizado para designar uma onda mecânica cuja frequência é maior que a faixa audível, ou seja maior que $20 \mathrm{kHz}$. O uso normal em ensaios não destrutivos de ultra-som é nas frequências entre $500 \mathrm{kHz}$ e 12MHz. Para transmitir ou receber um campo acústico de ultra-som é utilizado tipicamente um transdutor feitocom cerâmica piezoelétrica que se deforma sob tensão elétrica sendo capaz de converter um sinal elétrico em uma onda acústica e vice-versa. Existem, contudo ooutros utros métodos de transmissão de ondas acú,sticas, por efeitos térmicos, geralmente com excitação, laser, por processos eletromagnéticos e magnetostrictivos [ா].

Uma característica fundamental das ondas mecânicas é a necessidade de um meio físico para que haja propagação. Um campo acústico obedece a todos os princípios de ondas propagantes, tais como reflexão, refração e difração. Ao encontrar um obstáculo parte da onda é refletida e parte transmitida, dependendo do coeficiente de reflexão e transmissão que é função das característica acústicas do meio e do obstáculo e do ângulo de incidência.

O ensaio por ultra-som é uma das formas de avaliação não destrutiva mais importantes, sendo amplamente utilizado na inspeção de materiais com a finalidade de detectar, localizar e avaliar descontinuidades internas, eiciais, medir espessuras e detectar corrosão. É também possível o seu uso para determinação de propriedades físicas do meio tais os com oso valores das casnstantes elásticas.

Utiliza-se o ultra-som em ensaios não destrutivos fundamentalmente com um ou dois transdutores. O método chamado de Pulso-Eco utiliza apenas um transdutor, no qual um pulso elétrico de tensão elevada o excita, fazendo com que uma frente de onda acústica seja transmitida ao meio e se propague até encontrar um obstáculo refletor. Parte dessa onda é, então, refletida e, dependendo da sua direção de propagação, atinge o transdutor sendo detectada. Quando as ondas refletidas em um obstáculo, como um defeito, possuem ângulos não necessariamente retos é necessária a presença de um outro 
transdutor adequadamente posicionado para permitir a recepção da onda. Esse é o princípio do método pitch-catch. O método por transparência também utiliza dois transdutores, contudo posicionados diametralmente opostos em uma peça. Nesse caso a presença de um defeito faz com que não seja recebido sinal no receptor.

Transdutores de ultra-som podem ter um único elemento emissor e receptor emissor e receptor ou vários. O Phased Array é um aparelho de ultrasom capaz de controlar de forma independente os diversos elementos em um mesmo transdutor. Excitando cada elemento com defasagens específicas podese fazer com que a frente de onda acústica por ele gerada assuma diversas formas, devido a interferência dos campos produzidos individualmente em cada elemento. Desse modo, pode-se gerar feixes angulares, varreduras e focalizações pontuais [《] .

Uma revisão dos princípioss do ultra-som e de seu uso em ensaios não destrutivos podem ser encontrados no livro de Santin [ா].

Ondas de Lamb são ondas guiadas propagantes no interior de uma placa de faces paralelas devido a reflexões múltiplas nas superfícies. Após algum percurso de propagação a superposição dos modos presentes faz com que se formemm pacotes de onda, que são os chamados modos de ondas guiadas. Existem duas formas básica de ondas de Lamb, as simétricas e anti-simétricas, cada qual dividida em diversos modos cujas velocidade de propagação variam para cada frequência, ou seja, possuem comportamento dispersivo [3] .

A inversão temporal é uma técnica conhecida de focalização de ondas propagantes, amplamente utilizada em ondas acústicas desde os anos 90 [ [ $]$ ]. O princípio básico dessa técnica é retransmitir o sinal recebido, contudo, invertendo-o no tempo. Quando usado em sistema multielementos essa técnica fornece um conjunto de sinais capazes de focalizar de maneira ótima, no sentido de maximizar a energia, para posição da fonte transmissora inicial [ []] . Todavia, a aplicação desse técnica não é possível em aparelhos de ultra-som convencionais, sobretisdoa impossi devidobilidade de transmissão de um sinal arbitrário. Esse é um detalhe fundamental da técnica, que requ,er a transmissão do sinal recebido, o qual poo qual a princípio, assumir qualquer forma.

Quando aplicada em ondas guiadas, a inversão temporaltemporal compensa a dispersão dos diversos modos propagantes, aplicando a cada modo o retardo preciso para fazer com que todos convirjam em sincronia na posição de focalização [G], sendo também eficaz para o uso em sistemas com apenas um elemento. A inversão temporal em meios limitados, tais como placas, é bastante dependente da geometria e características físicas do meio [ [ $]$ ] 
Propõe-se o uso da boa capacidade de focalização da técnica de inversão temporal em ondas guiadas para a detecção de mudança nas condições de contorno do meio. Variações da função de transferência do meio, sobretudo na fase de cada componente em frequência, causam perda da qualidade de focalização, degradando o sinal de inversão temporal recebido.

O objetivo desse trabalho é estudar a sensibilidade do sinal de inversão temporal de ondas guiadas em placa de faces paralelas, dada a variação do estado de tensão a que essa está submetida, mais precisamente a variação da tração longitudinal.

É transmitido inicialmente um sinal de amplo espectro, em uma extremidade da placa, e na outra extremidade é recebida a resposta a essa excitação, a qual é registrada, invertida e retransmitida. O sinal de inversão temporal é então obtido.

Traciona-se a placa e para cada valor de tração observa-se o sinal de inversão temporal, dada a transmissão do primeiro sinal recebido e invertido. Devido compensação da dispersão de cada modo presente o sinal de inversão temporal é focalizado e possui forma bem definida, o que facilita a análise da sensibilidade do processo à tração.

\section{1 \\ Organização da Dissertação}

A presente dissertação é estruturada de modo a apresentar inicialmente a base teórica necessária à compreesão do problema analisado e dos experimentos e cálculos computacionais executados, sendo organizada da seguinte maneira:

- O capítulo $\mathbb{\text { ⿴囗十 }}$ introduz o problema de estudo do presente trabalho.

- O capítulo $\boldsymbol{\nabla}$ faz uma revisão da propagação de ondas mecânicas em meios isotrópicos e, sobretudo, de ondas guiadas em placas de faces paralelas. No final do mesmo é apresentado o procedimento computacional para resolução das equações de dispersão de ondas guiadas, tanto para meios isotrópicos quanto anisotrópicos.

- O capítulo \ traz uma sucinta introdução da acustoelasticidade visando a expressão do tensor de elasticidade de um meio isotrópico sujeito a um estado de tensão inicial. Esse é necessário para a obtenção das curvas de dispersão de ondas guiadas em uma placa sujeita a uma tração longitudinalmente aplicada.

- O capítulo 甘 expõe a teoria da inversão temporal aplicada a ondas acústicas, junto com um breve resumo de seu estado da arte. É analisado 
a teoria da inversão temporal de ondas guiadas no domínio da frequência. A qualidade de focalização fornecida pela técnica é discutida junto com formas de aprimoramento baseado na análise de seu conteúdo em frequência. A sensibilidade do sinal de inversão temporal para ondas guiadas é analisada, e, um modelo para o sinal recebido é proposto. Esse modelo é apresentado em duas versões, elástica e acustoelástica.

- O capítulo $\mathbf{\square}$ traz a parte experimental deste trabalho. Utiliza-se processamento de sinal a fim de aprimorar a qualidade da focalização temporal e sensibilidade à tração. Para cada caso são analisados a sensibilidade do valor e instante de pico do sinal de inversão temporal recebido, em função da variação de tração, tanto crescente quanto decrescente. O instante de pico medido é comparado com aquele obtido pelo o modelo proposto.

- O capítulo $\mathbf{0}$ conclui o presente estudo abordando os resultados encontrados, aplicações e aperfeiçoamentos. 


\section{2}

\section{Ondas Guiadas em Placas}

Ondas de corpo são ondas que se propagam pelo volume do material, cujas dimensões são grandes o suficiente para que as interações com a fronteira não sejam consideradas.

No caso de uma placa de faces paralelas cada vez que uma onda atinge uma das superfícies, essa é refletida e pode ocorrer a conversão entre os modos propagantes. Após algum percurso de propagação a superposição dos modos presentes faz com que se formem pacotes de onda, que são os chamados modos de ondas guiadas.

Do ponto de vista matemático, as ondas guiadas devem atender às mesmas equações de movimento e são governadas pelo mesmo conjunto de equações diferenciais que as ondas de corpo. A diferença entre elas está nas condições de contorno. Ondas guiadas devem satisfazer às condições de contorno impostas pelo problema, enquanto ondas de corpo propagam-se em meios ilimitados.

Existem várias espécies de ondas guiadas. Dentre essas, as chamadas ondas de Lamb, são ondas propagantes em uma placa atendendo a condição de tensão nula nas superfícies. Nessas há infinitos modos propagantes, os quais são determinados através da solução da equação de onda atendendo às condições de contorno. Nesse caso não há solução analítica para as mesma e deve-se dispor de recursos computacionais para resolvê-las.

As ondas de Lamb são ondas propagantes longitudinais e cisalhantes polarizadas transversalmente ao plano da placa que convertem de modo entre si. Existem, contudo, ondas guiadas em placa de faces paralelas onde apenas os modos cisalhantes polarizados paralelamente ao plano da placa estão presentes. Ambas são ondas dispersivas. Uma onda é dita dispersiva se a velocidade de fase é diferente para diferentes frequências, e por consequência, a forma de um pulso, contendo várias componentes de frequência, é deformado a medida que esse se propaga.

Inicia-se o presente capítulo com uma revisão das equações de movimento 
para as ondas elásticas em meios isotrópicos. Em seguida aplica-se as soluções de contorno a fim de obter as solução dos modos propagantes de ondas guiadas em placa de faces paralelas. Há diversos textos que expõem as ondas guiadas e derivam suas equações de dispersão, usa-se como referência neste texto os livros de Rose e Achenbach [3, $\mathbf{3}]$. Salienta-se que esse conteúdo é necessário à compreensão de ondas guiadas em placa e que algumas das expressões são utilizadas no decorrer da dissertação, contudo este se mostra mais detalhado por ter servido como fonte de estudo do próprio autor ajudando-o no aprendizado do mesmo. Encerra-se o capítulo com um procedimento numérico para a obtenção dos modos propagantes em meios anisotrópicos.

\section{1}

\section{Equação de movimento para ondas elásticas}

Da teoria da elasticidade tem-se três equações necessárias a derivação da equação de movimento. A primeira delas é a segunda lei de Newton. A equação $\mathbb{Z}-\mathbf{a}$ representa a mesma em notação diferencial e a equação $\mathbb{L}-\mathbb{E}$ em notação indicial.

$$
\begin{gathered}
\nabla \cdot \boldsymbol{\sigma}+\rho \boldsymbol{f}=\rho \ddot{\boldsymbol{u}} \\
\sigma_{i j, j}+\rho f_{i}=\rho \ddot{u}_{i}
\end{gathered}
$$

Onde, o símbolo $\boldsymbol{\sigma}$ representa o tensor de tensões, $\rho$ a densidade do material, $\boldsymbol{u}$ o vetor de deslocamento e $\boldsymbol{f}$ representa as forças de corpo por unidade de massa aplicadas ao material. Utiliza-se a notação usual de um ponto sobre uma grandeza para representar a derivada parcial em relação à variável tempo, e consequentemente dois pontos representam a derivada segunda em relação ao tempo.

Na notação indicial os índice representam as três coordenadas espaciais, que em um sistema cartesiano são $x_{1}, x_{2}$ e $x_{3}$. Desse modo, grandezas com dois índices são tensores de segunda ordem, com três índices tensores de terceira ordem e assim sucessivamente. Índices após uma vírgula representam derivadas parciais. Na notação indicial é implícito o somatório quando há índices repetidos em relação à coordenada correspondente.

A segunda equação relaciona a deformação com o deslocamento. A deformação, $\varepsilon$, é um tensor de segunda ordem definido pela parte simétrica do gradiente do deslocamento, como mostrado pela equação $\mathbb{Z - \lambda}$ tanto na forma 
diferencial, $\mathbb{L - 2}$, quanto indicial, $\mathbf{L - 2 0}$.

$$
\begin{gathered}
\boldsymbol{\varepsilon}=\frac{1}{2}\left(\nabla \boldsymbol{u}+\nabla \boldsymbol{u}^{T}\right) \\
\varepsilon_{i j}=\frac{1}{2}\left(u_{i, j}+u_{j, i}\right)
\end{gathered}
$$

Onde o gradiente de um vetor, é definido como o gradiente de cada coordenada do mesmo, logo uma matriz, ou um tensor de segunda ordem.

A terceira expressão é a lei de Hooke generalizada que relaciona tensão à deformação através do tensor de elasticidade $\boldsymbol{C}$. Essa pode ser expressa, para pequenas deformações, na forma diferencial, dada pela equação $\mathbb{L - 3 a}$, onde o símbolo : representa o produto interno dos tensores, ou na forma indicial, através da equação ए-3.:

$$
\begin{aligned}
& \boldsymbol{\sigma}=\boldsymbol{C}: \boldsymbol{\varepsilon} \\
& \sigma_{i j}=C_{i j k l} \varepsilon_{k l}
\end{aligned}
$$

Sendo o tensor de elasticidade um tensor de quarta ordem esse pode ter, a priori, $3^{4}=81$ componentes independentes. Contudo considerando-se que o tensor de tensão, $\sigma$, é simétrico e, pela sua definição o tensor de deformação, $\varepsilon$, também. Pode-se concluir que o tensor de elasticidade possui no máximo 21 componentes independentes, apresentando as seguintes simetrias.

$$
\begin{aligned}
& C_{i j k l}=C_{j i k l} \\
& C_{i j k l}=C_{i j l k} \\
& C_{i j k l}=C_{k l i j}
\end{aligned}
$$

Para um material isotrópico o tensor de elasticidade tem apenas duas componentes independentes e é expresso da seguinte forma

$$
C_{i j k l}=\lambda \delta_{i j} \delta_{k l}+\mu\left(\delta_{i k} \delta_{j l}+\delta_{i l} \delta_{j k}\right)
$$

tal que $\lambda$ é a constante de Lamé, $\mu$ o módulo de cisalhamento e $\delta$ é o Delta de Kroenecker definido por

$$
\delta_{i j}= \begin{cases}1, & \text { se } i=j \\ 0, & \text { se } i \neq j .\end{cases}
$$

Aplicando [-. Hooke restrita a um meio isotrópico.

$$
\sigma_{i j}=\lambda \varepsilon_{k k} \delta_{i j}+2 \mu \varepsilon_{i j}
$$


Da equação

$$
\sigma_{i j}=\lambda u_{k, k} \delta_{i j}+\mu\left(u_{i, j}+u_{j, i}\right) \quad .
$$

Derivando a equação $\mathbb{L - \boldsymbol { \Xi }}$ em relação ao índice $j$ obtém-se

$$
\begin{aligned}
\sigma_{i j, j} & =\lambda u_{k, k j} \delta_{i j}+\mu\left(u_{i, j j}+u_{j, i j}\right) \\
\sigma_{i j, j} & =\lambda u_{k, k i}+\mu\left(u_{i, j j}+u_{j, j i}\right) .
\end{aligned}
$$

Trocando o somatório em $k$ por um somatório no índice $j$, chega-se a expressão.

$$
\sigma_{i j, j}=\mu u_{i, j j}+(\lambda+\mu) u_{j, j i} .
$$

Aplicando a equação $\mathbb{Z} \mathbb{\text { à }}$ equação $\mathbb{Z} \mathbb{Z}$ chega-se a equação que dita o comportamento do vetor de deslocamento, conhecida como equação de Navier. A equação $\mathbb{L}$ $\nabla^{2} \boldsymbol{u}$ representa o laplaciano de cada componente do vetor deslocamento. A equação $2-1$ tb apresenta a equação de Navier em notação indicial.

$$
\begin{aligned}
\mu \nabla^{2} \boldsymbol{u}+(\lambda+\mu) \nabla \nabla \cdot \boldsymbol{u}+\rho \boldsymbol{f} & =\rho \ddot{\boldsymbol{u}} \\
\mu u_{i, j j}+(\lambda+\mu) u_{j, j i}+\rho f_{i} & =\rho \ddot{u}_{i}
\end{aligned}
$$

Para se obter uma expressão mais simples da equação de movimento é conveniente lançar mão da decomposição de Helmhotz onde o vetor de deslocamento é decomposto em uma componente irrotacional (rotacional nulo) e uma componente solenoidal (divergente nulo). Define-se assim o potencial escalar $\phi$ e o potencial vetorial $\boldsymbol{\psi}$, tal que $\nabla \cdot \boldsymbol{\psi}=0$. Escreve-se então o vetor deslocamento da seguinte forma

$$
\boldsymbol{u}=\nabla \phi+\nabla \times \boldsymbol{\psi}
$$

O mesmo pode ser feito com a força de corpo aplicada, onde a componente irrotacional e solenoidal são $f_{\phi}$ e $\boldsymbol{f}_{\psi}$, respectivamente,

$$
\boldsymbol{f}=\nabla f_{\phi}+\nabla \times \boldsymbol{f}_{\psi}
$$

A fim de obter a equação de onda, substitui-se as equações $2-1$ e $2-1.3$ na equação de Navier, $2-1$ a

$$
\begin{array}{r}
\mu \nabla^{2}(\nabla \phi+\nabla \times \boldsymbol{\psi})+(\lambda+\mu) \nabla \nabla \cdot(\nabla \phi+\nabla \times \boldsymbol{\psi})+ \\
\rho\left(\nabla f_{\phi}+\nabla \times \boldsymbol{f}_{\psi}\right)=\rho(\nabla \ddot{\phi}+\nabla \times \ddot{\boldsymbol{\psi}})
\end{array}
$$

Reagrupando os termos contendo $\phi$ e $\rho$ obtém-se a expressão

$$
\nabla\left[(\lambda+2 \mu) \nabla^{2} \phi+\rho f_{\phi}-\rho \ddot{\phi}\right]+\nabla \times\left[\mu \nabla^{2} \boldsymbol{\psi}++\rho \boldsymbol{f}_{\psi}-\rho \ddot{\boldsymbol{\psi}}\right]=0 .
$$


A solução da mesma é obtida quando ambos os termos são nulos. O que implica nas seguintes equações de onda.

$$
\begin{gathered}
\nabla^{2} \phi+\frac{1}{c_{L}^{2}} f_{\phi}=\frac{1}{c_{L}^{2}} \ddot{\phi} \\
\nabla^{2} \boldsymbol{\psi}+\frac{1}{c_{T}^{2}} \boldsymbol{f}_{\psi}=\frac{1}{c_{T}^{2}} \ddot{\boldsymbol{\psi}}
\end{gathered}
$$

tal que $c_{L}$ e $c_{T}$ são as velocidades de onda primária, ou longitudinal, e secundária, ou transversal, respectivamente. Essas são definidas pela equação 四

$$
\begin{aligned}
c_{L} & =\sqrt{\frac{\lambda+2 \mu}{\rho}} \\
c_{T} & =\sqrt{\frac{\mu}{\rho}}
\end{aligned}
$$

Pode-se escrever as equações de onda na notação indicial, como mostrado a baixo.

$$
\begin{aligned}
\phi_{, j j}+\frac{1}{c_{L}^{2}} f_{\phi} & =\frac{1}{c_{L}^{2}} \ddot{\phi} \\
\psi_{i, j j}+\frac{1}{c_{T}^{2}} f_{\psi i} & =\frac{1}{c_{T}^{2}} \ddot{\psi}_{i} .
\end{aligned}
$$

É importante salientar que o desenvolvimento acima só é válido para ondas propagantes em meios isotrópicos. As equações de movimento acima devem ser respeitadas para qualquer onda elástica que se propaga em um material isotrópico seja esse ilimitado ou restrito às condições de contorno.

\section{2}

\section{Ondas elásticas em placas de faces paralelas}

Considerando as equações de onda para pontos suficientemente longe das fontes, tem-se que a força de corpo, $\boldsymbol{f}$, é nula e, logo, $f_{\phi}$ e $\boldsymbol{f}_{\psi}$ também são. Então, a equação de onda se torna.

$$
\begin{aligned}
\nabla^{2} \phi & =\frac{1}{c_{L}^{2}} \ddot{\phi} \\
\nabla^{2} \boldsymbol{\psi} & =\frac{1}{c_{T}^{2}} \ddot{\boldsymbol{\psi}}
\end{aligned}
$$

Seja o vetor deslocamento definido por $\boldsymbol{u}=u_{1} \boldsymbol{e}_{\mathbf{1}}+u_{2} \boldsymbol{e}_{\mathbf{2}}+u_{3} \boldsymbol{e}_{\mathbf{3}}$, onde $\boldsymbol{e}_{\mathbf{1}}$, 
$\boldsymbol{e}_{2}$ e $\boldsymbol{e}_{3}$ são os vetores unitários na direção dos eixos de um sistema cartesiano. A fim de obter a relação entre cada componente de $\boldsymbol{u}$ com os seus potenciais explicita-se o gradiente do potencial escalar e o rotacional do potencial vetorial

$$
\begin{gathered}
\nabla \phi=\frac{\partial \phi}{\partial x_{1}} \boldsymbol{e}_{\mathbf{1}}+\frac{\partial \phi}{\partial x_{2}} \boldsymbol{e}_{\mathbf{2}}+\frac{\partial \phi}{\partial x_{3}} \boldsymbol{e}_{\mathbf{3}} \\
\nabla \times \boldsymbol{\psi}=\left(\frac{\partial \psi_{3}}{\partial x_{2}}-\frac{\partial \psi_{2}}{\partial x_{3}}\right) \boldsymbol{e}_{\mathbf{1}}+\left(\frac{\partial \psi_{1}}{\partial x_{3}}-\frac{\partial \psi_{3}}{\partial x_{1}}\right) \boldsymbol{e}_{\mathbf{2}}+\left(\frac{\partial \psi_{2}}{\partial x_{1}}-\frac{\partial \psi_{1}}{\partial x_{2}}\right) \boldsymbol{e}_{\mathbf{3}}
\end{gathered}
$$

Nessa seção estuda-se o caso particular de uma placa de faces paralelas disposta como mostrada na figura $\square$. nos planos $x_{3}=h$ e $x_{3}=-h$. Ondas que se propagam no interior da placa, ao incidirem em uma das superfícies livres são refletidas de volta ao interior da mesma onde propagam-se até atingirem a superfície oposta, na qual ocorre nova reflexão. A onda refletida pode apresentar polarização diferente da onda incidente, quando isso ocorre diz-se que há a conversão de modo. Refletindo nas superfícies as ondas se propagam na direção longitudinal no interior da placa, diz-se então que as ondas são guiadas pela placa.

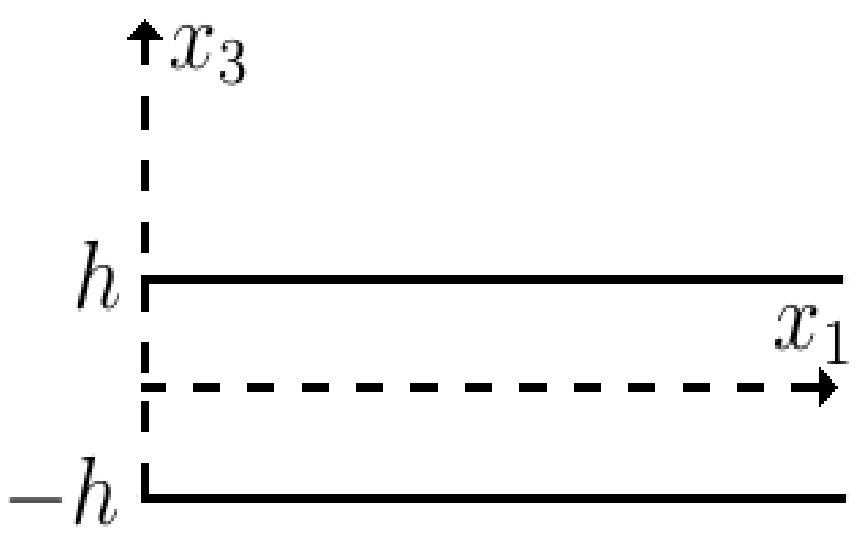

Figura 2.1: Geometria da Placa. [3]

Desse modo em regime permanente tem-se uma onda propagante na direção $x_{1}$, longitudinal a placa, e estacionária em $x_{2}$ e $x_{3}$. Supondo-se que a dimensão da placa na direção $x_{2}$ é muito maior que o comprimento de onda, pode-se considerar a placa como infinita nessa direção e o problema fica restrito a duas dimensões. Assim, não há dependência em relação a coordenada $x_{2} \mathrm{o}$

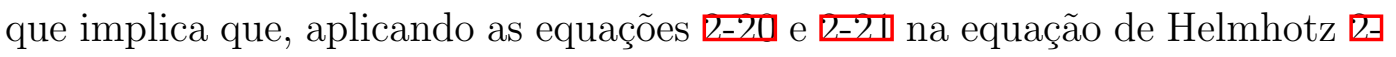

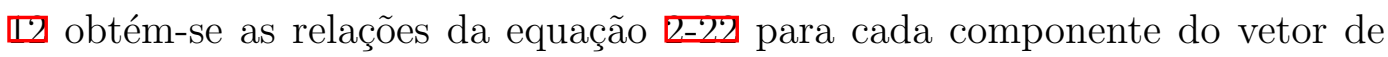


deslocamento.

$$
\begin{aligned}
& u_{1}=\frac{\partial \phi}{\partial x_{1}}-\frac{\partial \psi_{2}}{\partial x_{3}} \\
& u_{2}=\frac{\partial \psi_{1}}{\partial x_{3}}-\frac{\partial \psi_{3}}{\partial x_{1}} \\
& u_{3}=\frac{\partial \phi}{\partial x_{3}}+\frac{\partial \psi_{2}}{\partial x_{1}}
\end{aligned}
$$

Como a direção de propagação é $x_{1}$ uma onda que apresente apenas deslocamento na componente $u_{1}$ é classificada como uma onda primária, ou longitudinal, por estar polarizada na direção de propagação, sendo chamada de onda P. Uma onda cujo deslocamento tenha a componente $u_{2}$ é uma onda secundária, ou transversal, horizontal, chamada SH. Finalmente uma onda na qual o vetor deslocamento é $u_{3}$ é uma onda secundária, ou transversal, vertical, denominada SV.

É possível observar que, nesse problema específico, as ondas SH são desacopladas das ondas P e SV, isso porque as ondas SH dependem de $\psi_{1}$ e $\psi_{3}$ enquanto as ondas P e SV dependem de $\phi$ e $\psi_{2}$. Assim é possível a conversão de modo entre P e SV, o que não ocorre entre P e SH ou SV e SH.

Como as superfícies da placa são livres, as tensões normais e cisalhantes nas mesmas são nulas, ou seja, as condições de contorno que devem ser respeitadas para que existam ondas guiadas são expressas por

$$
\begin{aligned}
& \left.\sigma_{13}\right|_{x_{3}= \pm h}=0 \\
& \left.\sigma_{23}\right|_{x_{3}= \pm h}=0 \\
& \left.\sigma_{33}\right|_{x_{3}= \pm h}=0 \quad .
\end{aligned}
$$

Utilizando a equação $\mathbb{E - \varangle}$ e considerando que não haja dependência com $x_{2}$ as condições da equação ए-T:3, em $x_{3}= \pm h$, são expressas por

$$
\begin{aligned}
& \sigma_{13}=\mu\left(\frac{\partial u_{1}}{\partial x_{3}}+\frac{\partial u_{3}}{\partial x_{1}}\right)=0 \\
& \sigma_{23}=\mu \frac{\partial u_{2}}{\partial x_{3}}=0 \\
& \sigma_{33}=\lambda\left(\frac{\partial u_{1}}{\partial x_{1}}+\frac{\partial u_{3}}{\partial x_{3}}\right)+2 \mu \frac{\partial u_{3}}{\partial x_{3}}=0 .
\end{aligned}
$$

Utilizando os potenciais escalar e vetorial para escrever cada componente do 
deslocamento obtém-se

$$
\begin{aligned}
\sigma_{13} & =\mu\left(2 \frac{\partial^{2} \phi}{\partial x_{1} \partial x_{3}}+\frac{\partial^{2} \psi_{2}}{\partial x_{1}^{2}}-\frac{\partial^{2} \psi_{2}}{\partial x_{3}^{2}}\right)=0 \\
\sigma_{23} & =\mu\left(\frac{\partial^{2} \psi_{1}}{\partial x_{3}^{2}}-\frac{\partial^{2} \psi_{3}}{\partial x_{1} \partial x_{3}}\right)=0 \\
\sigma_{33} & =\lambda\left(\frac{\partial^{2} \phi}{\partial x_{1}^{2}}+\frac{\partial^{2} \phi}{\partial x_{3}^{2}}\right)+2 \mu\left(\frac{\partial^{2} \phi}{\partial x_{3}^{2}}+\frac{\partial^{2} \phi}{\partial x_{1} \partial x_{3}}\right)=0
\end{aligned}
$$

\subsection{1}

\section{Ondas primárias e secundárias verticais}

Considera-se inicialmente que se propague apenas apenas ondas de Lamb, ou seja ondas P e SV guiadas na placa, o que implica que $u_{2}=0$. Desse modo, a equação $\mathbb{L} \mathbb{L}$ é escrita sob a forma

$$
\begin{aligned}
\frac{\partial^{2} \phi}{\partial^{2} x_{1}}+\frac{\partial^{2} \phi}{\partial^{2} x_{3}} & =\frac{1}{c_{L}^{2}} \frac{\partial^{2} \phi}{\partial^{2} t} \\
\frac{\partial^{2} \psi_{2}}{\partial^{2} x_{1}}+\frac{\partial^{2} \psi_{2}}{\partial^{2} x_{3}} & =\frac{1}{c_{T}^{2}} \frac{\partial^{2} \psi_{2}}{\partial^{2} t}
\end{aligned}
$$

Como $u_{2}=0$ considera-se somente as condições de contorno dadas pelas

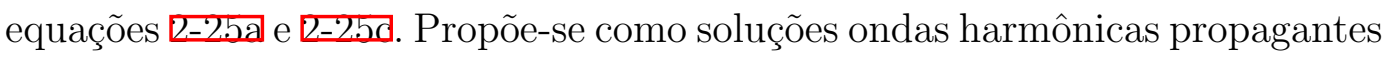
na direção $x_{1}$ e estacionárias em $x_{3}$

$$
\begin{gathered}
\phi=\Phi\left(x_{3}\right) e^{j\left(k x_{1}-\omega t\right)} \\
\psi_{2}=\Psi\left(x_{3}\right) e^{j\left(k x_{1}-\omega t\right)} .
\end{gathered}
$$

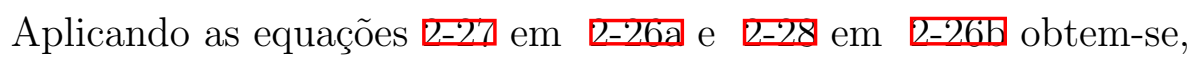

$$
\frac{\partial^{2} \Phi\left(x_{3}\right)}{\partial x_{3}^{2}}+\left(\frac{\omega^{2}}{c_{L}^{2}}-k^{2}\right) \Phi\left(x_{3}\right)=0
$$

e

$$
\frac{\partial^{2} \Psi\left(x_{3}\right)}{\partial x_{3}^{2}}+\left(\frac{\omega^{2}}{c_{T}^{2}}-k^{2}\right) \Psi\left(x_{3}\right)=0,
$$

respectivamente.

Para ambas as equações diferenciais acima a solução geral é da seguinte forma

$$
\begin{aligned}
& \Phi\left(x_{3}\right)=A_{1} \sin \left(p x_{3}\right)+A_{2} \cos \left(p x_{3}\right) \\
& \Psi\left(x_{3}\right)=B_{1} \sin \left(q x_{3}\right)+B_{2} \cos \left(q x_{3}\right)
\end{aligned}
$$

onde 


$$
p^{2}=\frac{\omega^{2}}{c_{L}^{2}}-k^{2} \quad \text { e } \quad q^{2}=\frac{\omega^{2}}{c_{T}^{2}}-k^{2}
$$

$\omega$ é a frequência angular da componente harmônica, dada por $\omega=2 \pi f, f$ representa a frequência, $k$ é o número de onda, dado por $k=\frac{2 \pi}{\lambda}, \lambda$ é o comprimento de onda e $c_{L}$ e $c_{T}$ são as velocidades de corpo definidas na equação $\mathbb{L - 1 ]}$.

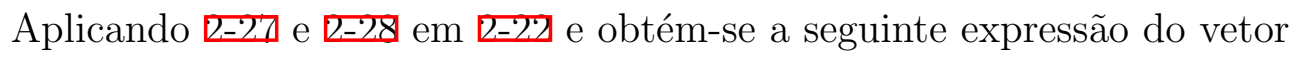
de deslocamento

$$
\begin{aligned}
& u_{1}=\left(\begin{array}{r}
j k A_{2} \cos \left(p x_{3}\right)-q B_{1} \cos \left(q x_{3}\right) \\
+j k A_{1} \sin \left(p x_{3}\right)+q B_{2} \sin \left(q x_{3}\right)
\end{array}\right) e^{j\left(k x_{1}-\omega t\right)} \\
& u_{3}=\left(\begin{array}{r}
-p A_{2} \sin \left(p x_{3}\right)+j k B_{1} \sin \left(q x_{3}\right) \\
+p A_{1} \cos \left(p x_{3}\right)+j k B_{2} \cos \left(q x_{3}\right)
\end{array}\right) e^{j\left(k x_{1}-\omega t\right)}
\end{aligned}
$$

Divide-se os modos propagantes em dois grupos, aqueles que apresentam deslocamento $u_{1}$ simétrico em relação o plano $x_{3}=0$, e aqueles que apresentam deslocamento anti-simétrico. As componentes simétricas são aqueles que têm $\cos \left(x_{3}\right)$ na expressão de $u_{1}$ e as anti-simétricas as que têm $\sin \left(x_{3}\right)$. Ou seja, as componentes simétricas possuem as constantes $A_{2}, B_{1} \neq 0$ e $A_{1}, B_{2}=0$, e as anti-simétricas possuem $A_{2}, B_{1}=0$ e $A_{1}, B_{2} \neq 0$. As componentes simétricas são também denominadas de ondas de compressão e as componentes antisimétricas de ondas de flexão. A figura एZla mostra o vetor deslocamento para um dado instante de tempo para onda de compressão e a figura एख్b para a onda de flexão em uma placa.

A fim de obter os modos propagantes deve-se resolver as equações $\mathbf{⿴ 囗 十}$

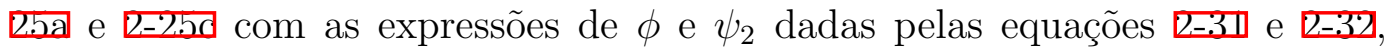
respectivamente. Após alguma manipulação chega-se às expressões

$$
\frac{\tan (q h)}{\tan (p h)}=-\frac{4 k^{2} p q}{\left(q^{2}-k^{2}\right)^{2}} \quad, \text { para modos simétricos }
$$

e

$$
\frac{\tan (q h)}{\tan (p h)}=-\frac{\left(q^{2}-k^{2}\right)^{2}}{4 k^{2} p q} \quad, \text { para modos anti-simétricos. }
$$

Apenas há propagação para os valores de $p, q$ e $k$ que forem raízes da equação ए-3. Ou seja, como $p$ e $q$ são funções de $\omega$ e $k$, apenas os pares $\omega$ e $k$ que forem solução da equação एँ.3., para uma dada espessura $2 h$, representam ondas guiadas propagantes. Contudo não existe solução analítica para essas equações. Deve-se dispor de recursos computacionais para obter os pares $\omega$ e 


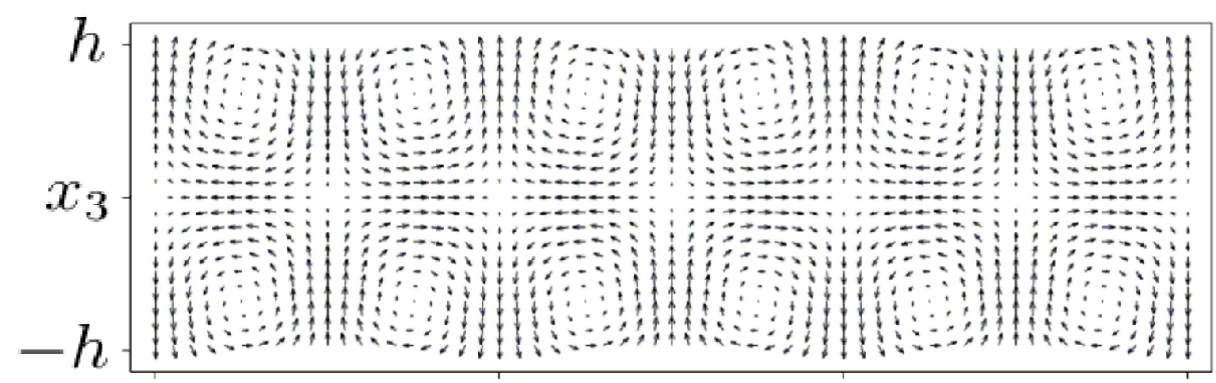

$x_{1}$

(a)

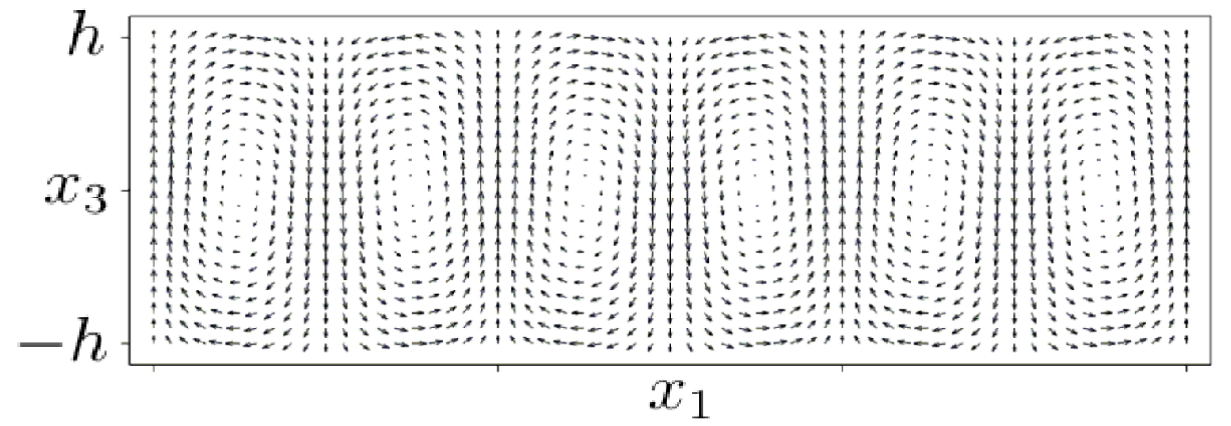

(b)

Figura 2.2: Deslocamento para o modo simétrico (a) e anti-simétrico (b) de ondas de Lamb para um dado instante de tempo. Eixo horizontal representa $x_{1}$ e vertical $x_{3}$. [q]

$k$ que sejam raízes dos modos propagantes. Para tal é conveniente o uso das seguintes variáveis adimensionais $[\mathbf{\nabla}]$

$$
\Omega=\frac{2 h \omega}{\pi c_{T}}, \quad \xi=\frac{2 k h}{\pi}, \quad \alpha=\frac{c_{L}}{c_{T}}
$$

desse modo a equação tz-3. transforma-se em

$$
\frac{\tan \left(\frac{\pi}{2} \sqrt{\Omega^{2}-\xi^{2}}\right)}{\tan \left(\frac{\pi}{2} \sqrt{\Omega^{2} / \alpha^{2}-\xi^{2}}\right)}=-\frac{4 \xi^{2} \sqrt{\Omega^{2}-\xi^{2}} \sqrt{\Omega^{2} / \alpha^{2}-\xi^{2}}}{\left(\Omega^{2}-2 \xi^{2}\right)^{2}}
$$

para modos simétricos e

$$
\frac{\tan \left(\frac{\pi}{2} \sqrt{\Omega^{2}-\xi^{2}}\right)}{\tan \left(\frac{\pi}{2} \sqrt{\Omega^{2} / \alpha^{2}-\xi^{2}}\right)}=-\frac{\left(\Omega^{2}-2 \xi^{2}\right)^{2}}{4 \xi^{2} \sqrt{\Omega^{2}-\xi^{2}} \sqrt{\Omega^{2} / \alpha^{2}-\xi^{2}}}
$$

para modos anti-simétricos.

A figura 2.3 ilustra os modos simétricos, em vermelho, e anti-simétricos, em azul, para uma placa de alumínio de parâmetros dados pela tabela $\square$ em função de $\Omega$ e $\xi$. Os modos são numerados crescentemente em função da frequência para números de onda nulos. Ou seja, os modos anti-simétrico e 
simétrico cujas curvas de dispersão iniciam-se em $\xi=0$ são chamados modos anti-simétrico 0 e simétrico 1 , ou $A 0$ e $S 0$ respectivamente, o modo antisimétrico cuja curva inicia-se em $\xi=1$, é chamado de $A 1$, os simétricos em $\xi=2$, são $S 1$ e $S 2$, e assim sucessivamente.

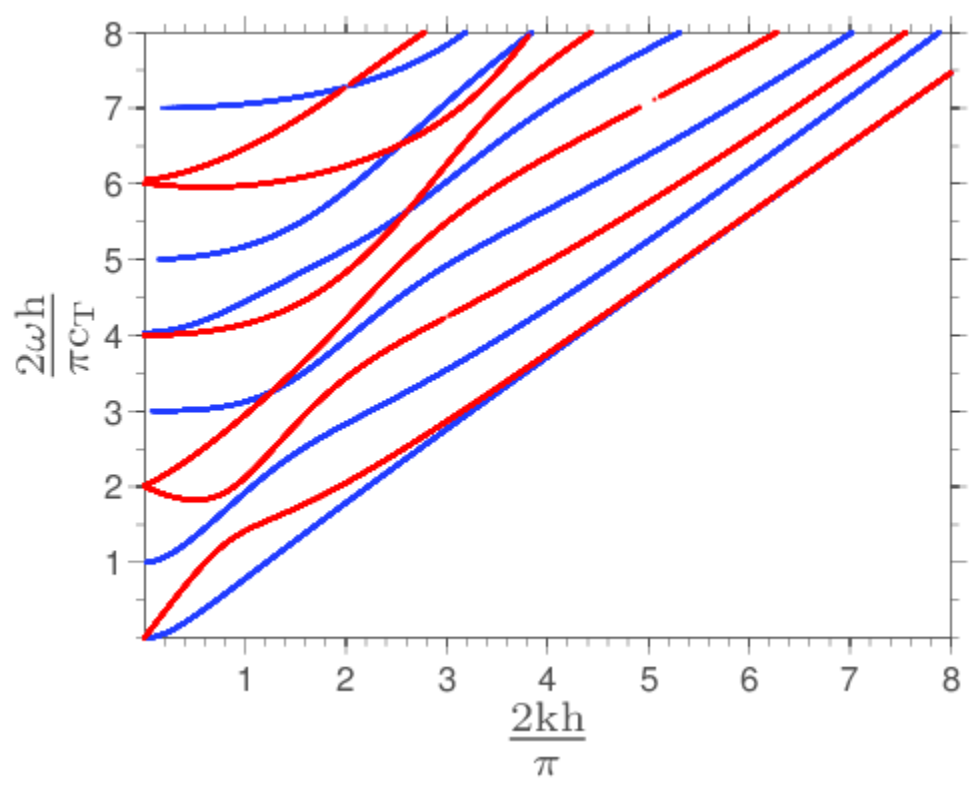

Figura 2.3: Curva de dispersão para ondas de Lamb em uma placa de alumínio, modos simétricos em vermelho e anti-simétricos em azul.

Tabela 2.1: Parâmetros elásticos do alumínio [ㅍ]].

\begin{tabular}{ccc}
\hline$\lambda$ & $\mu$ & $\rho$ \\
$G P a$ & $G P a$ & $k g / m^{3}$ \\
\hline 54.9 & 26.5 & 2700 \\
\hline
\end{tabular}

Com esse valores de constantes elásticas e densidade as velocidades de corpo assumem os valores

$$
\begin{aligned}
& c_{L}=6321.4 \mathrm{~m} / \mathrm{s} \\
& c_{T}=3132.9 \mathrm{~m} / \mathrm{s} .
\end{aligned}
$$

A velocidade de fase de uma onda é dada por

$$
c=\frac{\omega}{k}
$$

em uma onda de corpo a velocidade de fase é igual a $c_{L}$ para ondas primárias e $c_{T}$ para secundárias.

Pode-se expressar os modos propagantes em termo da velocidade de fase para cada frequência. Usando as variáveis adimensionais da equação Z-36 pode- 
se definir a velocidade de fase adimensional por

$$
\Gamma=\frac{\Omega}{\xi}=\frac{c}{c_{T}} .
$$

A figura एـ mo mostra as velocidades de fase adimensional $\Gamma$ em função da frequência adimensional $\Omega$ para cada modo propagante. Como na figura $\square$ os modos simétricos estão representados pelas curvas na cor vermelha e os modos anti-simétricos pelas curvas em azul.

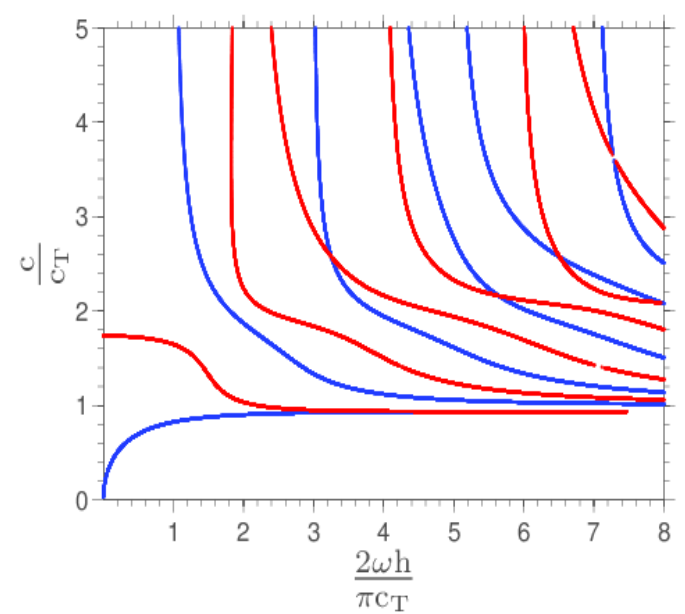

(a)

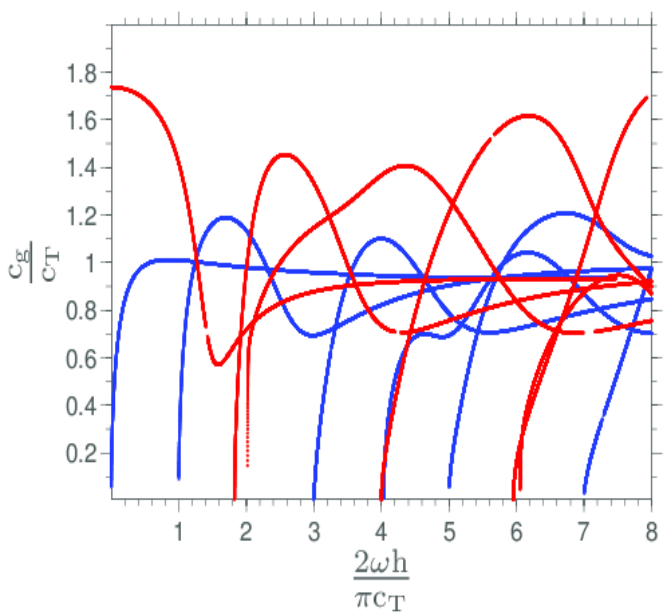

(b)

Figura 2.4: Curva de dispersão para a velocidade de fase (a) e grupo (b) de ondas de Lamb em uma placa de alumínio, modos simétricos em vermelho e anti-simétricos em azul.

A velocidade de grupo é definida como a velocidade de propagação dos pacotes de onda formados no guia, essa é definida por

$$
c_{g}=\frac{d \omega}{d k}
$$

É possível demonstrar que a velocidade de grupo é numericamente igual a velocidade de transporte de energia.

Do mesmo modo como feito para a velocidade de fase, define-se a velocidade de grupo adimensional

$$
\Gamma_{g}=\frac{d \Omega}{d \xi}=\frac{c_{g}}{c_{T}}
$$

A figura एـ্b traz as velocidades de grupo adimensional $\Gamma_{g}$ em função da frequência adimensional $\Omega$ seguindo as mesmas cores que nos casos anteriores.

Observa-se pela figura $\square .3$ que a relação entre os $\omega$ e $k$ não é linear e logo a

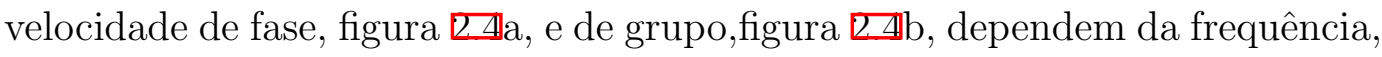
ou seja, as ondas de Lamb são dispersivas. Sua dispersividade é bastante dependente da frequência. Há regiões onde a dispersividade é negligenciável 
se muito pequena, em tais regiões a velocidade de grupo é quase invariante, como para frequências baixas do primeiro modo simétrico ou para frequências $\operatorname{com} \Omega>3$ para o primeiro modo anti-simétrico, e há regiões onde a velocidade de grupo vária considerávelmente em uma faixa de frequência, como para o terceiro modo simétrico em frequências em torno a $\Omega=4$. Nessas últimas um pulso não monocromático teria sua forma alargada no tempo ao se propagar devido a diferente velocidade de cada componente em frequência, enquanto que para a propagação em uma região de pouca dispersividade a forma temporal se manteria quase constante a medida que o pulso se propaga, devido as componentes em frequência se propagarem com velocidades próximas.

É interessante observar que todos os modos tendem a $c_{g}$ constante para $\Omega$ tendendo ao infinito, não sendo mais dispersivos. Ou seja, em uma placa muito grossa para a frequência de operação, há propagação de ondas não dispersivas equivalentemente às ondas de corpo, já que a dimensão da placa é grande o suficiente para não mais permitir a propagação de ondas guiadas. Assim todos os modos se confundem para a velocidade de propagação da onda de corpo no material.

\subsection{2}

\section{Ondas secundárias horizontais}

Considera-se nessa subseção a propagação apenas de ondas SH, desse modo, ao contrário do visto anteriormente, há apenas o deslocamento da componente $u_{2}$, sendo $u_{1}$ e $u_{3}=0$.

Para obtenção dos modos propagantes é possível um desenvolvimento utilizando os potenciais, nesse caso, pela equação [-220, os únicos relevantes são $\psi_{1}$ e $\psi_{3}$. Contudo, como há apenas uma componente deslocamento relevante pode-se obter a equação de onda diretamente para $u_{2}$. Para tal aplica-se $\boldsymbol{u}=u_{2} \boldsymbol{e}_{2}$ na equação de Navier [-耳. Observe-se que, como não há dependência com $x_{2}$ e havendo apenas a componente $u_{2}$ do deslocamento, tem-se que $\nabla \cdot \boldsymbol{u}=0$. Dese modo a equação de Navier simplifica-se para a equação de onda em $u_{2}$

$$
\frac{\partial^{2} u_{2}}{\partial^{2} x_{1}}+\frac{\partial^{2} u_{2}}{\partial^{2} x_{3}}=\frac{1}{c_{T}^{2}} \frac{\partial^{2} u_{2}}{\partial^{2} t}
$$

Do mesmo modo como feito para ondas P e SV, propões-se como solução uma onda harmônica propagante na direção $x_{1}$ e estacionária em $x_{3}$

$$
u_{2}=U\left(x_{3}\right) e^{j\left(k x_{1}-\omega t\right)} .
$$


Aplicando-a na equação de onda [-4.3 obtém-se a equação diferencial

$$
\frac{\partial^{2} U\left(x_{3}\right)}{\partial x_{3}^{2}}+\left(\frac{\omega^{2}}{c_{T}^{2}}-k^{2}\right) U\left(x_{3}\right)=0
$$

cuja solução geral é da forma

$$
U\left(x_{3}\right)=C_{1} \sin \left(q x_{3}\right)+C_{2} \cos \left(q x_{3}\right),
$$

onde q está definido na equação tz-3.3. O deslocamento assume, então, a expressão

$$
u_{2}=\left[C_{1} \sin \left(q x_{3}\right)+C_{2} \cos \left(q x_{3}\right)\right] e^{j\left(k x_{1}-\omega t\right)} .
$$

Mais uma vez divide-se o deslocamente em uma componente simétrica e anti-simétrica. A componente simétrica possui apenas a variação com $\cos \left(q x_{3}\right)$, ou seja $C_{1}=0$ e $C_{2} \neq 0$, já a compoente anti-simétrica possui apenas a parcela com $\sin \left(q x_{3}\right)$, ou seja $C_{1} \neq 0$ e $C_{2}=0$.

A fim de obter os modulos propagantes deve-se resolver a condição de contorno de tensão nula nas superfícies da placa, representada pela equação $\mathbf{\Xi}$ 24. Levando em conta as simplificações desse caso particular apenas a codição representada pela equação $2-240$ é relevante. Aplicando, então, a equaçãp $\mathbb{L - 4 7}$ em $2-240$ obtém-se

$$
\sigma_{23}=q\left[C_{1} \cos \left(q x_{3}\right)-C_{2} \sin \left(q x_{3}\right)\right] e^{j\left(k x_{1}-\omega t\right)}
$$

a qual deve ser nula em $x_{3}= \pm h$.

As soluções devem respeitar

$$
q h=\frac{n \pi}{2}, \text { tal que } n \text { é } \begin{cases}\text { par, } & \text { para os modos simétricos } \\ \text { impar, } & \text { para os modos anti-simétricos. }\end{cases}
$$

Pela definição de $q$, equação [-3:31, pode-se escrever a condição de propagação como

$$
\frac{\omega^{2}}{c_{T}^{2}}-k^{2}=\left(\frac{n \pi}{2 h}\right)^{2}
$$

usando as variáveis adimensionais $\Omega$ e $\xi$ definidas na equação L-36, os modos propagantes são aqueles que são raízes da equação

$$
\Omega^{2}-\xi^{2}=n^{2}
$$

onde $n$ é um inteiro par para os módulos simétricos e ímpar para os antisimétricos.

A figura $\$$ ilustra os modos simétricos, em rosa, e anti-simétricos, em verde, para uma placa de alumínio com os mesmos parâmetros usados para as ondas na seção ए】.

Do mesmo modo como feito para os modos de Lamb, pode-se expressar os modos propagantes das ondas SH guiadas na placa pela velocidade de fase 


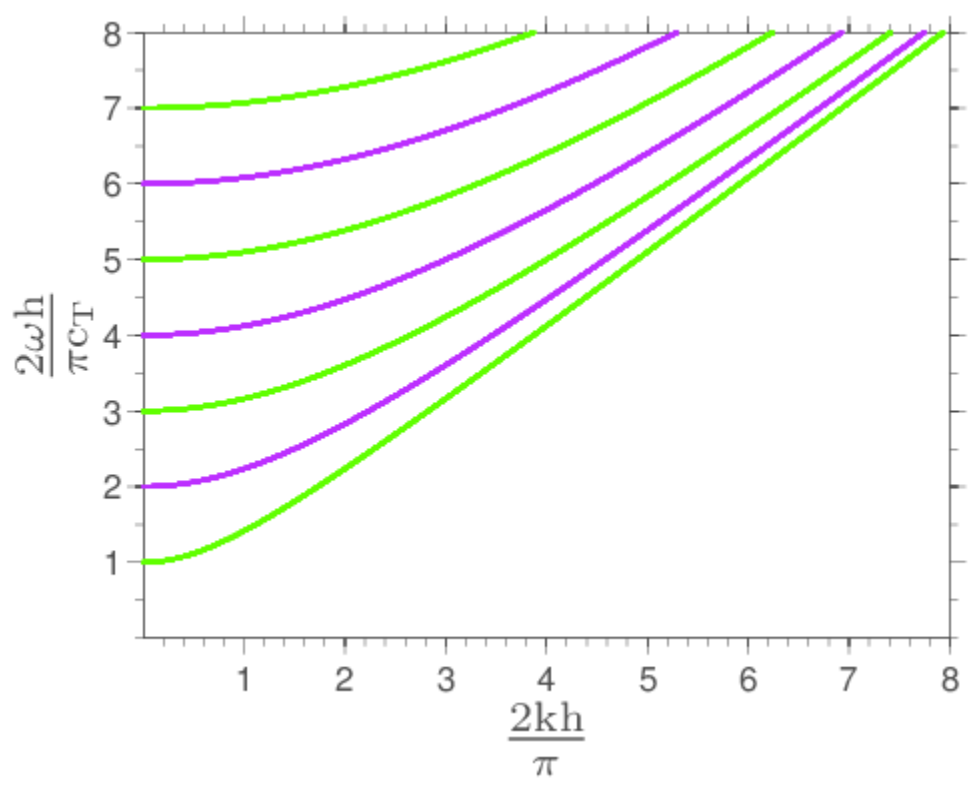

Figura 2.5: Curva de dispersão de ondas SH em uma placa de alumínio de faces paralelas, modos anti-simétricos estão representados em verde e simétricos em rosa.

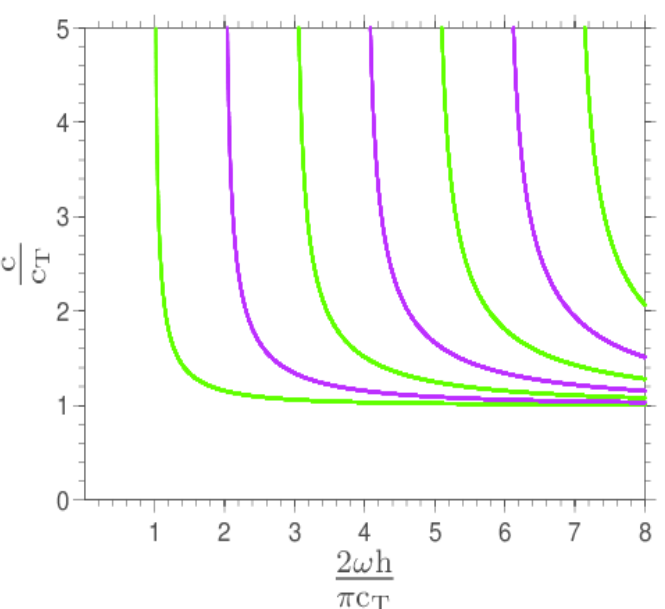

(a)

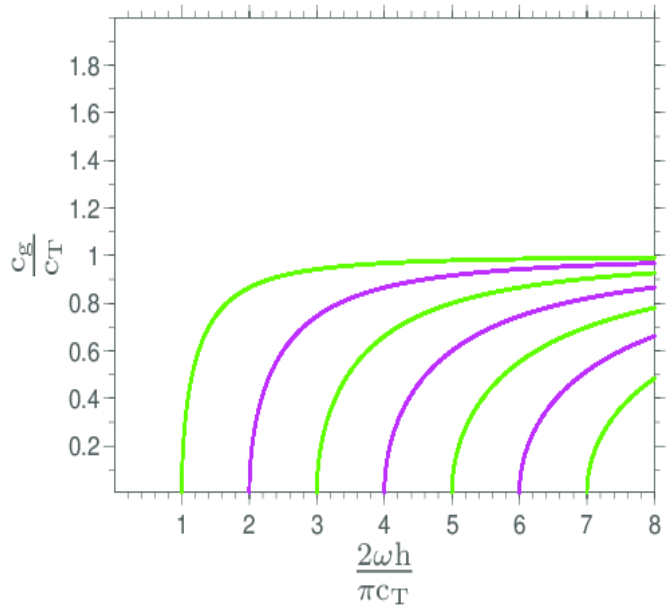

(b)

Figura 2.6: Curva de dispersão para a velocidade de fase (a) e grupo (b) de ondas SH em uma placa de alumínio de faces paralelas. Curvas verdes representam os modos anti-simétricos e rosas simétricos.

em função da frequências. A figura ए耳a ilustra as curvas para a velocidade de fase adimensional $\Gamma$ em função de $\Omega$.

Por fim, a velocidade de grupo se define do mesmo modo, equação [L-4]. A figura ए■b trás as curvas para a velocidade de grupo adimensional $\Gamma_{g}$ em função de $\Omega$.

Observe-se que o comportamento dispersivo das ondas $\mathrm{SH}$ é menos complexo que as ondas de Lamb. As velocidades de grupo aprensentam característica monótona em função da frequência de operação. Cada modo 
apresenta comportamento dispersivo mais intenso apenas para frequências perto de suas frequências de corte inferior.

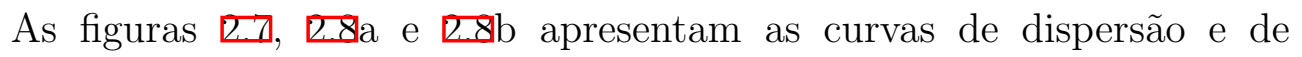
velocidade de fase e de grupo em função da frequência, respectivamente, para os modos de lamb simétricos, em vermelho, anti-simétricos, em azul, e modos SH simétricos, em rosa, e anti-simétricos, em verde.

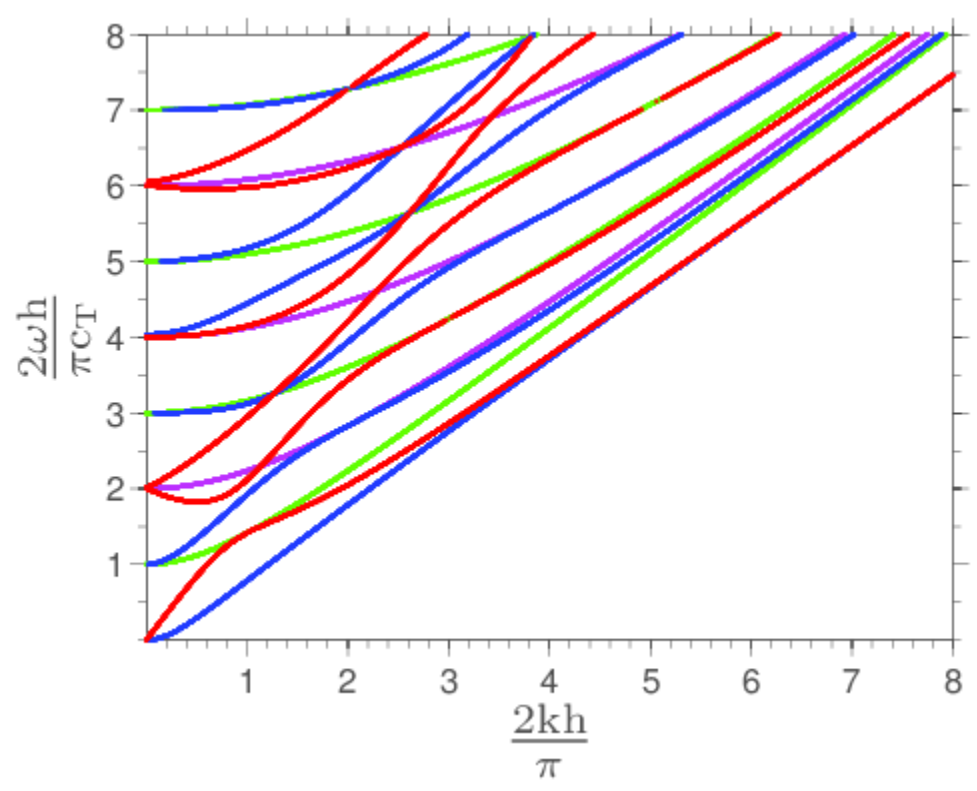

Figura 2.7: Curva de dispersão para ondas de Lamb e SH em uma placa de alumínio de faces paralelas. linhas vermelhas representam ondas de Lamb simétricas, azul ondas de Lamb anti-simétrica, rosa ondas SH simétrica e verde ondas SH anti-simétricas. 


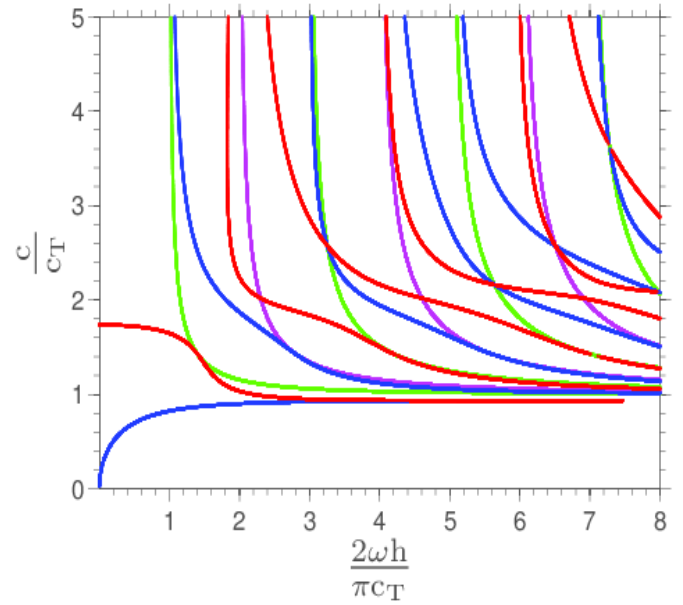

(a)

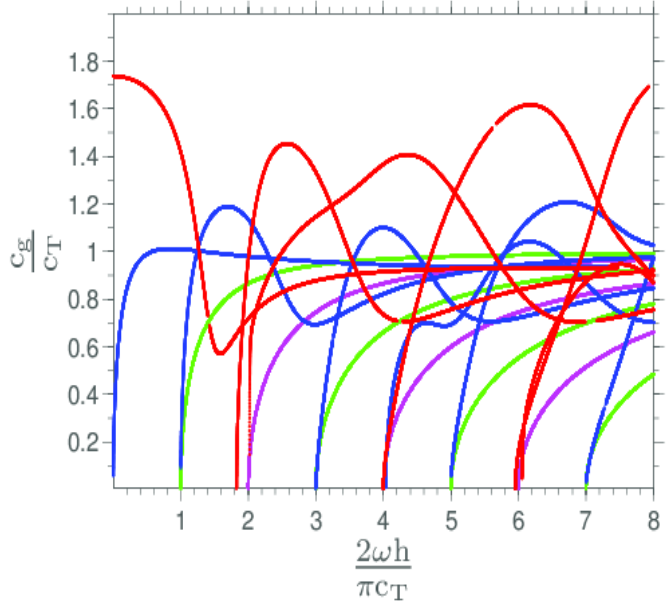

(b)

Figura 2.8: Curva de dispersão para a velocidade de fase (a) e de grupo (b) de ondas de Lamb e SH em uma placa de alumínio de faces paralelas. Linhas vermelhas representam ondas de Lamb simétricas, azul ondas de Lamb antisimétrica, rosa ondas SH simétrica e verde ondas SH anti-simétricas

\section{3}

\section{Modos Propagantes em Placas em Meios Anisotrópicos}

Em meios anisotrópicos as soluções para a equação de dispersão são bem mais complicadas e não se deve buscar formas analíticas para as mesmas. Essa seção expõe um desenvolvimento para o cálculo da equação de dispersão para meios anisotrópicos homogêneos, bem como uma rotina computacional para obtenção das curvas de dispersão. Usa-se nesse desenvolvimento o conceito do vetor de estado e matriz de propagação apresentado por Braga e Hermann em 1992 [II]].

\subsection{1}

\section{Equação de Dispersão}

Define-se o vetor de estado $\chi\left(x_{3}\right)$ como o vetor contendo as três coordenadas do deslocamento e as três coordenadas da tensão normal multiplicadas por $j$, todas em função da posição $x_{3}$ no interior da placa, tal que $x_{3}=-h$ e $x_{3}=h$ são as posições das superfícies livres da placa. Desse modo tem-se 


$$
\chi\left(x_{3}\right)=\left(\begin{array}{c}
u_{1}\left(x_{3}\right) \\
u_{2}\left(x_{3}\right) \\
u_{3}\left(x_{3}\right) \\
j \sigma_{13}\left(x_{3}\right) \\
j \sigma_{23}\left(x_{3}\right) \\
j \sigma_{33}\left(x_{3}\right)
\end{array}\right)=\left(\begin{array}{c}
u_{1}\left(x_{3}\right) \\
u_{2}\left(x_{3}\right) \\
u_{3}\left(x_{3}\right) \\
j \eta_{1}\left(x_{3}\right) \\
j \eta_{2}\left(x_{3}\right) \\
j \eta_{3}\left(x_{3}\right)
\end{array}\right),
$$

ou simplesmente

$$
\boldsymbol{\chi}\left(x_{3}\right)=\left(\begin{array}{c}
\boldsymbol{u}\left(x_{3}\right) \\
j \boldsymbol{\eta}_{1}\left(x_{3}\right)
\end{array}\right),
$$

tal que $\boldsymbol{\eta}$ é a componente de tensão na direção $x_{3}$, normal à superfície da placa, dado por

$$
\eta=\sigma e_{3}
$$

O comportamento do vetor de estado em função da posição $x_{3}$ se dá pela equação seguinte diferencial [II]].

$$
\frac{d}{d x_{3}} \boldsymbol{\chi}\left(x_{3}\right)=-j \mathbf{N}\left(x_{3}\right) \chi\left(x_{3}\right)
$$

tal que $\boldsymbol{N}\left(x_{3}\right)$ é uma matriz $6 \times 6$ definida por

$$
\boldsymbol{N}\left(x_{3}\right)=\left[\begin{array}{cc}
k \boldsymbol{S}_{\mathbf{1}}\left(x_{3}\right) & \boldsymbol{S}\left(x_{3}\right) \\
k^{2} \boldsymbol{S}_{\mathbf{1 1}}\left(x_{3}\right)+\rho\left(x_{3}\right) \omega^{2} \boldsymbol{I} & k \boldsymbol{S}_{\mathbf{1}}^{T}\left(x_{3}\right)
\end{array}\right],
$$

onde $k$ é o numero de onda na direção de propagação $x_{1}, \omega$ a frequência angular, $\boldsymbol{S}_{\mathbf{1}}\left(x_{3}\right), \boldsymbol{S}\left(x_{3}\right)$ e $\boldsymbol{S}_{\mathbf{1 1}}\left(x_{3}\right)$ são matrizes $3 \times 3$ que dependem apenas do Tensor Acústico de Christoffell $\boldsymbol{Q}(\boldsymbol{v})$ e do Tensor Acústico Associado $\boldsymbol{R}(\boldsymbol{v}, \boldsymbol{w}), \boldsymbol{I}$ é a matriz identidade no $\mathbb{R}^{3 \times 3}$ e $\rho\left(x_{3}\right)$ é a densidade. O sobrescrito ${ }^{T}$ denota a matriz transposta.

Os tensores $\boldsymbol{Q}(\boldsymbol{v})$ e $\boldsymbol{R}(\boldsymbol{v}, \boldsymbol{w})$ são definidos em notação indicial por

$$
\begin{aligned}
Q_{i k}(\boldsymbol{v}) & =C_{i j k l} v_{j} v_{l} \\
R_{i k}(\boldsymbol{v}, \boldsymbol{w}) & =C_{i j k l} v_{j} w_{l},
\end{aligned}
$$

onde $\boldsymbol{v}$ e $\boldsymbol{w}$ são vetores pertencentes ao $\mathbb{R}^{3}$ e $C_{i j k l}$ é o tensor de elasticidade de quarta ordem.

Em um meio homogêneo ambos os tensores $\boldsymbol{Q}(\boldsymbol{v})$ e $\boldsymbol{R}(\boldsymbol{v}, \boldsymbol{w})$ e a densidade não dependem da posição $x_{3}, \operatorname{logo} \boldsymbol{S}_{\mathbf{1}}\left(x_{3}\right), \boldsymbol{S}\left(x_{3}\right)$ e $\boldsymbol{S}_{\mathbf{1 1}}\left(x_{3}\right)$ e, consequentemente, $\boldsymbol{N}\left(x_{3}\right)$ também são constantes em relação a $x_{3}$. Como é de interesse apenas meios homogêneos, doravante será suprimido a dependência da posição nas grandezas acima relacionadas. 
As matrizes $\boldsymbol{S}_{\mathbf{1}}, \boldsymbol{S}$ e $\boldsymbol{S}_{\mathbf{1 1}}$ são expressas por

$$
\begin{aligned}
S & =Q^{-1}\left(e_{3}\right) \\
S_{1} & =-Q^{-1}\left(e_{3}\right) R\left(e_{3}, e_{1}\right) \\
S_{11} & =R^{T}\left(e_{3}, e_{1}\right) Q^{-1}\left(e_{3}\right) R\left(e_{3}, e_{1}\right)-R\left(e_{1}, e_{1}\right) .
\end{aligned}
$$

Avaliando os tensores $\boldsymbol{Q}(\boldsymbol{v})$ e $\boldsymbol{R}(\boldsymbol{v}, \boldsymbol{w})$ nas direções de interesse obtém-se

$$
\begin{aligned}
Q_{i k}\left(\boldsymbol{e}_{\mathbf{3}}\right) & =C_{i j k l} e_{3 j} e_{3 l}=C_{i j k l} \delta_{j 3} \delta_{l 3}=C_{i 3 k 3} \\
R_{i k}\left(\boldsymbol{e}_{\mathbf{3}}, \boldsymbol{e}_{\mathbf{1}}\right) & =C_{i j k l} e_{3 j} e_{1 l}=C_{i j k l} \delta_{j 3} \delta_{l 1}=C_{i 3 k 1} \\
R_{i k}\left(\boldsymbol{e}_{\mathbf{1}}, \boldsymbol{e}_{\mathbf{1}}\right) & =C_{i j k l} e_{1 j} e_{1 l}=C_{i j k l} \delta_{j 1} \delta_{l 1}=C_{i 1 k 1} .
\end{aligned}
$$

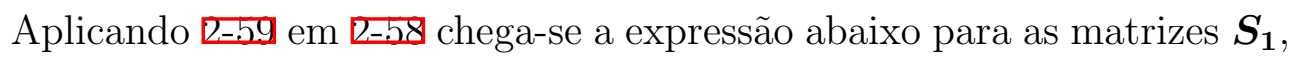
$\boldsymbol{S}$ e $\boldsymbol{S}_{\mathbf{1 1}}$, que depende apenas do tensor de elasticidade

$$
\begin{aligned}
\boldsymbol{S} & =C_{i 3 k 1}^{-1} \\
\boldsymbol{S}_{\mathbf{1}} & =-\boldsymbol{S}_{i 3 k 1} \\
\boldsymbol{S}_{\mathbf{1 1}} & =C_{i 3 k 1}^{T} \boldsymbol{S}_{i 3 k 1}-C_{i 1 k 1} .
\end{aligned}
$$

Soluções da equação diferencial [-..5 são da forma

$$
\boldsymbol{\chi}\left(x_{3}\right)=\boldsymbol{M}\left(x_{3}\right) \boldsymbol{M}^{-1}\left(z_{0}\right) \chi\left(z_{0}\right)
$$

onde $z_{0}$ é uma posição constante arbitrária no eixo $x_{3}$ e a matriz $\boldsymbol{M}\left(x_{3}\right)$ é definida por

$$
\boldsymbol{M}\left(x_{3}\right)=e^{-j \boldsymbol{N} x_{3}} .
$$

É verificável que a matriz $\boldsymbol{M}\left(x_{3}\right)$ possui as seguintes propriedades

$$
\begin{aligned}
\boldsymbol{M}\left(-z_{0}\right) & =\boldsymbol{M}^{-1}\left(-z_{0}\right) \\
\boldsymbol{M}\left(z_{1}+z_{2}\right) & =\boldsymbol{M}\left(z_{1}\right) \boldsymbol{M}\left(z_{2}\right) .
\end{aligned}
$$

logo, pode-se escrever a solução dada pela equação ए-ద్ర na forma

$$
\chi\left(x_{3}\right)=\boldsymbol{M}\left(x_{3}-z_{0}\right) \chi\left(z_{0}\right)
$$

Seja $z_{0}=-h$, a posição da superfície inferior da placa, reavaliando a solução da equação diferencial para essa constante tem-se a seguinte solução de interesse

$$
\chi\left(x_{3}\right)=\boldsymbol{M}\left(x_{3}+h\right) \chi(-h)
$$

É conveniente escrever a matriz $\boldsymbol{M}\left(x_{3}\right)$ utilizando 4 matrizes $3 \times 3$, sejam 
$\boldsymbol{M}_{\mathbf{1 1}}\left(x_{3}\right), \boldsymbol{M}_{\mathbf{1 2}}\left(x_{3}\right), \boldsymbol{M}_{\mathbf{2 1}}\left(x_{3}\right)$ e $\boldsymbol{M}_{\mathbf{2 2}}\left(x_{3}\right)$, de valores complexos arrumadas da seguinte maneira

$$
M\left(x_{3}\right)=\left[\begin{array}{ll}
M_{11}\left(x_{3}\right) & M_{12}\left(x_{3}\right) \\
M_{21}\left(x_{3}\right) & M_{22}\left(x_{3}\right)
\end{array}\right] .
$$

Desse modo a equação $2-h .5$ se escreve como

$$
\left(\begin{array}{c}
\boldsymbol{u}\left(x_{3}\right) \\
j \boldsymbol{\eta}\left(x_{3}\right)
\end{array}\right)=\left[\begin{array}{ll}
\boldsymbol{M}_{\mathbf{1 1}}\left(x_{3}+h\right) & \boldsymbol{M}_{\mathbf{1 2}}\left(x_{3}+h\right) \\
\boldsymbol{M}_{\mathbf{2 1}}\left(x_{3}+h\right) & \boldsymbol{M}_{\mathbf{2 2}}\left(x_{3}+h\right)
\end{array}\right]\left(\begin{array}{c}
\boldsymbol{u}(-h) \\
j \boldsymbol{\eta}(-h)
\end{array}\right)
$$

que equivale ao sistema

$$
\begin{aligned}
\boldsymbol{u}\left(x_{3}\right) & =\boldsymbol{M}_{\mathbf{1 1}}\left(x_{3}+h\right) \boldsymbol{u}(-h)+j \boldsymbol{M}_{\mathbf{1 2}}\left(x_{3}+h\right) \boldsymbol{\eta}(-h) \\
j \boldsymbol{\eta}\left(x_{3}\right) & =\boldsymbol{M}_{\mathbf{2 1}}\left(x_{3}+h\right) \boldsymbol{u}(-h)+j \boldsymbol{M}_{\mathbf{2 2}}\left(x_{3}+h\right) \boldsymbol{\eta}(-h)
\end{aligned}
$$

Avaliando as equações $\mathbb{L - 6 \nabla}$ para $x_{3}=h$ e considerando a condição de contorno de tensão normal nula nas superfícies da placa, ou seja, $\boldsymbol{\eta}( \pm h)=\mathbf{0}$, obtém-se a condição

$$
\boldsymbol{M}_{\mathbf{2 1}}(2 h) \boldsymbol{u}(-h)=\mathbf{0},
$$

que possui solução não trivial se o determinante da matriz $\boldsymbol{M}_{\mathbf{2 1}}\left(x_{3}\right)$, avaliada para a posição $x_{3}$ igual a espessura da placa for nulo, ou seja,

$$
\operatorname{det}\left[\boldsymbol{M}_{\mathbf{2 1}}(2 h)\right]=0 .
$$

Encontrando todos os pares de valores de $\omega$ e $k$ que satisfazem a equação [-T] obtém-se a curva de dispersão para o material em questão. Para obtenção das curvas de dispersão dentro de intervalos predefinidos dos parâmetros $\omega$ e $k$ foi proposto a rotina computacional abaixo exposta.

\subsection{2}

\section{Rotina Computacional para Obtenção da Curva de Dispersão}

Os parâmetros de entrada para a rotina são os valores das constantes do tensor de elasticidade de quarta ordem, $\boldsymbol{C}$, a densidade do meio $\rho$, valores iniciais, final e de resolução para variáveis adimensionais $\Omega$ e $\xi$, como definidas em L-36. Para $\Omega$ ter sentido deve-se também definir um valor para a velocidade $c_{T}$, que não necessariamente precisa ser a velocidade secundária.

Deve-se proceder a varredura de todos os valores de $\Omega$ e $\xi$ contidos nos intervalos definidos. Para isso usa-se dois laços aninhados o externo em $\Omega$ e o interno em $\xi$. Para cada dois valores sucessivos de $\xi$ avalia-se a equação $⿴ 囗 十$ 四 e observa-se se o sinal de cada parte, real e imaginária, do determinante 
dessa equação muda de sinal. Se há uma mudança de sinal usa-se uma rotina de bisseção para encontrar o ponto $\xi_{0}$, entre os dois valores de $\xi$, que zera as partes real e imaginária da equação $\mathbb{E}-\mathbb{Z}$. Repete-se esse processo para todos os valores de $\Omega$ e $\xi$ dentro do intervalo definido.

Uma observação relevante é que o mesmo procedimento é feito para obtenção das curvas de dispersão para meios isotrópicos apresentada nas seções anteriores. Contudo, ao invés procurar soluções para a equação $\mathbb{E - T}$, deve-se

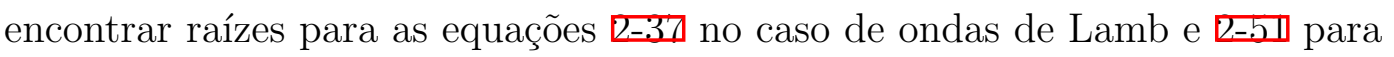
ondas SH.

Para avaliar a equação $\mathbb{L}-\boldsymbol{C}$ para um par de valores $\Omega$ e $\xi$ é preciso ter $\omega$ em função de $\Omega$ e $k$ em função de $\xi$. Usa-se então relação inversa da equação L-36, dada por

$$
\omega=\frac{\Omega \pi c_{T}}{2 h}, \quad k=\frac{\xi \pi}{2 h}
$$

Esses valores e as matrizes $\boldsymbol{S}_{\mathbf{1}}, \boldsymbol{S}$ e $\boldsymbol{S}_{\mathbf{1 1}}$ calculadas em função do tensor de elasticidade $\boldsymbol{C}$ pela equação $\mathbf{W - n}$, são usados como entrada de uma subrotina que monta a matriz $\boldsymbol{N}$ avaliada para o par de valores $\omega$ e $k$ correspondentes

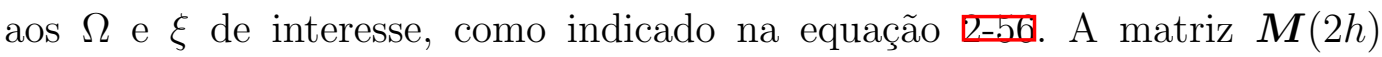
é então calculada pela equação $\mathbb{L}-{ }^{2}$ que é avaliada usando uma rotina de exponenciação de matrizes. Dela se extrai a matriz $\boldsymbol{M}_{\mathbf{2 1}}(2 h)$ cujo determinante é calculado.

Plotando-se os pontos $\Omega$ em função de $\xi$, que satisfazem a equação $\mathbb{\Xi}$ 四 obtém-se, então, a curva de dispersão. Para cada par de pontos pode-se, facilmente, calcular a velocidade de fase, pela equação L-40, os quais se plotados em função da frequência $\Omega$, fornecem a curva de dispersão para a velocidade de fase. O mesmo pode ser feito para a velocidade de grupo, dada pela equação L-42, contudo, nesse caso deve-se calcular numericamente o valor da derivada da frequência em relação a número de onda.

É importante salientar que o valor de $\xi_{0}$ obtido pelo algoritmo de bisseção deve ser utilizado para se recalcular $\operatorname{det}\left[\boldsymbol{M}_{\mathbf{2 1}}(2 h)\right]$ e garantir que esse é menor que um valor de tolerância pré estabelecido. Isso deve ser feito não somente em $\xi_{0}$ mas também em uma vizinhança próxima do mesmo, i.e. $\xi_{0}+\Delta$ e $\xi_{0}-\Delta$, tal que $2 \Delta$ representa um intervalo pequeno. O determinante nesses pontos deve ser ainda muito pequeno, ou seja, menor que a tolerância estabelecida. Esse procedimento mostra-se necessário para que se possa garantir que o valor encontrado pela bisseção, $\xi_{0}$, não se trate de uma singularidade. A determinação dos valores da tolerância e de $\Delta$ é feita empiricamente.

Outro ponto interessante diz respeito ao condicionamento da matriz $\boldsymbol{M}(2 h)$ dada pela equação [-h? . A rotina de exponenciação de matrizes pode 
nos fornecer como resultados matrizes mal condicionadas, com números de condicionamento muito elevados, que podem implicar em falsas raízes, fazendo com que a curva de dispersão encontrada não tenha sentido. Torna-se então conveniente um teste do número de condicionamento da matriz com um valor de limiar preestabelecido empiricamente. Caso uma solução produza um número de condicionamento muito maior que o limiar essa não é relevante.

Uma observação importante é que as soluções para a equação $\mathbb{E - T \mathbb { T }}$ representam quaisquer ondas guiadas na placa no meio, inclusive as ondas $\mathrm{SH}$.

Conclui-se que para quaisquer meios anisotrópicos homogêneos, dentro das restrições numéricas impostas, o modelo apresentado representa uma ferramenta obtenção numérica das curvas de dispersão e pode ser usado no de estudo de ondas guiadas em placas. 


\section{3}

\section{Acustoelasticidade}

O acustoelasticidade é o ramo da acústica que trata das variações na velocidade de propagação de ondas mecânicas em função da deformação mecânica e o estado de tensão que o meio esteja submetido [ए].

A teoria da elasticidade assume que a deformação imposta a um corpo seja pequena o suficiente para que a coordenada final de um ponto possa ser aproximada por sua coordenada inicial. Contudo quando um corpo está submetido a um estado de tensão mecânica esse modelo não é capaz de explicar fenômeno observável da alteração da velocidade de propagação de ondas acústicas.

Segundo o modelo linear haveria a superposição do tensor de tensão devido a propagação da onda acústica ao estado inicial de tensão, do mesmo modo como se houvesse duas ondas propagando-se em um meio linear, ou seja, a deformação ou tensão de uma onda se somaria a da outra sem que a velocidade de propagação fosse alterada [ㅍ.3]

A teoria da acustoelasticidade apresenta um modelo não-linear para as deformações finitas onde a aproximação de que as coordenadas de um corpo não se alteram, independentemente da deformação que esse esteja submetido, não é mais válida. O que implica em uma formulação mais complexa onde as leis de elasticidade são expandidas e torna-se necessário o uso de constantes de terceira ordem para expressar as equações de movimento e, consequentemente, a velocidade de propagação de ondas acusticas.

É de interesse no presente trabalho a obtenção de uma expressão para o tensor de elasticidade em um meio submetido a um estado de tensão para que se possa traçar as curvas de dispersão para ondas guiadas em placas submetidas a uma tração. Para isso é usado o desenvolvimento presente no importante artigo de 1953 de Hughes e Kelly [14] que faz uso da formulação introduzida por Murnaghan em 1951 [1.5].

O resultado mais célebre do artigo de Hughes e Kelly é a obtenção de expressões para as velocidades de corpo de ondas mecânicas propagantes em 
meios submetidos a um estado de deformação inicial. Contudo nessa seção utiliza-se o resultado intermediário desse artigo que é uma expressão para o tensor de elasticidade em um meio sujeito a um estado de deformação inicial mais especificamente uma tensão axialmente aplicada.

Segue uma sucinta introdução da teoria de Hughes e Kelly [14] onde é apresentada a expressão para o tensor de elasticidade bem como a expressão para as ondas de corpo na direção da tensão.

\section{1}

\section{Tensor de Elasticidade em Meio sob Estado de Tensão Inicial}

Seja $\left(a_{1}, a_{2}, a_{3}\right)$ as coordenadas do sistema cartesiano original de um corpo livre de tensões mecânicas, chamadas de coordenadas Lagrangeanas, e $\left(x_{1}, x_{2}, x_{3}\right)$ as coordenadas finais, chamadas de Eulerianas, onde há deslocamento devido ao estado de tensão. Os sistemas de coordenas se relacionam pela equação

$$
x_{i}=A_{i} a_{i}+U_{i}, \quad i=1,2 \text { ou } 3,
$$

tal que, $A_{i}$ é a razão de deslocamento do sistema de coordena original ao final e $U_{i}$ é o deslocamento infinitesimal, muito menor que o deslocamento original, ou seja

$$
U_{i} \ll A_{i}-1 .
$$

A deformação infinitesimal no sistema de coordenadas final é dado por

$$
e_{i j}=\frac{1}{2}\left(\frac{\partial U_{i}}{\partial x_{j}}+\frac{\partial U_{j}}{\partial x_{i}}\right)
$$

e a relação entre a tensão e a deformação é dada por

$$
\sigma_{i j}=T_{i j}+C_{i j k l} e_{k l}
$$

tal que $T_{i j}$ representa o tensor de tensão inicial do sistema, responsável pela deformação do sistema de coordenadas original ao final.

O tensor de elasticidade $\boldsymbol{C}$ de um meio, originalmente, isotrópico na presença de um estado de tensão inicial dada por

$$
\begin{aligned}
C_{r s t u}= & \left(\lambda+2(l-\lambda-m) \theta+2(\lambda+m)\left(\alpha_{r}+\alpha_{t}\right)-2 \mu \alpha_{r}\right) \delta_{r s} \delta_{t u}+ \\
& \left(\mu+(\lambda+m-\mu) \theta+2 \mu\left(\alpha_{r}+\alpha_{s}+\alpha_{u}\right)\right)\left(\delta_{r t} \delta_{s u}+\delta_{r u} \delta_{s t}\right)+ \\
& \frac{n}{2} \sum_{v=1}^{3}\left(\delta_{s v t}^{r v u}+\delta_{s v u}^{s v t}\right) \alpha_{v} .
\end{aligned}
$$


tal que $\lambda$ é a constante de Lamé, $\mu$ o módulo de cisalhamento e $\delta_{i j}$ é o Delta de Kroenecker definidos na seção $\square$. Os parâmetros $l, m$ e $n$ são as constantes elásticas de terceira ordem ou constantes de Murnaghan. Define-se ainda

$$
\begin{aligned}
\alpha_{i} & =\frac{A_{i}^{2}-1}{2}, \\
\theta & =\sum_{i=1}^{3} \alpha_{i} \quad \text { e }
\end{aligned}
$$

$\delta_{i j k}^{l m n}$ é a função delta geral de Kronecker que para o conjunto $\mathbb{R}^{3}$ é igual ao produto dos símbolo de permutação de Levi-Civita [प]6]

$$
\delta_{i j k}^{l m n}=\epsilon_{i j k} \times \epsilon_{l m n},
$$

o qual no $\mathbb{R}^{3}$ pode ser simplificado a

$$
\epsilon_{i j k}=\frac{(j-i)(k-i)(k-j)}{2} .
$$

Observe-se que no caso do sistema livre de deformação inicial, tem-se $a_{i}=x_{i}$, ou seja, que $A_{i}=1 \mathrm{e}, \operatorname{logo}, \alpha_{i}=0$, fazendo com que o tensor de elasticidade assuma a expressão exposta na equação $\mathbb{L - 5}$, para o meio isotrópico.

As velocidade de ondas de corpo $c$ são dadas pela solução da equação

$$
\operatorname{det}\left[C_{r s t u} n_{r} n_{u}-c^{2} \delta_{s t}\right]=0
$$

onde $n_{k}$ é a o vetor unitário na direção de propagação da onda.

É de interesse no presente estudo o caso da aplicação de uma tração inicial na direção $x_{1}$. Ou seja, o tensor de tensão inicial apresenta apenas a componente $T_{11}=\tau$ não nula. A fim de obter as componentes do tensor de deformação devido a aplicação de $\tau$ emprega-se a aproximação linear da teoria da elasticidade, do mesmo modo como feito por Hughes e Kelly [14]. Resulta-se que as componente de tensor de deformação não nulas são

$$
\begin{gathered}
\varepsilon_{11}=\varepsilon=\frac{1}{E} \tau \\
\varepsilon_{22}=\varepsilon_{33}=-\nu \varepsilon=-\frac{\nu}{E} \tau,
\end{gathered}
$$

tal que $E$ é o módulo de Young e $\nu$ o coeficiente de Poisson que se relacionam com a constante de Lamé e módulo de cisalhamento pelas expressões abaixo [3] 


$$
\begin{aligned}
& E=\mu \frac{3 \lambda+2 \mu}{\lambda+\mu} \\
& \nu=\frac{\lambda}{2(\lambda+\mu)} .
\end{aligned}
$$

O mesmo resulto é obtido aplicando o tensor de tensão inicial $T_{i j}$ na equação $[-7$ e invertendo o sistema resultante.

A deformação Lagrangeana é definida em relação ao sistema de coordenada original, o sistema Lagrangeano. Essa é calculada pela diferença entre as coordenadas finais e originais dividido pela coordenada original. Considerando que a deformação Lagrangeana do sistema de coordenadas seja igual a deformação acima calculada tem-se que

$$
\varepsilon_{i i}=\frac{x_{i}-a_{i}}{a_{i}}=\frac{x_{i}}{a_{i}}-1,
$$

observando-se que da equação [-] $A_{i}=\frac{x_{i}}{a_{i}}$, tem-se que

$$
A_{i}=\varepsilon_{i i}+1
$$

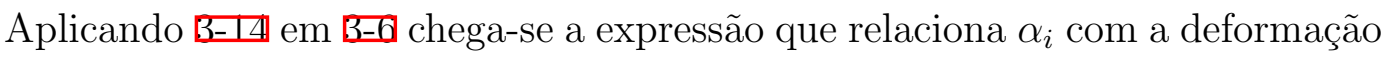
inicial

$$
\alpha_{i}=\varepsilon_{i i}+\frac{\varepsilon_{i i}^{2}}{2}
$$

e, por consequência, com a tensão inicial aplicada

$$
\begin{gathered}
\alpha_{1}=\frac{\tau}{E}+\frac{\tau^{2}}{2 E^{2}} \\
\alpha_{2}=\alpha_{3}=-\frac{\nu \tau}{E}+\frac{\nu^{2} \tau^{2}}{2 E^{2}} .
\end{gathered}
$$

Aplicando os valores de $\alpha$ obtidos pela equação [-10 em [-.5 obtém-se uma expressão para o tensor de elasticidade para cada valor de tração axial $\tau$ aplicado ao sistema.

Os valores de velocidade de corpo de ondas propagantes na mesma direção da tensão $\tau$ aplicada à placa, obtidos pela resolução da equação $\mathbf{B}-\mathbb{1}$, como expostos inicialmente por Hughes e Kelly, são

$$
\begin{aligned}
c_{L} & =\sqrt{\frac{\lambda+2 \mu}{\rho}+\frac{\tau}{\rho(3 \lambda+2 \mu)}\left[\frac{\lambda+\mu}{\mu}(4 \lambda+10 \mu+4 m)+\lambda+2 l\right]} \\
c_{T} & =\sqrt{\frac{\mu}{\rho}+\frac{\tau}{\rho(3 \lambda+2 \mu)}\left[\frac{\lambda n}{4 \mu}+4 \lambda+4 \mu+m\right]} .
\end{aligned}
$$


Para o alumínio com os valores das constates $\lambda$, $\mu$ e $\rho$ dados pela tabela $\square]$ e das constantes de terceira ordem dados pela tabela $[\mathbb{Z}$, os valores das velocidade em função de $\tau$ são iguais a

$$
\begin{aligned}
& c_{L}=\sqrt{39.96 \times 10^{6}-\tau \times 50.26 \times 10^{-4}} \mathrm{~m} / \mathrm{s} \\
& c_{T}=\sqrt{9.815 \times 10^{6}-\tau \times 3.084 \times 10^{-4}} \mathrm{~m} / \mathrm{s} .
\end{aligned}
$$

Tabela 3.1: Constantes de terceira ordem do alumínio [ㅍ]

\begin{tabular}{ccc}
\hline$l$ & $m$ & $n$ \\
$G P a$ & $G P a$ & $G P a$ \\
\hline-252.2 & -325.0 & -351.2 \\
\hline
\end{tabular}

\section{2}

\section{Curva de Dispersão para ondas Guiadas em Placas para Meio sob Deformação Inicial}

Utilizando o procedimento de cálculo exposto na seção $\square$ com a expressão do tensor de elasticidade dado pela equação [-. consegue-se obter as curvas de dispersão para ondas guiadas em uma placa sob a aplicação de um tração axial $\tau$.

Foi calculado a curva de dispersão para o alumínio em diversos valores de tensão aplicado com as constantes de Murnaghan presentes na tabela [. Essa não apresenta variações perceptíveis em uma investigação visual para valores de tração de até cerca de $100 M P a$. A fim de ilustrar a variação na curva de dispersão a figura $[$ mostra a curva de dispersão para o valor de tração excessivamente elevado de $750 \mathrm{MPa}$.

As velocidades de fase e grupo para o mesmo valor de tração são exibidas na figura $[\nabla$, onde percebe-se a leve variação comparado com as figuras $\square$ e $\overline{\nabla .8}$ respectivamente.

Explica-se que, nas figura expostas nesta seção, as curvas de dispersão para cada grupo de modo propagantes são apresentadas em mesma cor porque o procedimento exposto na seção $[.3$ para obtenção da curva de dispersão para ondas guiadas em placas de faces paralelas em meios anisotrópicos não permite a separação entre os modos propagantes na resolução numérica. 


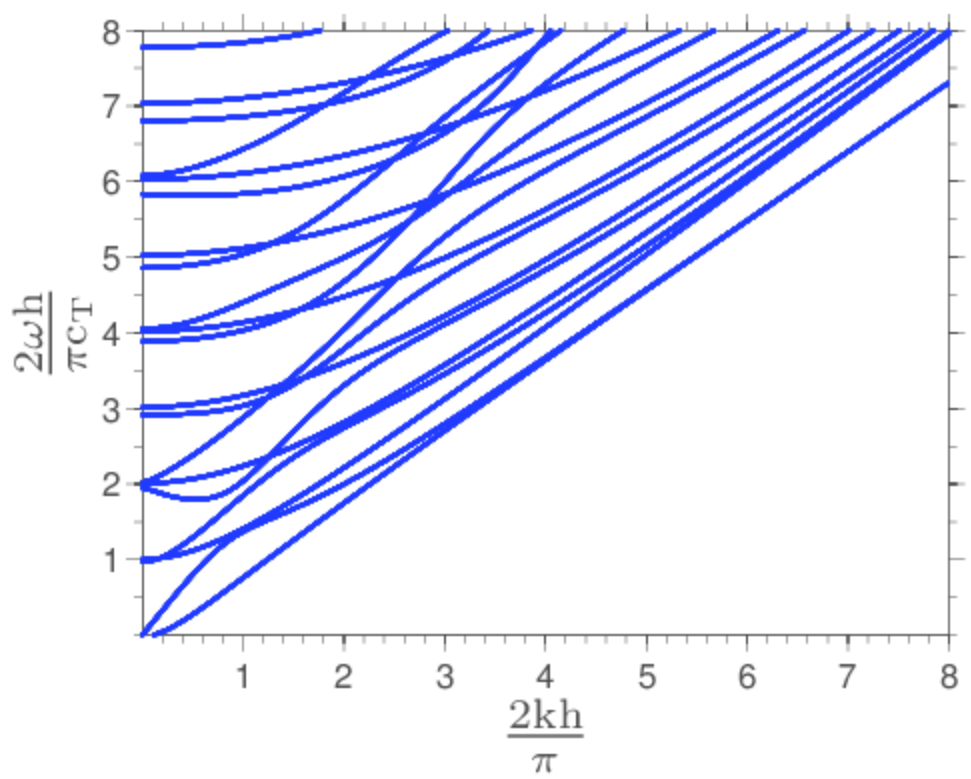

Figura 3.1: Curva de dispersão para ondas guiadas em uma placa de faces paralelas calculada para uma tração axial aplicada de $750 \mathrm{MPa}$.

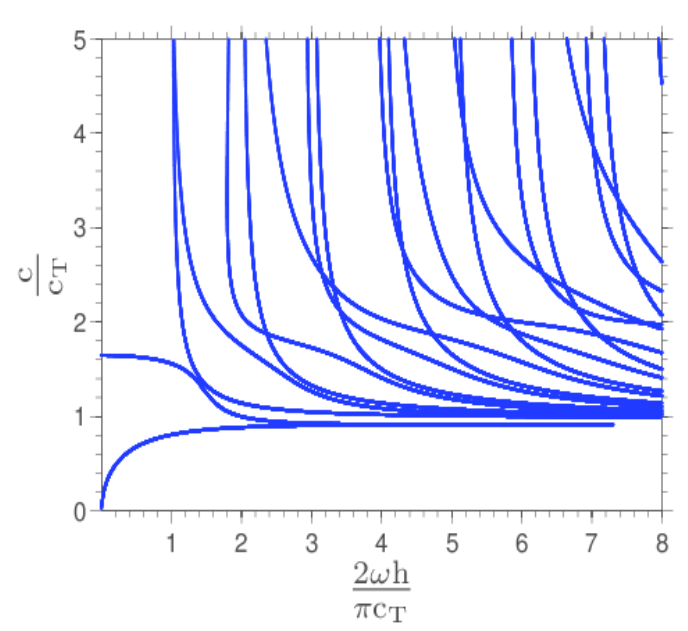

(a)

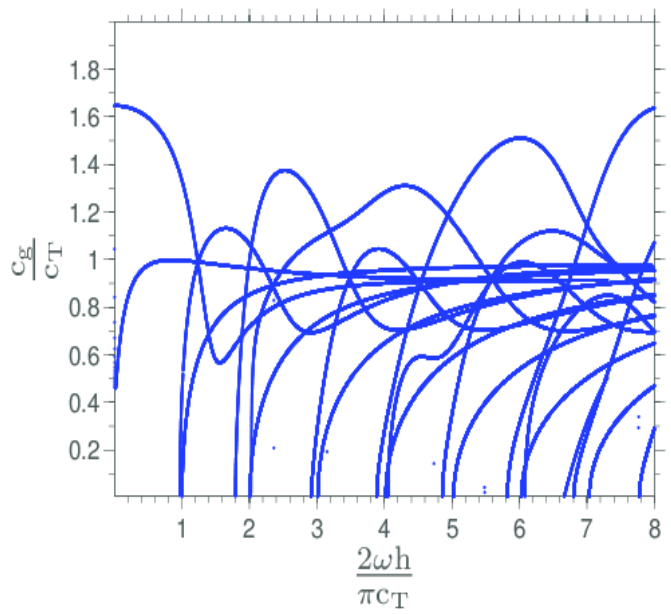

(b)

Figura 3.2: Curva de dispersão para a velocidade de fase (a) e de grupo (b) de ondas guiadas em uma placa de faces paralelas calculada para uma tração axial aplicada de $750 M P a$. 


\section{4 \\ Inversão Temporal}

O princípio da inversão temporal em sistemas físicos pode ser explicada através esse exemplo retirado de Lamb e Roberts [I7]. Imagina-se o seguinte cenário, um pêndulo ideal oscilando e sendo filmado por uma câmera. Se o filme for reproduzido de trás pra frente um espectador não seria capaz de identificar se a reprodução está no sentido correto ou inverso. Sistemas com essa características são ditos invariantes à inversão temporal e possuem simetria de inversão temporal. Um cenário parecido seria um pêndulo mais realista, onde haja a presença de atritos. Nesse caso seria possível a identificação do sentido de reprodução do filme, porque esse reproduzido em sentido direto apresentaria a amplitude das oscilações decrescendo no tempo, enquanto que no filme reproduzido em sentido inverso a amplitude aumentaria com o passar do tempo, o que representa um sistema físico impraticável. Esse último exemplo demonstra um sistema sem invariância à inversão temporal. Existem diversos exemplos teóricos onde a invariância à inversão temporal está presente. No caso de um sistema real essa pode ser violada e em cada situação prática deve ser analisada se a sua consideração é ou não aceitável.

No caso de ondas propagantes a invariância à inversão temporal implica que para cada onda divergente de uma fonte emissora e que passa a se propagar, podendo ser refletida, refratada ou espalhada pelo meio, existe em teoria um conjunto de ondas que precisamente percorrem esse caminho complexo em sentido oposto, convergindo em sincronia na posição da fonte original, tudo se passando como se o tempo estivesse andando para trás. Esse é o princípio da inversão temporal aplicado às ondas propagantes.

Para ondas acústicas, uma frente de onda ao atingir um transdutor é convertido em sinal elétrico. Esse sinal, se invertido no tempo e aplicado ao transdutor é convertido em uma onda propagante a qual percorrerá o mesmo caminho da onda incidente, mas em sentido contrário.

A equação de onda, derivada da equação de Navier, representada pela equação $\mathbb{L - 1}$, apresenta apenas derivadas temporais de segunda ordem. Isso 
implica que, se uma dada função de onda $f(\boldsymbol{x}, t)$ for solução, então $f(\boldsymbol{x},-t)$ também será. Tal propriedade é válida para qualquer meio sem perdas, homogêneo ou não, e é conhecido como teorema da reciprocidade [a]. Caso o meio apresente perdas haverá parcelas de derivada temporal de ordem ímpar e o teorema da reciprocidade não mais valerá. O princípio da reciprocidade é a propriedade básica da técnica de inversão temporal. Esse princípio é valido para qualquer onda propagante, seja eletromagnética ou mecânica, desde que o meio tenha comportamento linear.

A aplicação da inversão temporal às ondas acústicas vem sendo estudado por Fink e seu grupo da Université Denis Diderot em Paris desde a década de 1990. Eles desenvolveram o princípio do espelho de inversão temporal, conhecido pela sigla TRM, do inglés Time-Reversal Mirror. Uma visão geral da técnica do espelho de inversão temporal é encontrado em Fink et al. [ㅍ]. O TRM representa uma maneira auto-adaptativa de se focalizar uma onda em uma posição.

O TRM é usado com um conjunto de elementos receptores e transmissores, conhecido como Phased Array. A onda incide sobre o array de elementos e em cada elemento a mesma é convertida em sinal elétrico. Cada sinal é então amostrado e armazenado. Após um intervalo de tempo, suficientemente grande para que o sinal desvaneça, o conjunto de sinais é então invertido no tempo e transmitido. Em cada elemento o sinal elétrico é convertido em uma onda propagante que, superpondo-se as demais, seque o caminho contrário convergindo na fonte de onde foi transmitido o campo inicial. Assim o TRM faz com que cada componente de onda provinda de cada elemento do transdutor chegue em fase na posição do alvo e, desse modo, haja interferência construtiva, ou seja, focalização nessa posição. A teoria do TRM é exposta em três artigos célebres de Fink et al. [ㅁ, 피, 피].

Essa técnica pode ser usada no modo pulso-eco para a focalização de um transdutor do tipo Phased Array em um alvo refletor, o qual pode ser um defeito em uma estrutura. Para tal é transmitido inicialmente um pulso pelo transdutor com a mesma fase para todos os elementos. Uma onda acústica plana se propaga pelo meio até atingir algum alvo refletor, o qual reflete a onda que propaga-se na direção oposta, ou seja em direção ao transdutor. No caso de um alvo pontual a onda refletida é esférica. Ao atingir o transdutor essa onda é convertida em sinal elétrico por cada elemento do array. Esse conjunto de sinais, se invertidos no tempo e transmitidos simultaneamente pelo array, produz uma frente de onda acústica que converge no alvo.

Obtém-se assim um conjunto de sinais que fornece uma lei focal capaz 
de produzir uma onda acústica convergente no alvo sem o conhecimento da posição do mesmo ou de parâmetros do meio.

A eficiência dessa técnica foi comprovada em muitos experimentos em meios não limitados, como para alvos imersos em água [ㅍ] e utilizada para

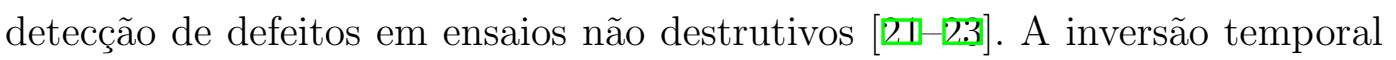
com transdutores multielementos foi inicialmente desenvolvida para focalização em alvos pontuais, contudo existem estudos para o uso da mesma em objetos extensos [ㅍ]].

Uma característica da técnica da inversão temporal usada no modo pulsoeco é o fato que o processo pode ser iterado. Ou seja, utiliza-se a resposta recebida após a primeira etapa de inversão como o sinal a ser transmitido em uma nova etapa. A vantagem da iteração mostra-se presente quando existe mais de um alvo refletor na mesma janela temporal que é invertida no tempo. Nesse caso a técnica não é capaz de focalizar diretamente em um único alvo e fornecerá duas frentes de ondas convergentes em cada um dos alvos refletores. Contudo se o processo for iterado fornece como resposta um sinal convergente apenas no alvo mais refletor […].

Para selecionar o alvo a ser focalizado é definido o operador de inversão temporal para o array de elementos. Esse consiste em uma matriz quadrada $N \times N$ onde $\mathrm{N}$ é o numero de elementos do array e cada elemento $i j$ da matriz representa a resposta impulsional no domínio da frequência sentida no elemento $j$ dada a transmissão de um impulso no elemento $i$, após todo o processo de inversão temporal. A decomposição desse operador fornece leis focais para a focalização em cada alvo refletor presente no meio. Essa especialização da inversão temporal é conhecido como técnica de Decomposição do Operador de Inversão Temporal, ou DORT, acrônimo em língua francesa, original de seus criadores. Uma análise completa da convergência do operador é apresentado em Prada et al. [2], [2]].

A técnica DORT já foi utilizada em diversos experimentos, tais como em

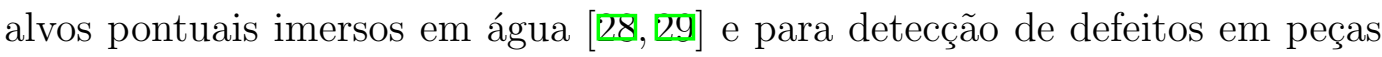
metálicas em ensaios não destrutivos [B]-[D] $]$. A mesma técnica também foi utilizada em construção de imagens [3:3, [34].

O sinal recebido em cada elemento em um meio ilimitado dada a transmissão de um pulso será composto de uma única frente de onda. Contudo em um meio fechado, tal como uma cavidade o sinal recebido é composto das reflexões nas fronteiras do meio, onde podem ocorrer possíveis mudanças de modo. Em um cenário como esse, a inversão temporal produz, idealmente, ondas acústicas que percorrem o caminho contrário, com cada reflexão, inclu- 
sive com mudanças inversas de modo. Assim um sinal invertido em apenas um elemento faz com que todos os caminhos sejam percorridos em sentido contrário de modo a haver a interferência construtiva dos modos propagantes na posição da onda transmitida. Uma análise do processo de inversão temporal em cavidades é apresentado em Draeger et al. [3.5, [36].

Uma configuração utilizada com cavidades consiste em uma cavidade imersa em água onde o sinal original é aplicado por uma fonte pontual no líquido e um transdutor de um único elemento é posicionada em uma superfície da cavidade onde é feita a inversão temporal a fim de focalizar na posição da fonte original imersa. Em Perez et al. [u, [37, $\mathbf{3 z}]$ é demostrado que quanto mais componentes de frequência são invertidas no tempo melhor a focalização. Isso se explica porque o espectro do sinal de inversão temporal torna-se mais amplo, o que melhora a focalização, diminuindo a banda espacial e aumentando a amplitude do foco.

Em Roux et al. [39] estuda-se a inversão temporal em um guia de onda em fluido. A estruta é composta por dois planos de aço paralelos imersos em água com um transdutor multielemetos em uma extremidade e uma fonte pontual em outra. O comportamento da técnica da inversão temporal frente as múltiplas reflexões nas superfícies foi analisado, mostrou-se o êxito da inversão temporal dos múltiplos ecos, onde todos chegam sincronicamente no receptor. Foi mostrado também que largura temporal do pulso recebido é tão menor quanto mais ecos forem invertidos e transmitidos.

\section{1}

\section{Etapas do Processo de Inversão Temporal}

O processo de inversão temporal em um meio onde sejam dispostos dois transdutores de ultrassom, sejam $A$ e $B$, que funcionam como atuadores e sensores alternadamente.pode ser divido em quatro etapas.

(i) Na primeira etapa é transmitido um pulso inicial, $x_{0 A}(t)$, pelo transdutor $A$. Um campo acústico é então excitado no meio e se propaga de acordo com a função de transferência do meio.

(ii) A segunda etapa consiste no registro pelo transdutor $B$, que funciona como um sensor, da forma de onda $y_{0 B}(t)$ recebida, em uma janela temporal de interesse, de $t_{0}$ a $t_{0}+T$, onde $t_{0}$ é o tempo de inicio do registro do sinal pelo transdutor $B$ em relação ao tempo de transmissão do pulso inicial, e $T$ é o tamanho da janela temporal. 
(iii) A terceira etapa é a inversão temporal do sinal recebido no transdutor $B$ e sua transmissão pelo próprio transdutor $B$, que funciona como atuador. Ou seja transmite-se

$$
x_{1 B}(t)=y_{0 B}\left(T+t_{0}-t\right)
$$

no transdutor $B$.

(iv) A quarta etapa é recepção do sinal no transdutor $A, y_{1 A}(t)$, funcionando como sensor.

\section{2}

\section{Inversão Temporal de Ondas Guiadas em Placas}

Uso de ondas de Lamb é complicado devido à dispersão presente. O sinal recebido é muito longo no tempo devido aos vários modos propagantes com velocidade de grupo distintas para cada modo em cada frequência que chegam ao ponto de detecção em tempos diferentes. Por tais características o uso de ondas de Lamb na presença de diversos modos propagantes, em ensaios não destrutivos por exemplo, é de difícil interpretação. O uso da inversão temporal pode contornar esse problema.

O uso da inversão temporal em ondas guiadas vem se difundindo nos últimos anos. Em Ing et al. [ㄸ, 40]] a inversão temporal é usada em ondas de Lamb com excitação impulsional sobre um transdutor de multielementos. Mostrou-se o sucesso da capacidade de auto focalização do processo e da compensação da dispersão das ondas guiadas implicando a recompresão temporal no sinal de inversão temporal recebido. A capacidade de focalização espacial, no qual o sinal recebido está presente apenas na posição original do transdutor, também foi comprovada sendo a banda espacial menor que em meios não dispersivos. Mostra-se que a combinação dos efeitos do guiamento de onda pela espessura, ondas de Lamb, e pela largura finita contribui ainda mais para a focalização. No trabalho citado a inversão temporal também é utilizada no modo pulso-eco para detecção de defeitos presentes na placa. No qual a reflexão acústica da frente de onda no defeito propaga-se até o array de elementos do transdutor onde o sinal recebido é invertido e retransmitido, há então a convergência dos campos acústicos no defeito, aumentando a razão sinal ruído do sinal recebido a seguir. Em Kerbrat et al. [41] é usada a técnica DORT para a detecção na presença de múltiplos defeitos na placa.

Wang et al. [42] utilizam a inversão temporal de ondas guiadas em uma rede de sensores utilizados em modo transmissão e recepção para o 
monitoramento contínuo da integridade da placa. A técnica permitiu um melhor padrão de sinal e aumentou a razão sinal ruído. Em Park et al. [4.3] a inversão temporal também é usada para o monitoramento contínuo de placa. Nesse o sinal é tratado com transformada de wavelet com a finalidade de obter um trecho de sinal mais sensível a presença de defeito.

Descreve-se nessa seção o processo de inversão temporal de ondas de Lamb para uma placa fina na qual sejam dispostos dois transdutores de ultrassom, sejam $A$ e $B$, que funcionam como atuadores e sensores alternadamente. É apresentado o processo com transdutores simples, isto é, transdutores que não são do tipo multielementos. Desse modo não se deseja usar a inversão temporal com a finalidade de se obter um sinal que representa a focalização de cada campo produzido por cada elemento do transdutor, compensando, assim, a fase de cada elemento para que, na posição de focalização, todas tenham a mesma fase e sejam, então, somadas construtivamente.

O uso da inversão temporal no presente capítulo tem a finalidade de por em fase cada modo em cada componente de frequência, compensando a dispersão imposta pelo meio. Cada componente em frequência passa a ter a mesma fase, na posição e instante adequado, havendo assim, a focalização dos modos de onda guiada propagantes. É importante, todavia, salientar que nada impediria que se utilizasse transdutores multielementos. Nesse caso haveria a combinação dos dois processos focalizadores.

Devido à dispersão das ondas de Lamb, o sinal aplicado na etapa (i) excita na placa e os modos de propagação de acordo com o espectro de dispersão. O sinal recebido na etapa (四) consiste, então, dos diversos pacotes de onda que chegam no transdutor $B$. Aqueles com velocidade de grupo mais elevada chegam antes, daqueles com velocidade de grupo menor, ao sensor $B$. A inversão temporal do sinal em $B$, etapa (四), faz com que aqueles que chegaram depois sejam transmitidos antes, e aqueles que chegaram antes sejam transmitidos depois. Desse modo, todos os pacotes propagantes, com diferentes velocidades, chegam no transdutor $A$, etapa (四), ao mesmo tempo, e o efeito da dispersão é então compensado.

\section{3}

\section{Análise do Processo de Inversão Temporal no Domínio de Frequência}

Segue uma análise teórica de cada etapa apresentada em t] a fim de se obter uma expressão para o sinal recebido após o processo. Essa baseiase e estende aquela encontrada em Park et al. [4.7] e Wang et al. [4.3, 44]. Para tal usa-se a representação dos sinais no domínio da frequência dada pela 
transformada de Fourier do mesmo. A notação do sinal em letra maiúscula é usada para designar a transformada de Fourier. Se $a(t)$ é um sinal no domínio do tempo, $A(f)$ é a transformada de Fourier de $a(t)$.

A presente seção apresenta uma análise aplicável a qualquer meio, sendo cada um representado pela função de transferência que relaciona à deformação na entrada à deformação na saída do sistema, denominada $G(f)$ no domínio da frequência. Para ondas guiadas existem expressões para $G(f)$ baseadas na teoria de ondas em placa de Mindlin [4.5], contudo no presente texto não é usada nenhuma expressão analítica para a mesma.

Segue uma propriedade importante da transformada de Fourier que é usada no decorrer do texto [46].

Proposição 4.1 Seja a(t) um sinal real no domínio do tempo, e sua transformada de Fourier dada por $A(f)$. Então, o sinal a $(\tau-t)$ tem transformada dada por $A^{*}(f) e^{-j 2 \pi f \tau}$. Tal que, o superescrito ${ }^{*}$ denota o complexo conjugado.

O sinal recebido na etapa (四) pode ser expresso, no domínio da frequência por

$$
Y_{0 B}(f)=X_{0 A}(f) A_{T A}(f) G_{A B}(f) A_{R B}(f) .
$$

Onde $X_{0 A}(f)$ é o sinal transmitido na etapa (i); $A_{T A}(f)$ é a resposta acustoelétrica de transmissão do transdutor $A$, ou seja, a função que relaciona o sinal elétrico aplicado ao transdutor com o campo acústico por esse excitado; $A_{R B}(f)$ é a resposta acusto-elétrica de recepção do transdutor $B$, que representa a função que relaciona o campo acústico sentido pelo transdutor com o sinal elétrico nesse recebido; e $G_{A B}(f)$ é a função de transferência que relaciona a deformação em $A$ à deformação em $B$.

Observe-se que o produto das três primeiras parcelas do lado direito da equação 1-Z representa a deformação mecânica no sensor $B$ dada a aplicação do sinal $X_{0 A}(f)$ em $A$, a qual é convertida em sinal elétrico pela resposta acustoelétrica de recepção do sensor $\mathrm{B}, A_{R B}(f)$. Desse modo define-se a função de transferência do sinal elétrico aplicado no sensor $A$ ao sinal elétrico recebido pelo sensor $B$ como

$$
H_{A B}(f)=A_{T A}(f) G_{A B}(f) A_{R B}(f) .
$$

Na etapa (四) inverte-se o sinal no tempo, conforme a equação 4-1, cujo equivalente no domínio da frequência é, de acordo com a proposição

$$
X_{1 B}(f)=Y_{0 B}^{*}(f) e^{-j 2 \pi f\left(T+t_{0}\right)} .
$$

Aplicando 14-2 em 1-4 obtém-se 


$$
X_{1 B}(f)=X_{0 A}^{*}(f) A_{T A}^{*}(f) G_{A B}^{*}(f) A_{R B}^{*}(f) e^{-j 2 \pi f\left(T+t_{0}\right)} .
$$

O sinal $y_{1 A}(t)$ é recebido na etapa (四). No domínio da frequência esse sinal é expresso pela deformação sentida no sensor $A$, convertida em tensão elétrica através da resposta acusto-elétrica de recepção do transdutor $A$, $A_{R A}(f)$, devido ao sinal $X_{1 B}(f)$ transmitido pelo transdutor $B$ e convertido em deformação mecânica pela resposta acusto-elétrica de transmissão de $B$, $A_{T B}(f)$ e que se propaga até o transdutor $A$ de acordo com $G_{B A}(f)$

$$
Y_{1 A}(f)=X_{1 B}(f) A_{T B}(f) G_{B A}(f) A_{R A}(f) .
$$

Do mesmo modo como estabelecido a função de transferência do transdutor $\mathrm{A}$ ao $\mathrm{B}$ faz-se o contrário,

$$
H_{B A}(f)=A_{T B}(f) G_{B A}(f) A_{R A}(f)
$$

representa a função de transferência do sinal elétrico aplicado em $B$ ao sinal elétrico recebido em A.

Aplicando 1-. em 1-6 tem-se a expressão

$$
Y_{1 A}(f)=\left(\begin{array}{c}
X_{0 A}^{*}(f) \quad \times \\
A_{T A}^{*}(f) A_{R B}^{*}(f) A_{T B}(f) A_{R A}(f) G_{A B}^{*}(f) G_{B A}(f) \quad \times \\
e^{-j 2 \pi f\left(T+t_{0}\right)}
\end{array}\right)
$$

Onde se define o operador de inversão temporal $T R O P(f)$ do sistema como o produto da conjugado da função de transferência de $A$ a $B$ pela função de transferência de $B$ a $A$.

$$
\operatorname{TROP}(f)=H_{A B}^{*}(f) H_{B A}(f)=A_{T A}(f) A_{R B}(f) A_{T B}^{*}(f) A_{R A}^{*}(f) G_{A B}(f) G_{B A}^{*}(f)
$$

Logo, a resposta recebida no sensor $A$ na etapa (四) se escreve como

$$
Y_{1 A}(f)=X_{0 A}^{*}(f) T R O P^{*}(f) e^{-j 2 \pi f\left(T+t_{0}\right)}
$$

Algumas simplificações podem ser feitas. Pelo princípio da reciprocidade a função de transferência que relaciona a deformação em $A$ dada uma onda provinda de $B$ é igual aquela que relaciona a deformação em $B$ dada uma onda provinda de $A$, ou seja

$$
G(f)=G_{A B}(f)=G_{B A}(f)
$$

Considera-se que ambos os trandutores sejam iguais, logo que suas respostas acustoelétricas sejam as mesma, ou seja 


$$
\begin{aligned}
& A_{T}(f)=A_{T A}(f)=A_{T B}(f) \\
& A_{R}(f)=A_{R A}(f)=A_{R B}(f) .
\end{aligned}
$$

Pode-se definir $A_{T R}(f)$ como a resposta acusto-elétrica de transmissão e recepção dada pelo produto das respostas acusto-elétricas de transmissão e recepção, ou seja,

$$
A_{T R}(f)=A_{T}(f) A_{R}(f) \quad .
$$

Isso posto, observe-se que pelas equações t-1 e 14-3 ambas as funções de transferência são iguais

$$
H(f)=H_{A B}(f)=H_{B A}(f)=A_{T R}(f) G(f) .
$$

As simplificações acima também implicam que o operador de inversão temporal assuma a forma

$$
T R O P(f)=H^{*}(f) H(f)=A_{T R}(f) A_{T R}^{*}(f) G(f) G^{*}(f)
$$

O operador de inversão temporal depende apenas da resposta do transdutor e do meio, sendo, de fato, o produto dos módulos quadrados da resposta acustoelétrica de transmissão e recepção e da função de transferência do meio

Seja $\phi(f)$ a fase da função de transferência do meio, pode-se escrevê-la em sua forma polar como

$$
H(f)=|H(f)| e^{j \phi(f)},
$$

e logo vê-se que o operador de reversão temporal tem fase nula,

$$
\begin{aligned}
\operatorname{TROP}(f) & =H^{*}(f) H(f)=|H(f)| e^{-j \phi(f)}|H(f)| e^{j \phi(f)} \\
& =|H(f)|^{2} e^{j(\phi(f)-\phi(f))}=|H(f)|^{2},
\end{aligned}
$$

sendo igual ao quadrado do módulo da função de transferência do meio, e logo real.

Outra característica do $T R O P(f)$ é que o mesmo é par. Isso se dá porque $H(f)$ é a função de transferência de um sistema real, logo, pelas propriedades da transformada de Fouier possui módulo par [46]. Como o operador de inversão é o quadrado do módulo da função de transferência do meio temse que $T R O P(f)$ é par.

A fim de se obter o sinal recebido em $A$ no domínio do tempo aplica-se a transformada inversa de Fourier na equação 4-10, resultando

$$
y_{1 A}(t)=\int_{-\infty}^{\infty} X_{0 A}^{*}(f) T R O P^{*}(f) e^{-j 2 \pi f\left(T+t_{0}\right)} e^{j 2 \pi f t} d f
$$

e, considerando-se que o TROP(f) seja real e igual a $|H(f)|^{2}$, 


$$
y_{1 A}(t)=\int_{-\infty}^{\infty} X_{0 A}^{*}(f)|H(f)|^{2} e^{-j 2 \pi f\left(T+t_{0}\right)} e^{j 2 \pi f t} d f
$$

\subsection{1}

\section{Focalização Temporal}

Para se entender como a inversão temporal é capaz de por cada componente de frequência em fase no sinal recebido na etapa (四) deve-se observar a expressão desse dado pela equação $1-1 \mathrm{M}$, no instante final da janela temporal de inversão, i.e., em $t=t_{0}+T$.

$$
\begin{aligned}
\left.y_{1 A}(t)\right|_{t=t_{0}+T} & =\int_{-\infty}^{\infty} X_{0 A}^{*}(f)|H(f)|^{2} e^{-j 2 \pi f\left(T+t_{0}\right)} e^{j 2 \pi f\left(t_{0}+T\right)} d f \\
& =\int_{-\infty}^{\infty} X_{0 A}^{*}(f)|H(f)|^{2} d f
\end{aligned}
$$

Ou seja, todas as componentes de frequências possuem fase nula no instante de tempo $t=t_{0}+T$, fazendo com que todas as componentes de frequência sejam somadas em fase na integral que representa o sinal recebido, e que esse seja máximo nesse instante.

No caso de uma excitação inicial de amplo espectro, ou no caso limite de um impulso, tem-se que a transformada da excitação inicial é constante e real, i.e., $X_{0 A}(f)=X_{0}$. Assim sendo, o valor do sinal recebido no instante de tempo em questão é máximo, sendo igual, a menos da constante $X_{0}$, ao quadrado da função de transferência do meio, ou seja, da energia do sistema, como mostra a equação

$$
\left.y_{1 A}(t)\right|_{t=t_{0}+T}=X_{0} \int_{-\infty}^{\infty}|H(f)|^{2} d f
$$

$\mathrm{Na}$ equação acima a integral é calculada em todo o espectro, contudo num caso prático a função de transferência possui uma banda de frequência finita. Desse modo o valor do sinal acima calculado é tão maior quanto maior for a banda de frequência presente na função de transferência. Um meio com resposta impulsional de espectro largo apresentará maior valor do sinal focalizado.

Outra característica importante da reposta do sinal de inversão temporal é que o mesmo é simétrico em relação ao instante de tempo $t_{0}+T$. Isso pode ser comprovado diretamente pela equação $1 \mathbf{- 1} \mathbf{8}$ para dois instantes igualmente distantes de $t_{0}+T$, sejam $t_{+}=t_{0}+T+\epsilon$ e $t_{-}=t_{0}+T-\epsilon$ 


$$
\begin{aligned}
\left.y_{1 A}(t)\right|_{t_{+}=t_{0}+T+\epsilon} & =\int_{-\infty}^{\infty} X_{0 A}^{*}(f)|H(f)|^{2} e^{-j 2 \pi f\left(T+t_{0}\right)} e^{j 2 \pi f\left(t_{0}+T+\epsilon\right)} d f \\
& =\int_{-\infty}^{\infty} X_{0 A}^{*}(f)|H(f)|^{2} e^{j 2 \pi f \epsilon} d f
\end{aligned}
$$

considerando que $X_{0 A}(f)$ seja real e par, o que é respeitado para uma excitação impulsional, e as simplificações impostas pelas equações t-1 e 1-1] que implicam que $\operatorname{TROP}(f)=|H(f)|^{2}$ seja, também, real e par, tem-se que

$$
\begin{aligned}
\left.y_{1 A}(t)\right|_{t_{+}=t_{0}+T+\epsilon} & =\int_{-\infty}^{\infty} X_{0 A}(f)|H(f)|^{2} \cos (2 \pi f \epsilon) d f \\
& +j \int_{-\infty}^{\infty} X_{0 A}(f)|H(f)|^{2} \sin (2 \pi f \epsilon) d f
\end{aligned}
$$

onde a segunda parcela é nula porque é a integral em um intervalo simétrico de uma função impar, produto de uma função par, $X_{0 A}(f) T R O P(f)$ (que é par por ser o produto de duas funções pares), por uma função impar, $\sin (j 2 \pi f \epsilon)$. Logo,

$$
\left.y_{1 A}(t)\right|_{t_{+}=t_{0}+T+\epsilon}=\int_{-\infty}^{\infty} X_{0 A}(f)|H(f)|^{2} \cos (2 \pi f \epsilon) d f
$$

Do modo análogo ao feito acima tem-se para $t_{-}$que

$$
\begin{aligned}
\left.y_{1 A}(t)\right|_{t_{-}=t_{0}+T-\epsilon} & =\int_{-\infty}^{\infty} X_{0 A}(f)|H(f)|^{2} \cos (2 \pi f \epsilon) d f \\
& -j \int_{-\infty}^{\infty} X_{0 A}(f)|H(f)|^{2} \sin (2 \pi f \epsilon) d f \\
& =\int_{-\infty}^{\infty} X_{0 A}(f)|H(f)|^{2} \cos (2 \pi f \epsilon) d f
\end{aligned}
$$

Das equações 14-24 e t-2. se conclui que $\left.y_{1 A}(t)\right|_{t_{+}=t_{0}+T+\epsilon}=\left.y_{1 A}(t)\right|_{t_{-}=t_{0}+T-\epsilon}$, demonstrando que $y_{1 A}(t)$ é simétrico em relação ao instante $t_{0}+T$.

É importante salientar que as observações feitas sobre compensação de fase, valor máximo em $t_{0}+T$ e simetria apenas valem para o caso de $T R O P(f)=|H(f)|^{2}$. É analisado no decorrer do texto as implicações da mudança da função de transferência nas diferentes etapas do processo de inversão temporal no sinal de inversão temporal recebido.

A presença do ruído faz com que haja uma contribuição aleatória na recepção do sinal, a qual não é compensada pela inversão temporal. Assim 
sendo, componentes de frequência que não representam informação do sinal, ou que foram muito corrompidas por um ruído, representando uma componente não determinística, não são compensadas pela inversão temporal. Como visto acima, a simetria do sinal ocorre no caso ideal onde todas as frequências foram invertidas corretamente. Pode-se usar a simetria do sinal como uma forma de determinar a qualidade da focalização por inversão temporal [ [ $]$.

A focalização temporal é tão melhor quanto mais estreito for o sinal recebido. Isso ocorre para sinais com maior riqueza espectral, ou seja sinais com muitas componentes de frequência, não havendo forte predominância de uma dada componente. Ou seja, uma focalização temporal ideal seria representado pelo caso extremo de um impulso no tempo localizado no instante $t_{0}+T$.

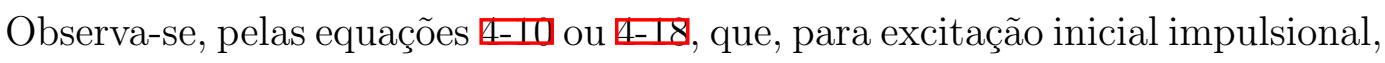
isso ocorre se $\operatorname{TROP}(f)$ for constante para todas as freguências.

Pode-se exemplificar o fato da qualidade da focalização temporal dada a maior riqueza espectral a partir da equação t-24, que representa o sinal de inversão temporal recebido para vizinhanças, $\epsilon$, do instante de focalização $t_{0}+T$, tal que, pela simetria do sinal $\epsilon$ pode assumir valores positivos ou negativos. Para tal, suponha-se que a excitação inicial seja impulsional e o operador de inversão temporal possua riqueza espectral ideal em uma banda $\Delta f$, ou seja,

$$
\operatorname{TROP}(f)=\left\{\begin{array}{l}
\frac{K}{2 \Delta f} \quad, f_{0}<|f|<f_{0}+\Delta f \\
0 \quad, \text { caso contrário }
\end{array}\right.
$$

Assim sendo o sinal recebido assume a forma,

$$
\begin{aligned}
\left.y_{1 A}(t)\right|_{t_{+}=t_{0}+T+\epsilon} & =X_{0} \frac{K}{2 \Delta f}\left(\int_{-f_{0}-\Delta f}^{-f_{0}} \cos (2 \pi f \epsilon) d f+\int_{f_{0}}^{f_{0}+\Delta f} \cos (2 \pi f \epsilon) d f\right) \\
& =X_{0} \frac{K}{\Delta f} \int_{f_{0}}^{f_{0}+\Delta f} \cos (2 \pi f \epsilon) d f \\
& =X_{0} K \frac{\sin \left(2 \pi \epsilon\left(f_{0}+\Delta f\right)\right)-\sin \left(2 \pi \epsilon f_{0}\right)}{2 \pi \Delta f \epsilon}
\end{aligned}
$$

Que é tão mais estreito em relação ao instante $t_{0}+T$ quanto maior for a banda $\Delta f$. Se $\Delta f \gg f_{0}$ a largura temporal de $-6 d B$ do sinal é $0.604 / \Delta f$. Ou seja, quanto maior for o número de componentes de frequências presente no operador de reversão temporal, melhor será a focalização temporal.

Contudo para casos práticos, sobretudo para ondas guiadas, $H(f)$ apresenta predomínio de magnitude de uma faixa de frequência [42-44], o que 
implica que $\operatorname{TROP}(f)$ tem ainda maior predomínio dessa faixa, frente as demais frequências, dado que $\operatorname{TROP}(f)$ é igual ao módulo quadrado da função de transferência do meio. A fim de contornar esse inconveniente pode-se usar o conhecimento da função de transferência, obtida na primeira recepção, etapa (四), quando excita-se o sistema com um sinal inicial impulsional, para transmitir um sinal na etapa seguinte, (四), que faça com que o sinal recebido na etapa (四) apresente melhor focalização temporal. A técnica do filtro inverso, exposta no decorrer desse capítulo, representa uma maneira de se obter melhor focalização espacial conhecendo-se a função de transferência do meio.

A obtenção da função de transferência é essencial para efetuar-se um bom processo de inversão temporal. Uma maneira de melhor obtê-la é apresentado em Pérez et al. [47] onde o conceito da inversão temporal no domínio da frequência, FDTR do acrônimo em inglês, é introduzido. Essa técnica se diferencia da técnica tradicional por obter a função de transferência do sistema diretamente no domínio da frequência. Para isso é transmitido uma séria de senóides, fazendo uma varredura em frequência. Mede-se a fase e amplitude da resposta recebida, a qual, considerando o sistema linear, é uma senóides na mesma frequência. Esse espectro criado é a função de transferência do sistema, o sinal no domínio do tempo é obtido aplicando-se a transformada inversa de Fourier. A partir daí o processo é igual ao tradicional, ou seja, o sinal é invertido no tempo e retransmitido. O uso dessa variante permite obter maior amplitude no instante de focalização, maior razão sinal ruído e melhor focalização espacial. Isso se deve a melhor caracterização das altas frequências, sobretudo de fase.

No modo tradicional é transmitido um pulso estreito no tempo, idealmente um delta de Dirac, a fim de se obter a resposta em frequência. Todavia por mais estreito que seja esse pulso ele é sempre finito no tempo e logo há uma banda finita de frequência. Na FDTR são transmitidos senos, esses idealmente devem ser infinitos no tempo para ser monocromático, contudo, é tecnologicamente mais simples construir senos largos, do que pulsos estreitos. Essa é uma opção de enriquecimento espectral, já que melhor caracteriza as altas frequências.

Outra característica interessante da técnica mencionada está na garantia de se trabalhar na região linear. Na técnica tradicional é transmitido um pulso de alta amplitude que pode provocar um comportamento não linear no meio, dependendo de sua intensidade, contudo na FDTR é transmitido sempre ondas de baixa amplitude. 


\subsection{2}

\section{Focalização Espacial}

A focalização espacial é representada por quanto o sinal desvanece para posições vizinhas à posição de medição do sinal na etapa (四). Pode-se medi-la pela correlação entre do sinal obtido em pontos próximos a posição de medição original. Uma forma de medir esses vários sinais é movendo-se o transdutor sensor na etapa (四).

Como demonstrado em Ing et al. [6, 41]] quanto mais dispersivo for o meio, como ondas guiadas em uma placa, melhor é a qualidade da focalização espacial, ou seja, menor a banda espacial na posição de focalização.

\subsection{3}

\section{Recuperação do Sinal Inicial}

Voltando à equação $1-1 \mathbf{d}$ observa-se que o sinal recebido pelo processo de inversão temporal, $y_{1 A}(t)$, se invertido na janela de $t_{0}$ a $t_{0}+T$ é igual a

$$
\begin{aligned}
y_{1 A}\left(T-t+t_{0}\right) & =\int_{-\infty}^{\infty} X_{0 A}^{*}(f) T R O P^{*}(f) e^{-j 2 \pi f\left(T+t_{0}\right)} e^{j 2 \pi f\left(T-t+t_{0}\right)} d f \\
& =\int_{-\infty}^{\infty} X_{0 A}^{*}(f) T R O P^{*}(f) e^{-j 2 \pi f t} d f \\
& =\left(\int_{-\infty}^{\infty} X_{0 A}(f) T R O P(f) e^{j 2 \pi f t} d f\right)^{*}
\end{aligned}
$$

Observe-se que se $T R O P(f)$ não depender da frequência, ou seja se $T R O P(f)=K$, constante para as freguências em que $X_{0 A}(f)$ não for nulo, a equação $1-18$ passa a ser

$$
y_{1 A}\left(T-t+t_{0}\right)=K\left(\int_{-\infty}^{\infty} X_{0 A}(f) e^{j 2 \pi f t} d f\right)^{*}
$$

onde a expressão dentro do parênteses é, justamente, a transformada inversa de Fourier de $X_{0 A}(f)$, ou seja, $x_{0 A}(t)$. Como esse sinal original é real, tem-se que

$$
y_{1 A}\left(T-t+t_{0}\right)=K x_{0 A}(t)
$$

ou seja, o sinal recebido e invertido na janela de $t_{0}$ a $t_{0}+T$ é igual ao sinal original, ou, equivalentemente, 


$$
y_{1 A}\left(t+t_{0}\right)=K x_{0 A}(T-t),
$$

isto é, o sinal recebido em $A$ na janela de tempo de $t_{0}$ a $t_{0}+T$ é igual ao sinal original enviado invertido no tempo. Desse modo o sinal enviado é reconstruído após o processo de inversão temporal.

Para ondas de corpo, $G(f)$ assume a expressão abaixo [4], 48$]$, para uma certa distância $r$ da fonte,

$$
G(f)=\frac{e^{j k r}}{r}
$$

onde $k$ é o número de onda. Logo,

$$
G(f) G^{*}(f)=\frac{e^{j k r}}{r} \frac{e^{-j k r}}{r}=\frac{1}{r^{2}}
$$

ou seja o módulo quadrado da função de transferência do meio, é constante, não depende da frequência, para meios ilimitados, i.e., para ondas de corpo. Se o sinal original possuir faixa de frequência dentro da banda de operação dos transdutores, onde pode-se assumir o módulo quadrado da resposta acustoelétrica constante, o sinal original será totalmente reconstruído.

Contudo para o caso geral das ondas de guiadas na placa $G(f) G^{*}(f)$ é bastante complexa e não constante na frequência. O sinal original não é, então, reconstruído no processo de inversão temporal a menos que se use um sinal bastante estreito em frequência, tal como um toneburst. Contudo o uso de um sinal de banda mais estreita implica em menos componentes de frequência sendo postas em fase pelo processo de inversão temporal, e logo menos componentes sendo somadas na integral no sinal recebido $y_{1 A}(t)$, dado pela equação H-1].

Em Alleyne et al. [4.9] usou-se a inversão temporal em ondas de Lamb para compensar a dispersão presente no primeiro modo anti-simétricos e simétrico, em duas experiências distintas, em uma placa de alguns centímetros de comprimento. Nessa era excitado um sinal tone burst, de espectro estreito, e o mesmo era reconstruído na recepção pelo processo de inversão temporal. A vantagem apontada nesse trabalho é que, ao compensar a dispersão, o sinal recebido tem forma bem definida, e assim a detecção de defeitos na placa é facilitada.

\subsection{4}

\section{Filtro Inverso}

A focalização temporal é tão melhor quanto mais componentes de 
frequência houver no sinal de inversão temporal recebido. A presença de uma faixa de frequência com amplitudes predominante na função de transferência faz com que o espectro do sinal de inversão temporal seja ainda menos equilibrado, como é observado pela equação 1-19. O filtro inverso é uma forma de equalizar o espectro do sinal de inversão temporal recebido, alterando o sinal a ser transmitido etapa (四) com base na função transferência do meio.

O filtro inverso encontra-se exposto em Tanter et al. [50-5] onde o mesmo é usado no modo pulso-eco com transdutores de vários elementos. Em Perez [ [ ] é aplicado o filtro inverso a um sistema de focalização com inversão temporal em cavidades acústicas de configuração igual ao usada no presente trabalho. O uso correto dessa filtro traz melhorias na focalização temporal.

A idéia do filtro inverso é não apenas inverter o sinal recebido no tempo, na etapa (四), mas também inverter o seu espectro de amplitude. Ou seja, o sinal transmitido nessa etapa, dado pela equação 4-4, passa a ter o sua a amplitude do espectro invertida resultando em

$$
X_{1 B}(f)=\frac{1}{\left|Y_{0 B}(f)\right|} e^{-j \phi_{Y_{O B}}(f)} e^{-j 2 \pi f\left(T+t_{0}\right)},
$$

onde $\phi_{Y_{O B}}(f)$ é a fase de $Y_{O B}(f)$. Pela definição de $Y_{O B}(f)$ seu módulo é dado por

$$
Y_{O B}(f)=\left|X_{O A}(f)\right||H(f)|
$$

e sua fase por

$$
\phi_{Y_{O B}}(f)=\phi_{X_{O A}}(f)+\phi(f)
$$

tal que, $\phi_{X_{O A}}(f)$ é a fase de $X_{O A}(f)$ e $\phi(f)$ a fase da função de transferência $H(f)$. Aplicando 4-3.3. e 4-36 em 1-34, reescreve-se a expressão do sinal recebido.

$$
X_{1 B}(f)=\frac{1}{\left|X_{O A}(f)\right|} \frac{1}{|H(f)|} e^{-j \phi_{X_{O A}}(f)} e^{-j \phi(f)} e^{-j 2 \pi f\left(T+t_{0}\right)} .
$$

O sinal recebido na etapa (国) é dado pela equação t-6, sendo o produto do sinal recebido pela função de tranferência $H(f)$, como mostrado na equação abaixo,

$$
\begin{aligned}
Y_{1 A}(f) & =\frac{1}{\left|X_{O A}(f)\right|} \frac{1}{|H(f)|} e^{-j \phi_{X_{O A}}(f)} e^{-j \phi(f)} e^{-j 2 \pi f\left(T+t_{0}\right)} H(f) \\
& =\frac{1}{\left|X_{O A}(f)\right|} \frac{|H(f)|}{|H(f)|} e^{-j \phi_{X_{O A}}(f)} e^{j(\phi(f)-\phi(f))} e^{-j 2 \pi f\left(T+t_{0}\right)}
\end{aligned}
$$

Observe-se que para uma inversão do módulo e de fase ideais tem-se que ambos são compensados. Ao recuperar o sinal no domínio do tempo todos as componentes em frequências são somadas com igual amplitude. Considerando a excitação inicial impulsional, ou $\left|X_{O A}(f)\right|=X_{0}$ e $\phi_{X_{O A}}(f)=0$, o sinal no tempo é dada por 


$$
y_{1 A}(t)=\frac{1}{X_{0}} \int_{-\infty}^{\infty} e^{-j 2 \pi f\left(T+t_{0}\right)} e^{j 2 \pi f t} d f=\frac{1}{X_{0}} \delta\left(t-\left(T+t_{0}\right)\right)
$$

onde $\delta(t)$ é o delta de Dirac. O sinal recebido é um impulso centrado em $t=T+t_{0}$, ou seja a focalização espacial é máxima.

Na prática o uso do filtro inverso da maneira como exposta introduz um fator de erro no sistema. Com essa técnica todas as frequências têm o mesmo peso na contribuição do sinal recebido, como se observa pela equação t-39, mesmo aqueles com maior componente aleatórias, tanto em amplitude quanto em fase. Sobretudo as componentes de baixa amplitude, dado que quando a amplitude tende a zero a fase se torna indeterminada. Assim, as componentes aleatórias são igualmente somadas no sinal, contaminando-o com erro.

Deve-se tomar cuidado com o uso do filtro inverso. Uma solução é estabelecer um conjunto de confiança para as frequências, ou seja, aquelas que podem, ou não, ser invertidas. Uma maneira é definir um limiar de amplitude, como uma percentagem do valor máximo de amplitude de todo o espectro, por exemplo, a partir do qual as componentes em frequências são ditas confiáveis ou, senão, erráticas. Somente as frequências confiáveis são invertidas.

\section{4}

\section{Variação da Função de Transferência do Meio}

Estuda-se nessa seção os efeitos da mudança da função de transferência do meio no decorrer do processo de inversão temporal. A consideração sobre a reciprocidade do sistema continua valendo sendo inerente à característica física do problema, ou seja $H_{A B}(f)=H_{B A}(f)=H(f)$, a mudança aqui analisada é da própria função de transferência durante as diferentes etapas do processo.

As etapas (i) e (四) são realizadas com o sistema em sua condição inicial, onde a função de transferência do mesmo é $H(f)$ recebendo-se o sinal $y_{0 B}(t)$, cujo espectro é igual

$$
Y_{0 B}(f)=X_{0 A}(f) H(f)
$$

O sinal é então invertido no tempo, etapa (四), e transmitido, com o espectro dado pela equação 10-5,e logo, igual a

$$
X_{1 B}(f)=X_{0 A}^{*}(f) H^{*}(f) e^{-j 2 \pi f\left(T+t_{0}\right)} .
$$

Contudo, na etapa (四) o sistema é, levemente, degenerado devido a alguma alteração em suas condições de contorno. Desse modo o sistema passa a ser caracterizado pela nova função de transferência $\tilde{H}(f)$. A resposta recebida nessa etapa é dada, então, pelo produto do lado direito da equação 14-4] pela 
nova função de transferência. Escrevendo ambas as funções em sua forma polar, como dado pela equação $1-16$, onde $\tilde{\phi}(f)$ é a fase de $\tilde{H}(f)$, chega-se à expressão para o sinal recebido

$$
\begin{aligned}
\tilde{Y}_{1 A}(f) & =X_{0 A}^{*}(f) H^{*}(f) e^{-j 2 \pi f\left(T+t_{0}\right)} \tilde{H}(f) \\
& =X_{0 A}^{*}(f)|H(f)| e^{-j \phi(f)} e^{-j 2 \pi f\left(T+t_{0}\right)}|\tilde{H}(f)| e^{j \tilde{\phi}(f)} \\
& =X_{0 A}^{*}(f)|H(f)||\tilde{H}(f)| e^{j(\tilde{\phi}(f)-\phi(f))} e^{-j 2 \pi f\left(T+t_{0}\right)} \\
& =X_{0 A}^{*}(f)|H(f)||\tilde{H}(f)| e^{j \Delta \tilde{\phi}(f)} e^{-j 2 \pi f\left(T+t_{0}\right)}
\end{aligned}
$$

tal que

$$
\Delta \tilde{\phi}(f)=\tilde{\phi}(f)-\phi(f)
$$

Observe-se que nesse caso o operador de inversão temporal não possui fase nula,

$$
\begin{aligned}
\operatorname{TROP}(f)=H^{*}(f) \tilde{H}(f) & =|H(f)||\tilde{H}(f)| e^{j(\tilde{\phi}(f)-\phi(f))} \\
& =|H(f)||\tilde{H}(f)| e^{j \Delta \tilde{\phi}(f)}
\end{aligned}
$$

e, logo, não é real.

Aplicando a transformado de inversa de Fourier na equação 4-42, a fim de obter uma expressão para o sinal recebido no domínio do tempo chega-se a equação

$$
\tilde{y}_{1 A}(t)=\int_{-\infty}^{\infty} X_{0 A}^{*}(f)|H(f)||\tilde{H}(f)| e^{j \Delta \tilde{\phi}(f)} e^{-j 2 \pi f\left(T+t_{0}\right)} e^{j 2 \pi f t} d f
$$

Da equação acima comprova-se que não há compensação de fase nem mesmo para o instante final da janela, $t_{0}+T$. No caso de excitação inicial impulsional, $X_{0 A}(f)=X_{0}$, vê-se que se houver diferença nas fases, i.e. $\tilde{\phi}(f) \neq \phi(f)$, o sinal recebido no instante $t_{0}+T$ não é igual ao produto dos módulos das funções de transferência, havendo o fator $e^{j \Delta \tilde{\phi}(f)}$ que deprecia o valor da integral, dado que é detectável a parte a real do sinal.

A consideração sobre a simetria do sinal recebido também falha quando há erro de fase, isso porque surgiria um termo da diferença de fase no cosseno da equação t--Z3 fazendo com que a mesma não seja simétrica em $\epsilon$. Contudo caso haja apenas diferença de amplitude, i.e. $\tilde{\phi}(f)=\phi(f)$, a simetria continua. Nesse caso, não há fator de fase no cosseno e o operador de inversão temporal, dado nesse caso por $|H(f)||\tilde{H}(f)|$, continua sendo par porque cada um dos módulos multiplicados é par. Fica claro porque a simetria do sinal é um indicativo da qualidade da focalização por inversão temporal 


\subsection{1}

\section{Influência da Tração Aplicada}

No presente trabalho, deseja-se observar como a variação da tração longitudinal aplicada à uma placa influencia o processo de inversão temporal das ondas guiadas que se propagam na mesma. Para tal executa-se as etapas (i) e (四) para uma condição de tração inicial, com a função de transferência do sistema sendo $H(f)$. Inverte-se, na janela de interesse, e transmite-se o sinal, após a placa ter sua tração alterada, e a função de transferência do sistema passa a ser $\tilde{H}(f)$.

Imagina-se, inicialmente, que a placa seja infinita em largura e comprimento, onde o único guiamento de ondas presente se dá pela sua espessura. Ao tracionar a placa a mesma sofre uma deformação, como os transdutores estão fixos à placa, o posicionamento relativo entre os mesmo é alterado logo o tempo de propagação para cada modo propagante muda, e por consequência a fase de cada componente em frequência também. Desse modo, é normal esperar-se que haja diferença entre as fases $\tilde{\phi}(f)$ e $\phi(f)$, e logo que a focalização temporal seja comprometida.

Se é considerado o guiamento de ondas devido a largura da placa e a reflexão no seu comprimento finito tem-se que os efeitos de erro de fase são ainda mais severos. Isso porque, dada uma excitação impulsional há várias espécies de ondas propagantes que tiveram seus tempos de propagação alterados devido a alteração de seus percursos provocada pela tração aplicada.

Considerando que haja apenas variação da fase durante o processo de tracionamento, ou seja, a amplitude da função de transferência não se altere e que a excitação inicial seja impulsional a equação do sinal obtido 1-4. pode ser simplificada a

$$
\tilde{y}_{1 A}(t)=X_{0} \int_{-\infty}^{\infty}|H(f)|^{2} e^{j \Delta \tilde{\phi}(f)} e^{-j 2 \pi f\left(T+t_{0}\right)} e^{j 2 \pi f t} d f
$$

Considerando que haja a variação de espessura e largura com o tracionamento, devido ao módulo de Poisson $(\nu)$, os modos propagantes podem se alterar e, por consequência, o módulo da função de transferência também.

Conclui-se que a aplicação de uma tração deve alterar o sistema e fazer com que o a resposta recebida seja alterada e a focalização temporal degradada.

Para sinais de inversão temporal com maior riqueza espectral, há contribuições de mais componentes de frequência fazendo com que a focalização temporal seja mais estreita. Sinais desse tipo são mais suscetíveis a degradação 
devido ao erro de fase, introduzido por um processo como o descrito acima, já que há mais componentes de frequência cuja fase que são alteradas. Em sinais com uma pequena faixa de frequência não nula, ou predominante, apenas essas frequências seriam importantes para a degradação devido ao erro de fase. Isso é compreendido observando que o sinal recebido é dado pela equação $1-40$ onde cada fase é multiplicada pela magnitude quadrada da função de transferência. Assim, mesmo que haja uma diferença de fase grande em uma dada frequência cujo módulo seja pequeno, essa tem pouca relevância. Observa-se assim que algum tratamento que vise equalizar o espectro, como o filtro inverso, deve tornar o sinal mais sensível a alteração de tração proposta.

Todavia, um sinal com maior riqueza espectral está mais sujeito a efeitos aleatórios de ruído, isso porque leva-se em conta maior banda frequência. Assim sendo um sinal de amplo espectro deve apresentar um erro aleatório de fase que está presente mesmo para a condição de tração inicial, o qual deve diminuir, por exemplo, a simetria na condição inicial de tração.

\subsubsection{1}

Modelo Proposto para Fase do Sinal de Inversão Temporal dada a Variação da Tração Aplicada

Nessa seção é proposto um modelo para a fase do sinal de inversão temporal dado um valor de variação da tração aplicada.

Inicialmente observa-se que apenas são registráveis na etapa (四) os modos cujo tempo de propagação para a distância $L$ entre o transdutor transmissor e receptor estejam dentro da janela de recepção, ou seja,

$$
t_{0} \leq t_{p_{i}}(f) \leq T+t_{0}
$$

tal que $t_{p_{i}}(f)$ é o tempo de propagação do modo de onda guiada $i$ na frequência $f$, que é igual a razão da distância entre os transdutores pela velocidade de propação de cada modo, ou seja,

$$
t_{p_{i}}(f)=\frac{L}{c_{g_{i}}(f)}
$$

tal que $c_{g_{i}}(f)$ é a velocidade de grupo de cada modo $i$ na frequência $f$. A figura [4b mostra as curvas da velocidade de grupo para os modos de Lamb propagantes em função da frequência adimensional $\Omega$

Ao inverter-se o sinal na janela de recepção para transmití-la na etapa (四) o que acontece nada mais é que aplicar um retardo no envio de cada modo em cada componente de frequência. Isto é, transmite-se cada modo com um 
retardo de transmissão de

$$
t_{r_{i}}(f)=T+t_{0}-t_{p_{i}}(f)=T+t_{0}-\frac{L}{c_{g_{i}}(f)} .
$$

A placa é então tracionada e na etapa (四) recebe-se cada modo com tempo de propagação igual a

$$
\tilde{t}_{p_{i}}(f)=\frac{\tilde{L}}{\tilde{c}_{g_{i}}(f)},
$$

onde $\tilde{L}$ representa o novo comprimento entre transmissor receptor devido ao tracionamento da placa e $\tilde{c}_{g_{i}}(f)$ nova velocidade de cada modo, devido a mudança na curva de dispersão devido ao tracionamento da placa. Como há um retardo de transmissão para cada modo tem-se que o tempo de chegada, $\tilde{t}_{a_{i}}(f)$, de cada modo $i$ na frequência $f$ é igual ao tempo de propagação mais o retardo, ou seja,

$$
\tilde{t}_{a_{i}}(f)=\tilde{t}_{p_{i}}(f)+t_{r_{i}}(f)=\frac{\tilde{L}}{\tilde{c}_{g_{i}}(f)}+T+t_{0}-\frac{L}{c_{g_{i}}(f)} .
$$

Convém escrever o tempo de chegada na forma

$$
\tilde{t}_{a_{i}}(f)=\Delta \tilde{t}_{a_{i}}(f)+T+t_{0},
$$

onde

$$
\Delta \tilde{t}_{a_{i}}(f)=\frac{\tilde{L}}{\tilde{c}_{g_{i}}(f)}-\frac{L}{c_{g_{i}}(f)} .
$$

Se se reconstruisse o sinal de inversão temporal da etapa (四), ter-seía que o tempo de chegada de cada componente em frequência imporia um deslocamento temporal em cada contribuição harmônica, o que se traduz em um fator de fase para cada componente, ou seja,

$$
\begin{aligned}
\tilde{y}_{1}(t) & =\int_{-\infty}^{\infty} \sum_{i} A_{i}^{2}(f) e^{-j 2 \pi f \tilde{t}_{a_{i}}(f)} e^{j 2 \pi f t} d f \\
& =\int_{-\infty}^{\infty} \sum_{i} A_{i}^{2}(f) e^{-j 2 \pi f \Delta \tilde{t}_{a_{i}}(f)} e^{-j 2 \pi f\left(T+t_{0}\right)} e^{j 2 \pi f t} d f
\end{aligned}
$$

tal que o $A_{i}(f)$ é a amplitude de cada componente harmônica de cada modo propagante que exista dentro da janela de recepção, dada pela equação 1-47. A janela de recepção pode ser escrita em função da velocidade de propagação por

$$
\frac{L}{T+t_{0}} \leq c_{g_{i}}(f) \leq \frac{L}{t_{0}}
$$

Se para uma dada componente de frequência houver apenas um modo propagante dentro da janela de velocidade receptíveis, dado pela condição 
acima, a sua amplitude é igual ao operador de inversão temporal do sistema nessa frequência, ou seja,

$$
A^{2}(f)=|H(f)|^{2}
$$

como não há mais sentido indexar os modos para tais frequências, foi retirado o índice $i$.

Para componentes de frequência que possuam mais de um modo receptível assume-se que haja iqualdade de energia entre cada modo, e que a soma deles seja igual a função de transferência do sistema nessa frequência, obtém-se assim a expressão geral para cada amplitude do espectro,

$$
A_{i}^{2}(f)=\frac{|H(f)|^{2}}{\left|\sum_{i} e^{-j 2 \pi f \Delta \tilde{t}_{a_{i}}(f)}\right|} .
$$

Observe-se que é suposto que o módulo da função de transferência não mude com a tração aplicada, ou seja $|H(f)|=|\tilde{H}(f)|$, sendo o efeito da tração apenas presente na fase do sinal. Essa hipótese é avaliada na parte experimental deste trabalho.

A equação para o sinal recebido torna-se, então

$$
\tilde{y}_{1}(t)=\int_{-\infty}^{\infty}|H(f)|^{2} \frac{\sum_{i} e^{-j 2 \pi f \Delta \tilde{t}_{a_{i}}(f)}}{\left|\sum_{i} e^{-j 2 \pi f \Delta \tilde{t}_{a_{i}}(f)}\right|} e^{-j 2 \pi f\left(T+t_{0}\right)} e^{j 2 \pi f t} d f .
$$

A parcela central da equação acima modela a fase de cada componente em frequência no sinal de inversão temporal. Observe-se que, a menos do fator de amplitude da excitação inicial, $X_{0}$, suposto constante para todos as frequências a expressão acima é igual a 1-4.5 onde o fator de diferença de fase é dada por

$$
e^{j \Delta \tilde{\phi}(f)}=\frac{\sum_{i} e^{-j 2 \pi f \Delta \tilde{t}_{a_{i}}(f)}}{\left|\sum_{i} e^{-j 2 \pi f \Delta \tilde{t}_{a_{i}}(f)}\right|} .
$$

Outra observação sobre o modelo proposto é que nele não é feita nenhuma consideração sobre o guiamento de ondas devido a largura da placa e a reflexão no seu comprimento finito. A diferença de fase acima exposta leva em conta apenas a deformação longitudinal.

Calculando-se o sinal recebido na vizinhança do instante $T+t_{0}$ para vários valores da tração $\tau$ pode-se obter uma curva do instante de máximo em função do valor de tração. Para isso usa-se a amplitude do espectro do sinal recebido na etapa $(\mathbb{\nabla})$ para o estado de tração inicialmente aplicado como $|H(f)|^{2}$ e os valores de velocidade de grupo para cada valor de tração obtido 
pelo procedimento exposto em $\mathbf{B}$ são usados para o cálculo de cada variação do tempo de chegada $\Delta \tilde{t}_{a_{i}}$

Três casos particulares são analisados a seguir. Onde não se aplica tração à placa ou essa é muito pequena; onde se aplica tração mas os efeitos elásticos sobre a placa são mais relevantes que os acustoelásticos, ou seja, considera-se que as velocidade de propagação de cada modo não se alterem; e, por fim, onde ambos os efeitos são relevantes.

Observa-se, primeiramente, que se não houver tração aplicada à placa tanto o comprimento da placa como as velocidade de propagação de cada modo não se alteram, ou seja, $\tilde{L}=L$ e $\tilde{c}_{g_{i}}(f)=c_{g_{i}}(f)$. Logo, todos os modos em todas as componentes de frequência chegam na posição do transdutor sensor na etapa $(\mathbf{\nabla})$ no instante de tempo $T+t_{0}$, fazendo com que haja interferência construtiva e que o sinal seja máximo nesse instante. Ou seja, $\Delta \tilde{t}_{a_{i}}(f)=0 \forall i, f$

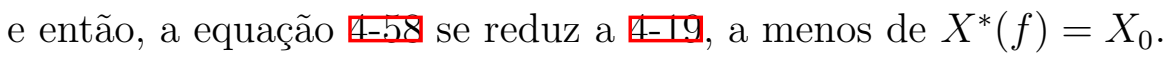

Doravante considera-se o cenário de interesse em que haja tração aplicada à placa. No caso mais simplificado assume-se que os efeitos elásticos sejam mais relevantes que os acustoelásticos. Isso significa que o valor do comprimento entre transdutores se altere, contudo a variação da velocidade de cada modo seja irrelevante. Assim o comprimento seria aumentado do valor do deslocamento, $\Delta L$, ocorrido devido a aplicação da tração,

$$
\tilde{L}=L+\Delta L=L+\varepsilon L=L(1+\varepsilon)=L\left(1+\frac{\tau}{E}\right),
$$

onde $\varepsilon$ é a deformação principal que se relaciona com a tração aplicada, $\tau$, pela

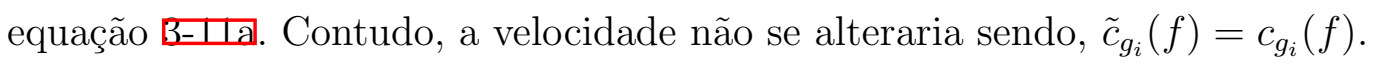

Nesse caso, tem-se que a variação do tempo de chegada, $\Delta \tilde{t}_{i_{a}}$, de cada modo em cada componente de frequência, dada pela equação 4-5.31, assume a forma,

$$
\begin{aligned}
\Delta \tilde{t}_{a_{i}}(f) & =\frac{\tilde{L}}{c_{g_{i}}(f)}-\frac{L}{c_{g_{i}}(f)}=\frac{\tilde{L}-L}{c_{g_{i}}(f)}=\frac{L(1+\varepsilon)-L}{c_{g_{i}}(f)} \\
& =\frac{L \varepsilon}{c_{g_{i}}(f)}=\frac{L \frac{\tau}{E}}{c_{g_{i}}(f)}=\frac{L \tau}{E c_{g_{i}}(f)} .
\end{aligned}
$$

Observe-se que os modos não chegam todos ao mesmo tempo, e, assim, não há interferência construtiva em $T+t_{0}$. Aplicando t-n em tem-se a expressão para o sinal de inversão temporal recebido

$$
\tilde{y}_{1}(t)=\int_{-\infty}^{\infty}|H(f)|^{2} \frac{\sum_{i} e^{-j 2 \pi f \frac{L \tau}{E c g_{i}(f)}}}{\left|\sum_{i} e^{-j 2 \pi f \frac{L \tau}{E c_{g_{i}}(f)}}\right|} e^{-j 2 \pi f\left(T+t_{0}\right)} e^{j 2 \pi f t} d f
$$


O caso mais geral é considerar que ambos os efeitos, elástico e acustoelásticos, sejam relevantes. Nesse caso, o valor do comprimento entre transdutores também é dado pela equação \$-bu, mas $\tilde{c}_{g_{i}}(f) \neq c_{g_{i}}(f)$.

A variação do tempo de chegada, equação 1-.5.3, não sofre simplificações, assumindo a forma,

$$
\begin{aligned}
\Delta \tilde{t}_{a_{i}}(f) & =\frac{\tilde{L}}{\tilde{c}_{g_{i}}(f)}-\frac{L}{c_{g_{i}}(f)}=\frac{L(1+\varepsilon)}{\tilde{c}_{g_{i}}(f)}-\frac{L}{c_{g_{i}}(f)}=L\left(\frac{1}{\tilde{c}_{g_{i}}(f)}-\frac{1}{c_{g_{i}}(f)}\right)+\frac{L \varepsilon}{\tilde{c}_{g_{i}}(f)} \\
& =L\left(\frac{c_{g_{i}}(f)-\tilde{c}_{g_{i}}(f)}{\tilde{c}_{g_{i}}(f) c_{g_{i}}(f)}\right)+\frac{L \tau}{E \tilde{c}_{g_{i}}(f)}
\end{aligned}
$$

e o fator de diferença de fase é dado por

$$
e^{j \Delta \tilde{\phi}(f)}=\frac{\sum_{i} e^{-j 2 \pi f L\left(\frac{c g_{i}(f)-\tilde{c} g_{i}(f)}{\tilde{c} g_{i}(f) c g_{i}(f)}\right)} e^{-j 2 \pi f \frac{L \tau}{E \tilde{c} g_{i}(f)}}}{\left|\sum_{i} e^{-j 2 \pi f L\left(\frac{c g_{i}(f)-\tilde{c} g_{i}(f)}{\tilde{c} g_{i}(f) c g_{i}(f)}\right)} e^{-j 2 \pi f \frac{L \tau}{E \tilde{c} g_{i}(f)}}\right|} .
$$

Enfim tem-se a expressão para o sinal de inversão temporal recebido para o caso geral

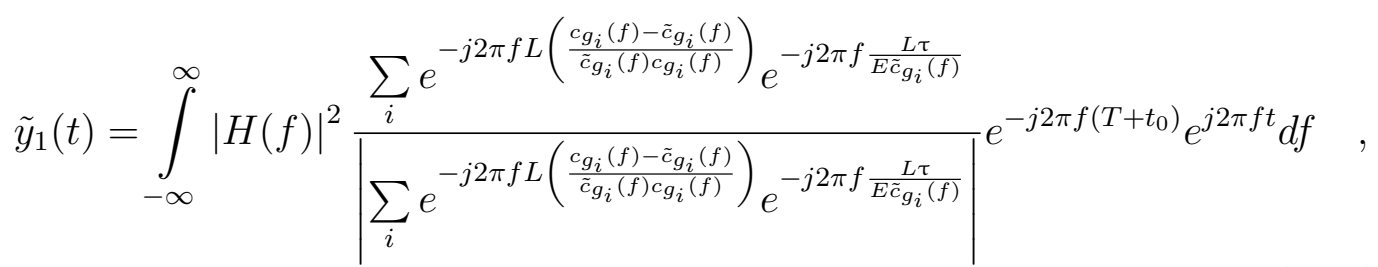

para os modos $i$ que estejam dentro da janela de velocidades receptíveis dado pela equação H-.5.

O tensor de elasticidade para cada valor de tração aplicado à placa é obtido pelo procedimento exposto na seção $[\mathbf{l}$, que faz uso do formulação de Hughes e Kelly [14]. Esse tensor é aplicado na rotina rotina computacional para obtenção da curva de dispersão exposta ne seção ए了. que a partir do vetor de estado e matriz de propagação apresentado em Braga e Hermann [ா], obtêm-se as curvas de dispersão em função do tensor de elasticidade. Calculase por esse meio o valor de velocidade de grupo, para cada modo em cada frequência, para uma placa submetida a uma dada tração.

Com esse valor de velocidade pode-se calcular a forma do sinal de inversão temporal recebido na etapa (四) para cada intensidade de tração aplicada. O modelo para o sinal recebido descrito pela equação 1-6 é doravante denominado modelo elástico e aquele descrito pela equação 1-h. denomina-se modelo acustoelástico. 
É possível obter assim uma curva para o instante de pico do sinal recebido pelo transdutor que é dado pela parte real do sinal modelado pela equação 田 Ђ.5. Essa curva teórica pode ser usada em um cenário onde não se conheça a variação de tração que a placa está submetida e, assim, estimá-la. A curva teórica, usando ambos os modelos elásticos e acustoelásticos, é comparada com a experimental usando um extensômetro resistivo como referência na próxima seção deste texto. 


\section{5}

\section{Parte Experimental}

Os experimentos feitos visam observar o comportamento do sinal de inversão temporal de ondas guiadas em uma placa submetida a uma tração longitudinal variável. Para tal a montagem experimental consiste em uma placa de alumínio montada em uma ponte tracionadora. Para que se aplique tração à placa, uma das extremidades dessa é fixa à ponte, enquanto a outra é fixa a um suporte móvel, preso a uma barra roscada. Rosqueando uma porca na barra roscada variam-se a posição do suporte móvel e, consequentemente, aplica-se tração à placa. Dois transdutores de ultra-som são fixados nas extremidades da placa para que sejam feitas todas as etapas de transmissão e recepção de ondas acústicas descritas na seção 1 ].

O projeto da ponte tracionadora foi desenvolvido pela equipe de mecânica do CPTI e sofreu ajustes até a sua versão final. Foi observado inicialmente a tendência da placa sofrer torção ao ser tracionada através do rosqueamento da barra. O projeto da ponte tracionadora foi revisto e um par de suportes horizontais na extremidade da placa fixa à barra foram instalados nas duas superfícies da placa a fim de evitar esse grau de liberdade, deixando-o livre apenas na direção longitudinal. A barra roscada também sofreu revisão, a primeira utilizada era do tipo M6 de $6 \mathrm{~mm}$ de diâmetro. Essa se mostrou inadequada para o uso sofrendo deformação da rosca. A mesma foi trocada por uma mais grossa, M8 de $8 \mathrm{~mm}$ que se mostrou apta à função. A figura [ـ mostra um desenho esquemático da ponte tracionadora e uma foto.

O equipamento de ultra-som utilizado é do tipo Phased Array denominado OPEN SYSTEM da companhia LeCoeur Electronique [a.j]. Esse possui interface USB por onde se pode controlá-lo através de um microcomputador por uma biblioteca de funções para a linguagem de script MATLAB [ [44]. Além disso, esse aparelho apresenta algumas características que o tornam bastante adequado para uma atividade de pesquisa, dentre elas as mais relevantes são: 


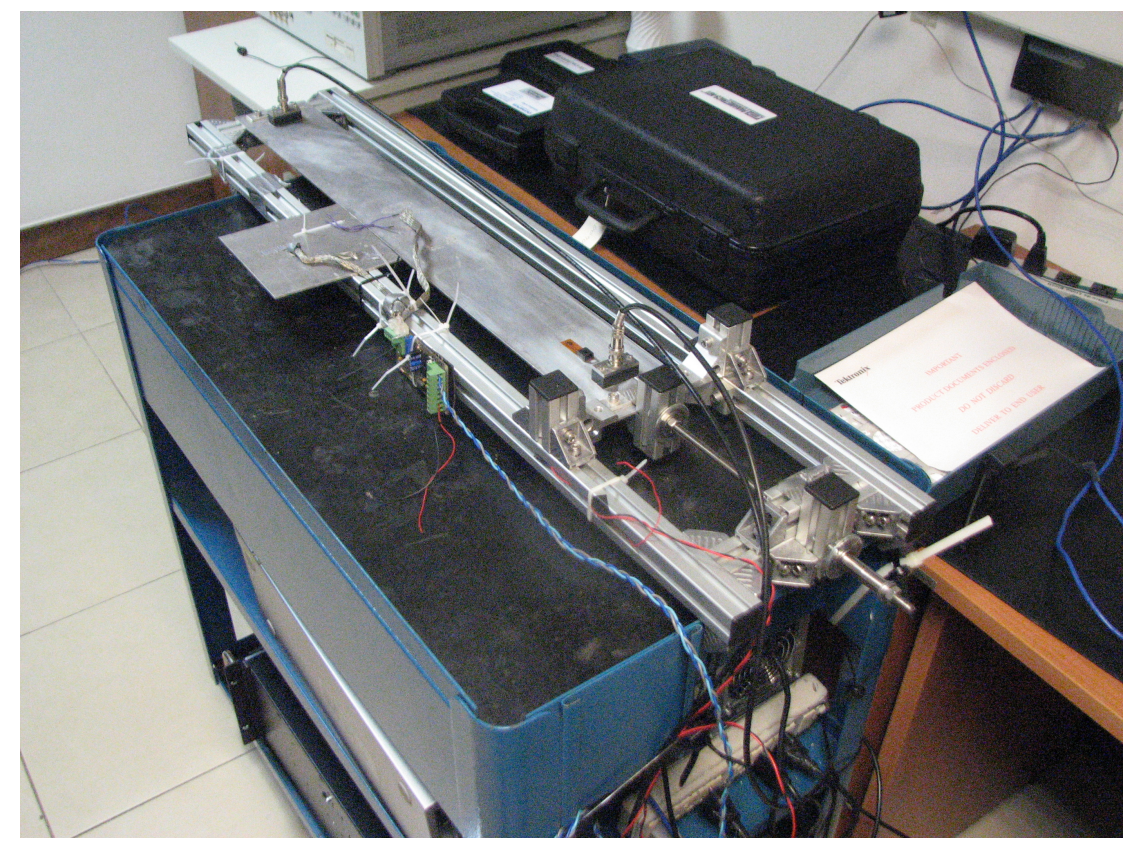

(a)

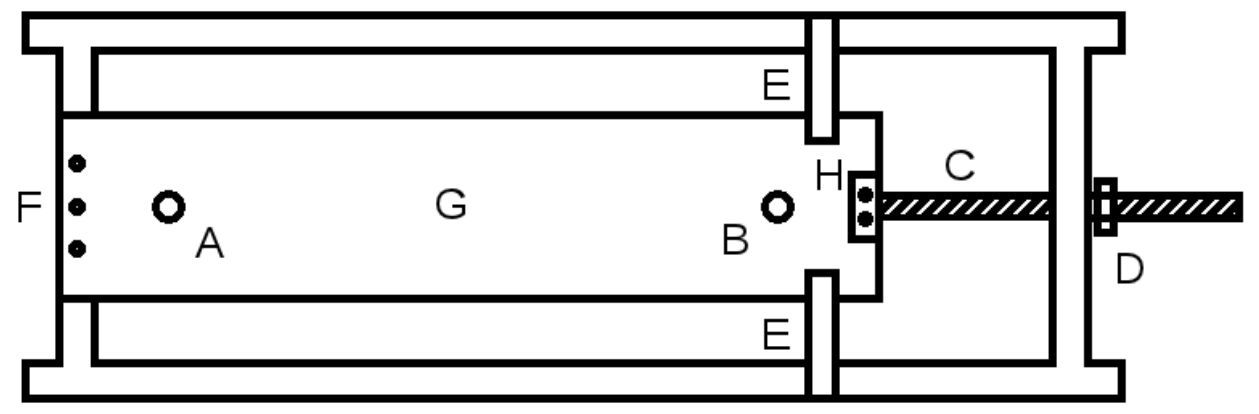

(b)

Figura 5.1: Ponte tracionadora. Foto (a) e desenho esquemático (b). É destacado, com letras, no desenho os transdutores $A$ e $B$, respectivamente por suas letras, posicionados sobre a placa de faces paralelas, $G$; a barra roscada, $C$; a porca, $D$; os suportes para evitar a torção, $E$; a fixação da placa à ponte tracionadora, $F$, e a fixação à parte móvel, $H$.

- 32 canais de recepção e transmissão

- frequência de amostragem na recepção de $F_{s}=80 \mathrm{MHz}$ amostrado em $12 b i t s$

- buffer de recepção de até 8192 amostras

- pré amplificador de recepção de ultra baixo ruído com ganho de até 80dB e banda de $25 \mathrm{MHz}$

- opção de tramissão de um pulso tipo spike ou um sinal analógico arbitrário com banda de $3 d B$ de $10 \mathrm{MHz}$, com até $120 \mathrm{Vpp}$ e largura 
de até 8192 amostras temporais com frequência de amostragem de até $80 M H z$.

Diferentemente de uma sistema fechado de ultra-som convencional a transmissão analógica arbitrária torna possível a aplicação da técnica da inversão temporal, onde deve-se transmitir o mesmo sinal recebido mas invertido no tempo. Adicionalmente a essas funcionalidades, o conjunto de funções da biblioteca já prontas em MATLAB [\$.5] fazem com que o seu uso para uma aplicação desse gênero seja facilitado.

A placa de alumínio utilizada tem dimensão de $800 \mathrm{~mm} \times 100 \mathrm{~mm} \times 3 \mathrm{~mm}$ (comprimento $\times$ largura $\times$ espessura). Orienta-se um sistema de eixo cartesiano de modo que a origem seja na extremidade fixa à ponte a meia largura e meia espessura, sendo o eixo $x$ correspondente ao comprimento, $y$ à largura e $z$ à espessura. Sobre a superfície superior da placa são posicionados dois trasdutores, $A$ e $B$, nas posições $x=5 \mathrm{~mm}, y=0 \mathrm{~mm}, z=1.5 \mathrm{~mm}$ e $x=75 \mathrm{~mm}, y=0 \mathrm{~mm}, z=1.5 \mathrm{~mm}$, respectivamente, sendo espaçados de $L=70 \mathrm{~mm}$.

Ambos os transdutores são da Panametrics modelo V405-SB [ [G] sua frequência central é $5 M H z$ e sua banda de $6 d B$ é $4 M H z$.

Um extensômetro, do tipo Strain Gauge, é colado no centro da superfície superior da placa. Esse instrumento fornece um valor de referência da deformação ou, equivalentemente, da tração aplicada à placa através da barra roscada. O mesmo é montado em um circuito eletrônico de Ponte de Wheatstone [ [5]], sendo sua saída aplificada por um amplificador de instrumentação diferencial AD620 [ $[\mathbf{b z}]$ que fornece uma saída amplificada e referenciada à terra. O sinal de saída é, então, aquisitado pelo osciloscópio e lido diretamente na rotina computacional em MATLAB juntamente com o tratamento da excitação e recepção dos sinais de ultra-som nas várias etapas do experimento. 


\section{1}

\section{Experimento Inicial: Excitação de Amplo Espectro}

A primeira parte do experimento consiste nas etapas apresentadas na seção 1 . Ou seja, na etapa (1), aplica-se um sinal estreito no tempo no transdutor A, $x_{0 A}(t)$, e na etapa (四), mede-se sua resposta no transdutor $B, y_{0 B}(t)$, a qual se aproxima da resposta impulsional do sistema. Na etapa (四) o sinal $y_{0 B}(t)$ é então invertido no tempo e aplicado em $B$, o sinal $x_{1 B}(t)$. Mede-se, na etapa (四), em $A$ a resposta, $y_{1 A}(t)$.

Como $x_{0 A}(t)$ é estreito no tempo, seu espectro possui banda larga. Essa sendo superior a banda do transdutor faz-se que a resposta $y_{0 B}$, recebida na etapa (四) seja uma aproximação da resposta impulsional do sistema $H_{A B}(f)$. A figura 2 apresenta a excitação aplicada no tempo e a magnitude da transformada de Fourier para as frequências positivas. A transformada de Fourier é obtida pela rotina computacional de Trasformada Rápida de Fourier, conhecida pelo acrônimo FFT, do inglês, Fast Fourier Transform, presente no pacote de funções do MATLAB [\$.5]].

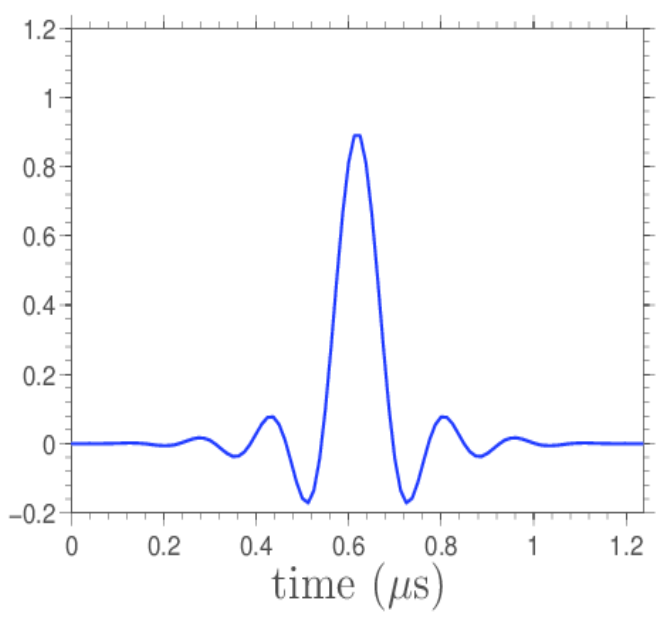

(a)

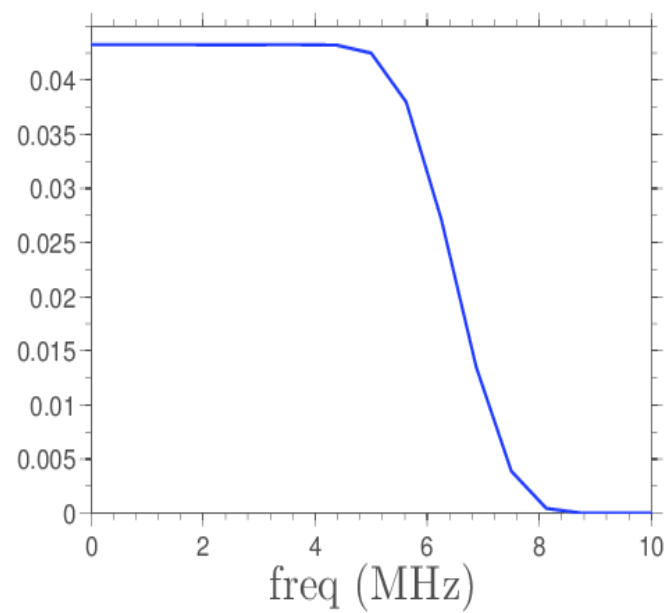

(b)

Figura 5.2: $x_{0 A}$. Pulso inicial transmitido no transdutor $A$ na etapa (i), no domínio do tempo (a) e magnitude da transformada de Fourier (b) para frequências positivas.

Na etapa (四) recebe-se a resposta $y_{0 B}(t)$ no transdutor $B$, a qual é uma aproximação da resposta impulsional do sistema do transdutor $A$ ao $B$. A figura 5.3 apresenta a resposta no tempo recebida no transdutor $B$ dada a aplicação da excitação da figura de Fourier para as frequencias positivas. Inicia-se o registro da resposta no transdutor no instante de tempo $t_{0}=230 \mu \mathrm{s}$. É usada a janela temporal de 
8192 amostras com uma frequência de amostragem de $80 \mathrm{MHz}$ ou $\mathrm{T}=102.4 \mu \mathrm{s}$, ou seja de $t_{0}=230 \mu \mathrm{s}$ a $t_{0}+T=332.4 \mu \mathrm{s}$. O ganho do amplificador receptor é posto bastante alto, $72 d B$, nessa etapa para se conseguir registrar algum sinal. Outro recurso utilizado a fim de diminuir o ruído no sinal recebido é a aquisição repetida do mesmo sinal e cálculo da média de todos os sinais recebidos. Nessa etapa são usadas 36 medidas sucessivas.

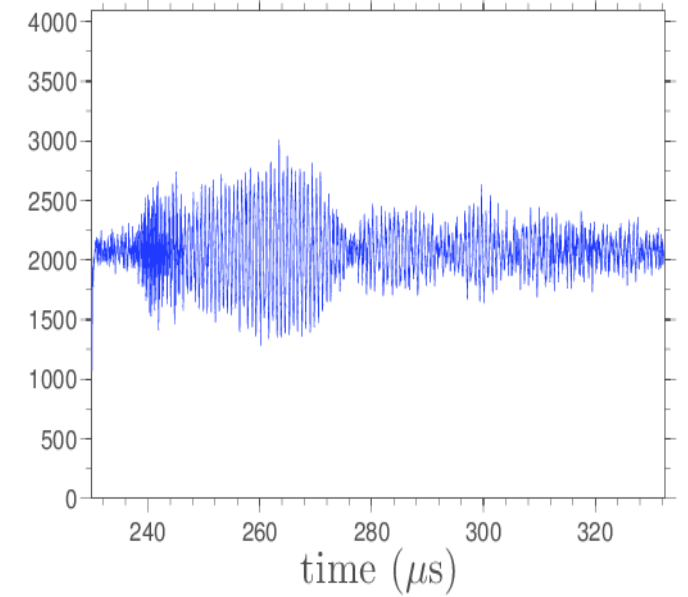

(a)

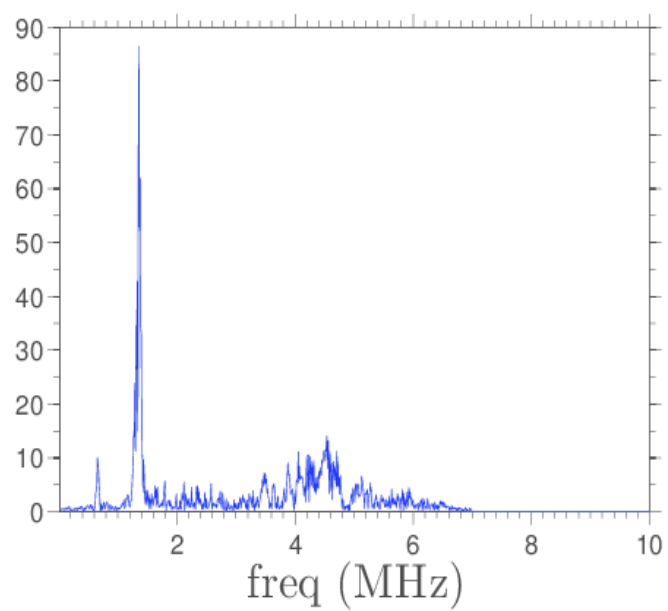

(b)

Figura 5.3: $y_{0 B}$. Sinal recebido no transdutor $B$ na etapa (四) com ganho do receptor de $72 d B$ na janela de tempo de $230 \mu s$ a $332.4 \mu s$, no domínio do tempo (a) e magnitude da transformada de Fourier (b) para frequências positivas.

É possível observar que há alguns picos de magnitude no espectro da resposta observada. $\mathrm{O}$ mais intenso em torno de $1.3 \mathrm{MHz}$, seguido por outro em torno de $4.4 \mathrm{MHz}$.

Considerando que as funções de transferência em ambos os sentidos sejam iguais, ou seja que a resposta ao impulso aplicado no transdutor $A$ e sentido no transdutor $B$ seja igual à resposta ao impulso aplicado no transdutor $B \mathrm{e}$ sentido no transdutor $A$, dado pela equação 4-14, tem-se que o operador de inversão temporal tem o módulo igual ao quadrado do módulo da função de transferência, dada pela figura 3.3 . Assim o módulo do TROP deve ter também um pico em torno de $1.3 \mathrm{MHz}$, contudo proporcionalmente ainda maior em relação ao restante do espectro do que a função de transferência inicial. Ou seja, deve haver ainda maior predomínio de uma estreita faixa de frequência e, logo, o sinal de inversão temporal recebido no domínio do tempo deve ser largo.

A função de transferência no sentido oposto ao exposto na figura $\mathbf{5 . 3}$ é registrada transmitindo o mesmo pulso inicial mostrado na figura $\mathbf{L} \mathbf{2}$, contudo através do transdutor $B$ e recebido no transdutor $A$ usado como sensor. A figura 5 mostra o sinal recebido no transdutor $A$, dada aplicação do pulso 
no transdutor $B$, no domínio do tempo, para a mesma janela temporal, e sua transformada de Fourier. É possível observar a semelhança entre os sinais

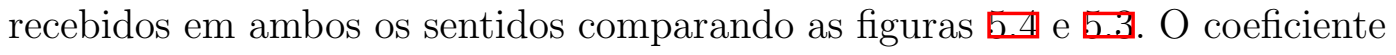
de correlação entre ambas equivale a 0.968 mostrando que a simplificação proposta pela equação |-14 é adequada e, consequentemente, a afirmação sobre o predomínio de um faixa estreita de frequência, feita no parágrafo anterior, correta. A diferença entre os sinais obtido deve-se ao ruído aleatório presente em cada medição e à não exatidão entre as respostas acusto-elétricas, de transmissão e recepção, de cada transdutor.

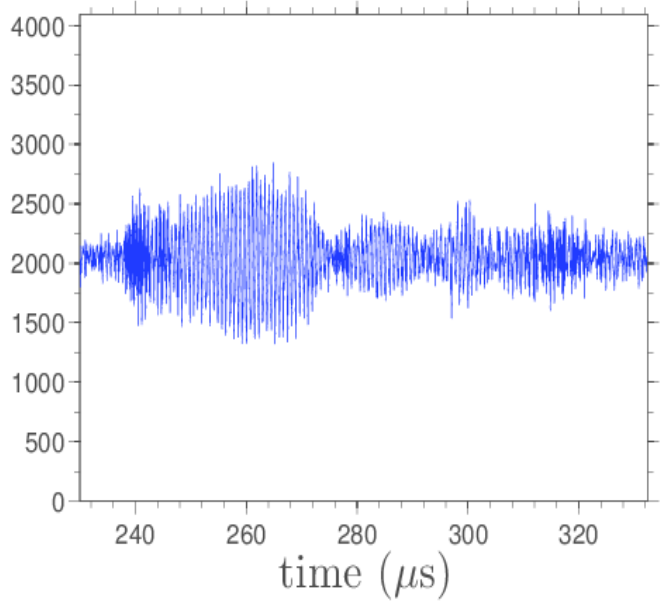

(a)

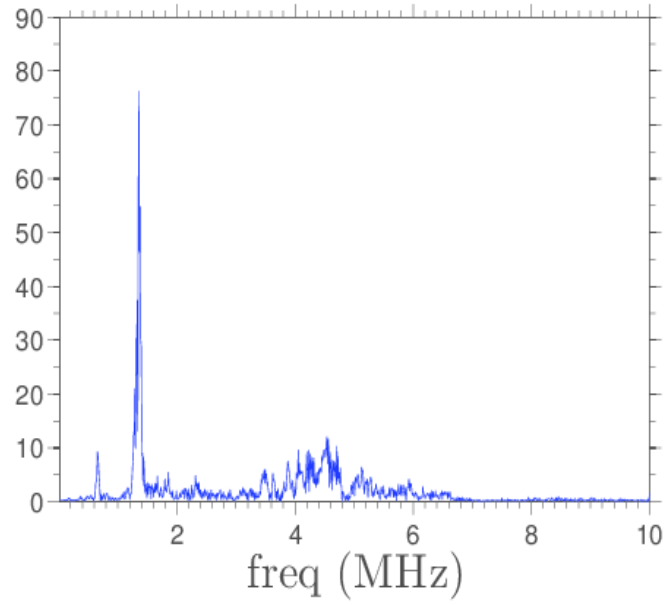

(b)

Figura 5.4: $y_{0 A}$. Sinal recebido no transdutor $A$ na etapa (四) com ganho do receptor de $72 d B$ na janela de tempo de $230 \mu s$ a $332.4 \mu s$, no domínio do tempo (a) e magnitude da transformada de Fourier (b) para frequências positivas.

A próxima etapa do experimento é a inversão do sinal recebido no transdutor $B$ e sua transmissão pelo próprio transdutor $B$, etapa (四). Para ser transmitido um sinal no aparelho utilizado, esse deve estar entre os valores $1 \mathrm{e}$ -1 e algumas amostras iniciais e finais devem ser nulas. O sinal recebido, figura 5.3, é então invertido na janela temporal, e normalizado para ter seu valor máximo e mínimo em 1 e -1 , respectivamente. Para mantê-lo longe da região de saturação do sistema de amplificação de transmissão, após a normalização multiplica-se o sinal por um ganho menor que 1. O valor usado na experiência é 0.9. São anuladas as 100 amostras iniciais e finais. O sinal transmitido é mostrado na figura 5.

É então recebido, na etapa (四), o sinal de inversão temporal no transdutor $A$, o mesmo de onde é enviada a primeira excitação. O sinal recebido é visualizado com uma janela temporal centrada no final da janela inicial, ou seja, de $t_{0}+T / 2$ a $t_{0}+3 T / 2$, centrada em $t_{0}+T$. Numericamente a janela temporal utilizada para visualização é de $281.2 \mu s=(230 \mu s+102.4 \mu s / 2)$ a 


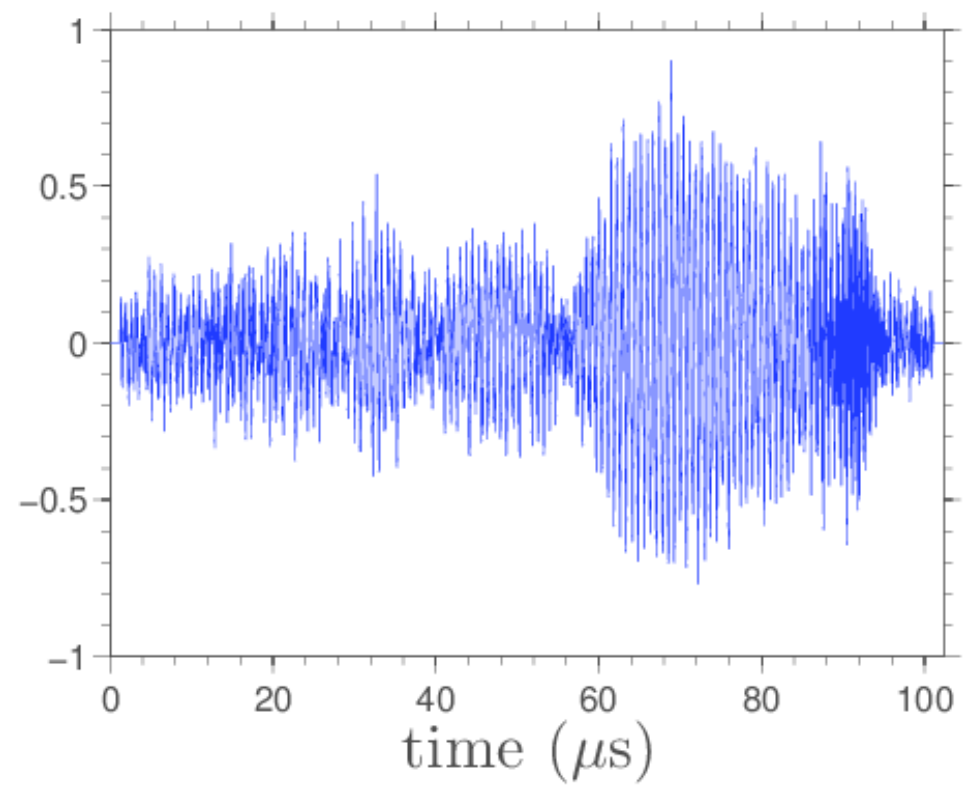

Figura 5.5: $x_{1 B}(t)$. Sinal invertido no tempo e transmitido no transdutor $B$ na etapa (四).

$383.6 \mu s=(230 \mu s+3 \times 102.4 \mu s / 2)$, centrada em $332.4 \mu s=(230 \mu s+102.4 \mu s)$. A figura 5 exibe o sinal recebido e sua transformada de Fourier. Nessa etapa o ganho de recepção pode ser bastante reduzido, para $40 d B$.

Houve ganho de energia do sinal, que pode ser observado pelo aumento da intensidade do sinal. A fim de calcular o ganho em amplitude deve-se considerar a diferença no ganho de recepção em ambas as etapas. O valor de pico para o sinal recebido na etapa (四), figura 5.3, é de 1006 amostras acima do valor médio com um ganho de recepção de $72 d B$. Para o sinal recebido na etapa (四), figura $\mathbf{5}$, o valor de pico é de 1719 amostras acima do valor médio com um ganho de recepção de $40 \mathrm{~dB}$. O que implica que o ganho em amplitude proporcionado pela focalização temporal usando a técnica de inversão temporal é de $72 d B-40 d B+20 \log (1719 / 1006)=36.65 d B$. É possível observar que o valor máximo se dá no ponto médio da janela, ou seja no instante $t_{0}+T$. Como prevê a teoria exposta no seção 4.3 nesse instante todas as componentes de frequência são postas em fase, sendo máximo o sinal recebido. Outra característica que se pode observar do sinal no domínio do tempo é sua simetria em relação ao instante central. O coeficiente de correlação entre as duas metades do sinal é de 0.974 . O valor bastante elevado mostra que há pouca interferência aleatória, devido, em grande parte, a estreita faixa de frequência predominante que faz com que influências aleatórias fora dessa mesma sejam muito pouco relevantes, de acordo com o comentado no final da sessão 4.4 .

Como observado anterioremente comprova-se que o sinal de inversão 


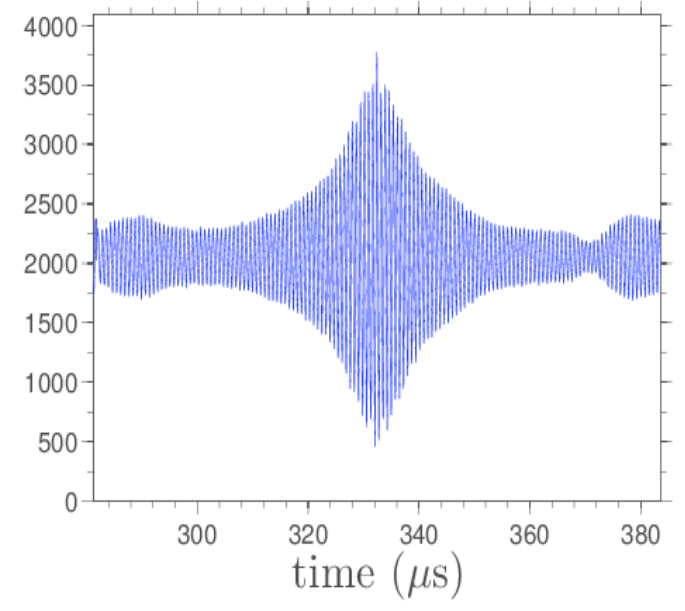

(a)

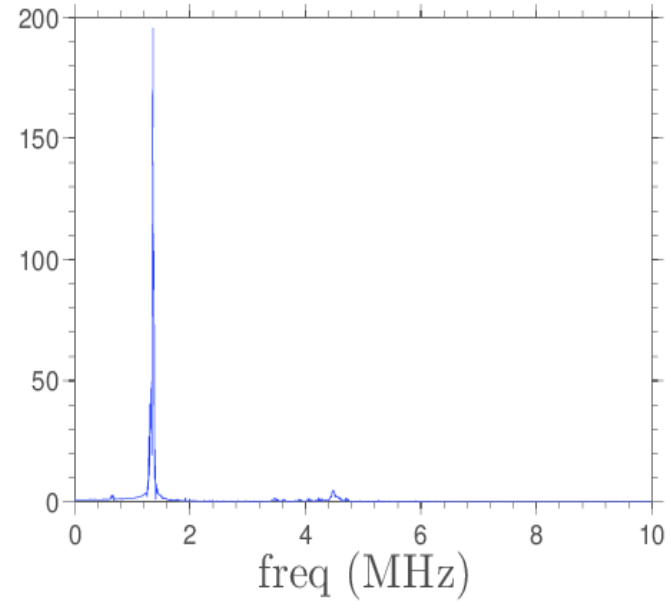

(b)

Figura 5.6: $y_{1 A}$. Sinal de inversão temporal recebido no transdutor $A$ na etapa (団) com ganho do receptor de $40 \mathrm{~dB}$ na janela de tempo de $281.2 \mu \mathrm{s}$ a 383.6 $\mathrm{s}$ s. No domínio do tempo (a) e no domínio da frequência, magnitude da transformada de Fourier (b) para frequências positivas.

temporal possui um pico de amplitude no espectro em torno de $1.3 \mathrm{MHz}$ ainda maior, proporcionalmente ao restante do espectro, do que o sinal obtido na etapa (四), figura [.3. Tem-se,então, que o sinal é largo no tempo proporcionando uma fraca focalização temporal. A largura de $-6 d B$ do sinal de inversão temporal recebido é igual $13.3 \mu \mathrm{s}$.

\subsection{1}

\section{Influência da Tração - tração inicial nula}

Analisa-se nessa seção a influência da tração aplicada à placa sobre o sinal de inversão temporal recebido. Para isso as etapas (i) e (四) são feitas com a placa submetida ao estado de tração inicial, nesse caso, nula. Em seguida transmite-se o sinal invertido no tempo, etapa (四), e recebe-se o sinal da etapa (四) para cada tração aplicada à placa e medida com extensômetro, até um valor de tração máximo e, em seguida, retorna-se ao valor inicial.

Nessa primeira experiência tracionou-se a placa até $12.6 \mathrm{MPa}$, o que equivale a uma deformação de $182.7 \mu$ strain no alumínio, medido com o extensômetro. Onde a tração $\tau$ e a deformação $\varepsilon$ se relacionam pelo equação B-1 a, sendo o módulo de Young para o alumínio vale $69 G P a$ no alumínio .

Observa-se o valor e instante de pico do sinal de inversão temporal recebido para cada valor de tração imposta. 


\subsubsection{1 \\ Valor de Pico}

A figura 5 mostra a queda percentual dos valores de pico acima do valor médio em função da tração relativa ao valor máximo encontrado. Os símbolos • representam as medições quando se aumenta a tração e os símbolos $\times$ representam as medições quando se diminui a tração após ter chegado no valor máximo de tração.

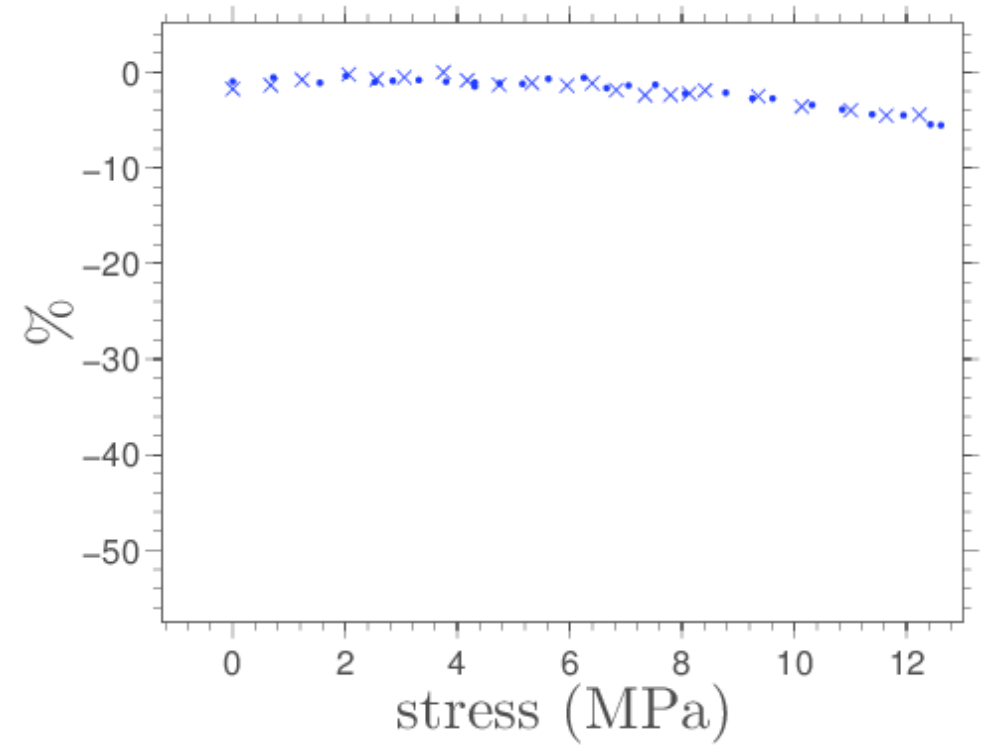

Figura 5.7: Valor de pico do sinal de inversão temporal, em função da tração aplicada para sistema inicialmente livre de tração. Os símbolos • representam as medições de tração crescente e os símbolos $\times$ representam as medições de tração decrescente.

É possível observar que o valor de pico apresenta a tendência de reduzir com o aumento da tração $(\bullet)$ e de voltar ao valor inicial com a diminuição da tração $(\times)$. Isso indica que o fator predominante sobre o sinal de inversão temporal é o tracionamento aplicado e não algum outro fator externo degenerativo, como, por exemplo, a temperatura.

Para valores pequenos de tração não é claro o comportamento do valor de pico, contudo a medida que aumenta a tração é notável a redução do valor de pico. Na condição de tração máxima, o valor de pico apresenta apenas $6.0 \%$ de queda ou $-0.5 d B$. A figura sugere um caimento linear a partir de um certo valor da tração aplicado. Se se considerar um caimento linear começando em torno a $5 M P a$ tem-se um queda de $0.59 \times 10^{-02}$ para cada $M P a$ de tração aplicada. 
Ou seja, a focalização temporal é prejudicada pelo aumento da tração aplicada à placa, como descrito na seção 14 .1.

\subsubsection{2}

\section{Instante de Pico}

A posição do tempo de máximo é observado e também calculada através do modelo proposto na seção 44 I guiadas tal que a velocidade de grupo esteja dentro do intervalo dado pela equação t-5.5 para cada componente de frequência, que para os valores reais do experimento é dado por

$$
2105.90 \mathrm{~m} / \mathrm{s} \leq c_{g_{i}}(f) \leq 3043.47 \mathrm{~m} / \mathrm{s}
$$

A figura $\mathbf{d}$ mostra as velocidade de grupo dos modos progantes para as condições reais do experimento para frequências até $10 \mathrm{MHz}$ e os limites de velocidade acima expostos.

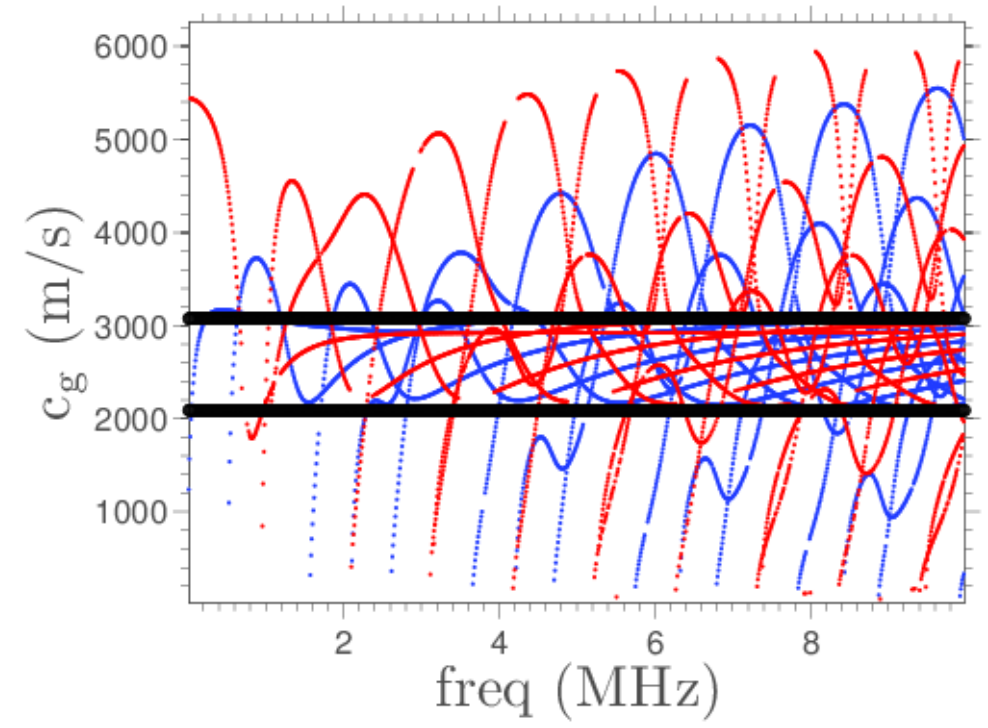

Figura 5.8: Velocidade de grupo em função da frequência para as condições do experimento e limites de velocidade receptíveis para a janela de visualização.

É calculado o instante de máximo dado pelo modelo elástico, equação 4-62, e pelo modelo acustoelástico, equação 4-6.5. Para isso é usado o módulo da transformada de Fourier do sinal de inversão temporal recebido na etapa (四), exibido na figura $\mathbf{n}$, como amplitude do espectro do sinal de inversão temporal recebido, $|H(f)|^{2}$, necessário para o cálculo de cada modelo.

A figura $5 \mathrm{~g}$ mostra os instantes de pico medidos junto com os instantes de pico calculados para as diferentes trações aplicadas. Os valores medidos 
se apresentam em saltos devido a frequência de amostragem do aparelho utilizado. Essa é de $80 \times 10^{6}$ amostras por segundo, logo o intervalo de tempo mínimo distinguível de 12.5ns. A rotina de cálculo é executada usando-se a mesma resolução temporal a fim de possibilitar a comparação entre os valores medidos e calculados. Os cálculos são feitos considerando-se apenas os efeitos de deformação dada a tração, modelo elástico, representado na figura pela linha tracejada, e considerando-se o efeito da mudança na velocidade de propagação no fator de fase de cada componente em frequência, modelo acustoelástico, representado pela linha cheia.

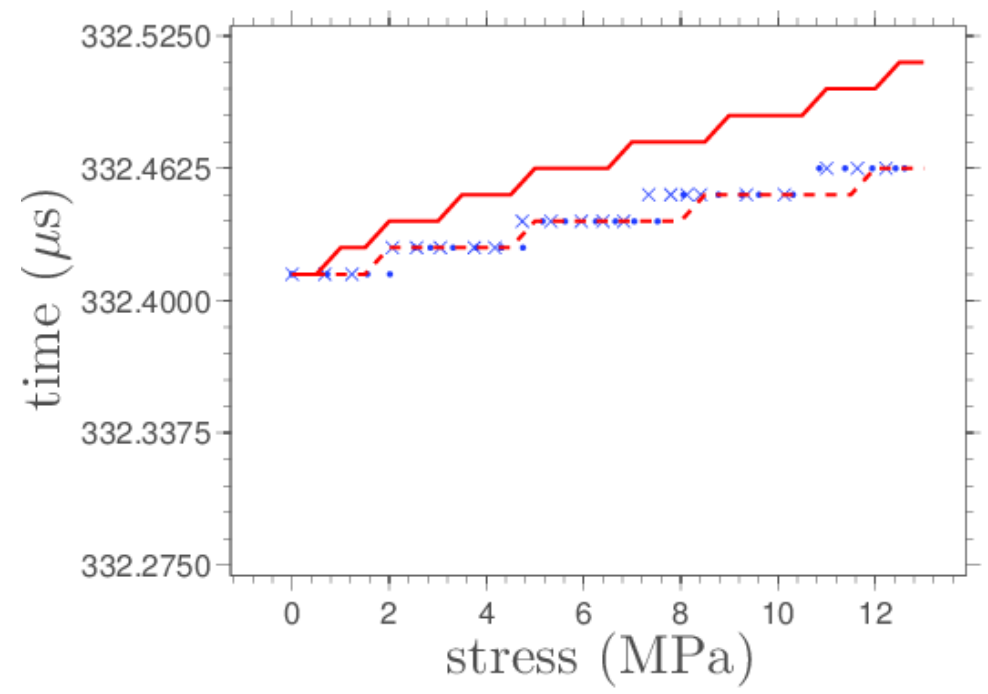

Figura 5.9: Instante de pico do sinal de inversão temporal, em função da tração aplicada para sistema inicialmente livre de tração. Os símbolos • representam as medições de tração crescente e os símbolos $\times$ representam as medições de tração decrescente. A linha contínua representa os valores calculados pelo modelo acustoelástico e a linha tracejada pelo modelo elástico.

O erro médio quadrático dos instantes de picos calculados em relação aos medidos são de 5.187ns para o modelo elástico e de 28.51ns para o modelo acustoelástico. Constata-se que o instante de pico teórico obtido considerandose apenas os efeitos da deformação condizem melhor com os valores medidos para essa experiência onde o espectro do sinal de inversão temporal apresenta predominância de uma faixa estreita de frequência.

\section{1 .2}

\section{Influência da Tração - sistema inicialmente tracionado}

Repete-se a experiência para a placa inicialmente tracionada. As etapas (1) e (四) são feitas com a placa em tração máxima. A tração aplicada é 
diminuída e o sinal da etapa (四) é recebido para cada valor de tração, medido com extensômetro, até a condição de tração nula, em seguida, retorna-se ao valor inicial, máximo.

Nessa experiência o valor inicial de tração imposto foi de $\tau_{\max }=$ 11.55MPa. Nos gráficos que seguem respeita-se a convenção dos símbolos • representarem os valores na $i d a$ das medições e dos símbolos $\times$ representarem os valores na volta das medições. Desse modo a marcação com • é usada para os valores de tração decrescentes, antes de chegar ao valor mínimo de tração nula, e a marcação com $\times$ para os valores de tração crescente, voltando-se ao valor inicial de tração máxima.

\subsubsection{1}

\section{Valor de Pico}

A figura 10 mostra a diminuição dos valores de pico acima do valor médio relativos pelo valor máximo encontrado em função da tração.

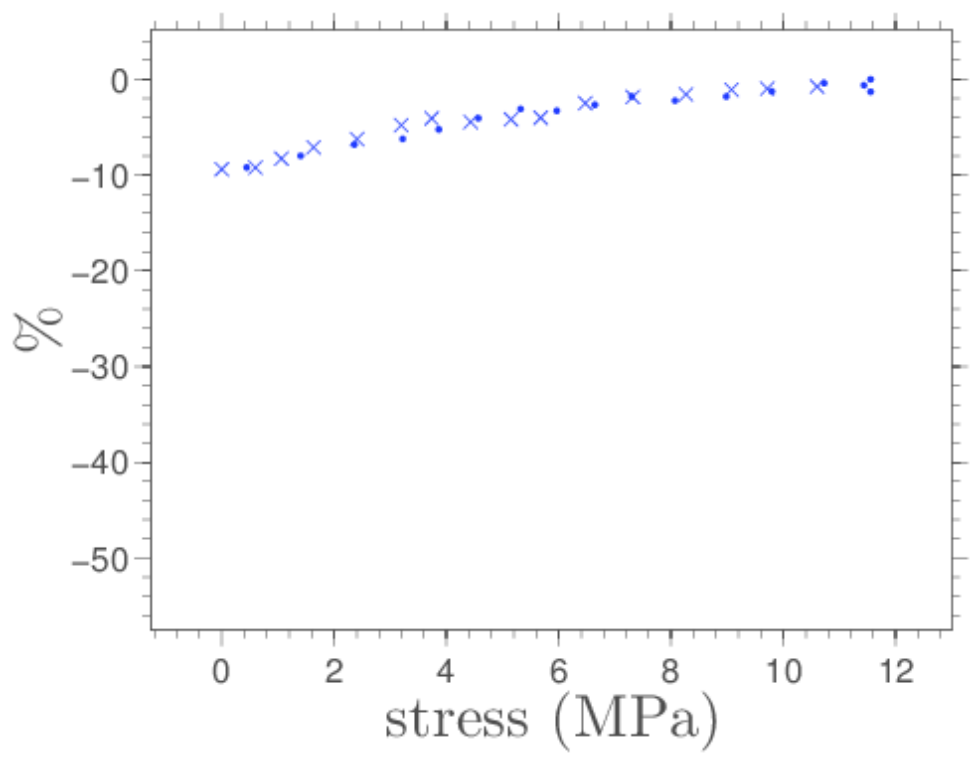

Figura 5.10: Valor de pico do sinal de inversão temporal, em função da tração aplicada para sistema inicialmente tracionado. Os símbolos $\bullet$ representam as medições de tração decrescente e os símbolos $\times$ representam as medições de tração crescente.

É possível observar que o valor de pico apresenta a mesma tendência de reduzir seu valor com o variação da tração $(\bullet)$ e de voltar ao valor inicial com a retirada de variação da tração $(\times)$. O comportamento do valor de pico é mais claro a medida que o valor de tração afasta-se do inicial. Para a posição de tração nula a queda é de $8.2 \%$ ou $-0.74 d B$. Do mesmo modo que para o 
experimento de tração inicial nula se se considerar um caimento linear a partir de uma diferença de $5 M P a$ do valor inicial de tração, i.e. para valores menores que $6.5 M P a$, há uma queda de $1.07 \times 10^{-02}$ para cada $M P a$ de variação de tração.

\subsubsection{2}

\section{Instante de Pico}

A posição do tempo de máximo é mostrada na figura [1] para as diferentes trações. Do mesmo modo como no caso da placa inicialmente livre de tração, há deslocamento no instante de pico. Nesse caso o instante de pico diminui a medida que a tração é reduzida.

É também calculado o instante de pico usando os modelos desenvolvidos na seção 4.4 . O intervalo de velocidade receptíveis é teoricamente alterado porque nesse caso o comprimento inicial da placa é aumentado pelo fator $1+\frac{\tau_{\max }}{E}$. Contudo isso não implica em mudança significatica porque na condição de tracionamento inicial do experimento esse fator equivale a $1+1.674 \times 10^{-4}$.

Nesse caso usa-se o módulo da transformada de Fourier do sinal obtido na etapa $(\mathbf{\nabla})$ para a placa inicialmente tracionada como amplitude de cada componente em frequência, usadas nos modelos propostos, e não o mesmo espectro, da placa inicialmente não tracionada, usado na seção anterior. Desse modo os valores são mais adequados. Porque, mesmo que o modelo não considere a variação de amplitude do espectro, essa pode existir e assim o modelo calculado é coerente ao estado inicial medido.

Para o caso da placa inicialmente tracionada o erro médio quadrático dos instantes de picos calculados em relação aos medidos é de $4.884 n$ s para o modelo elástico e de 29.52ns para o modelo acustoelástico. Do mesmo modo que no caso de tração crescente, observa-se que o valor teórico calculado considerando-se apenas os efeitos da deformação condizem melhor com os valores medidos para esse experimento. 


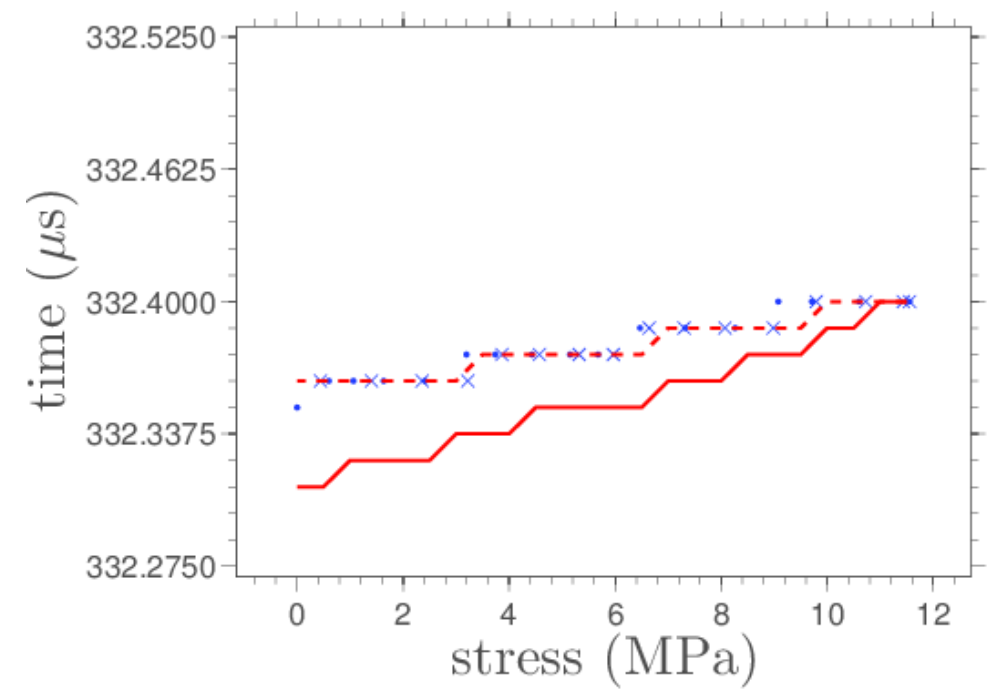

Figura 5.11: Instante de pico do sinal de inversão temporal, em função da tração aplicada para sistema inicialmente tracionado. Os símbolos • representam as medições de tração decrescente e os símbolos $\times$ representam as medições de tração crescente. A linha contínua representa os valores calculados pelo modelo acustoelástico e a linha tracejada pelo modelo elástico.

\section{2 \\ Análise da Função de Transferência Frente à Variação da Tração}

Nessa seção objetiva-se analisar da função de transferência do meio em função da variação da tração aplicada, sobretudo as componentes em frequência com maior sensibilidade à tração. Para isso é adquirida a resposta impulsional do sistema para vários valores de tração. Ou seja são repetidas

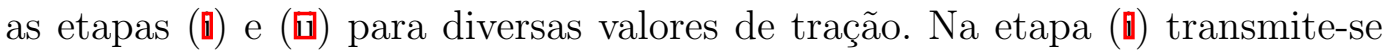
o pulso inicial apresentado na figura $[$ e na etapa (四) é recebida a resposta impulsional, dessa é tirada a transformada de Fourier a fim de se obter a função de transferência para cada valor de tração.

A resposta impulsional no domínio do tempo obtida para o estado de tração nula é mostrado na figura 5.3 junto com sua respectiva transformada de Fourier. A figura 2 mostra a resposta impulsional no domínio do tempo para o estado de tração máxima aplicada nesse experimento, 12.8M Pa. Observe-se que ambas são similares e uma distinsão visual não é simples.

Para se analisar as componentes de frequência com maior sensibilidade à variação de tração deve observar a transformada de Fourier de cada sinal recebido. A fim de facilitar a visualização é construída uma matriz de cores, exibida na figura [.13, onde cada linha é a diferença do espectro para um determinado valor de tração para o espectro original, sem tração aplicada. 


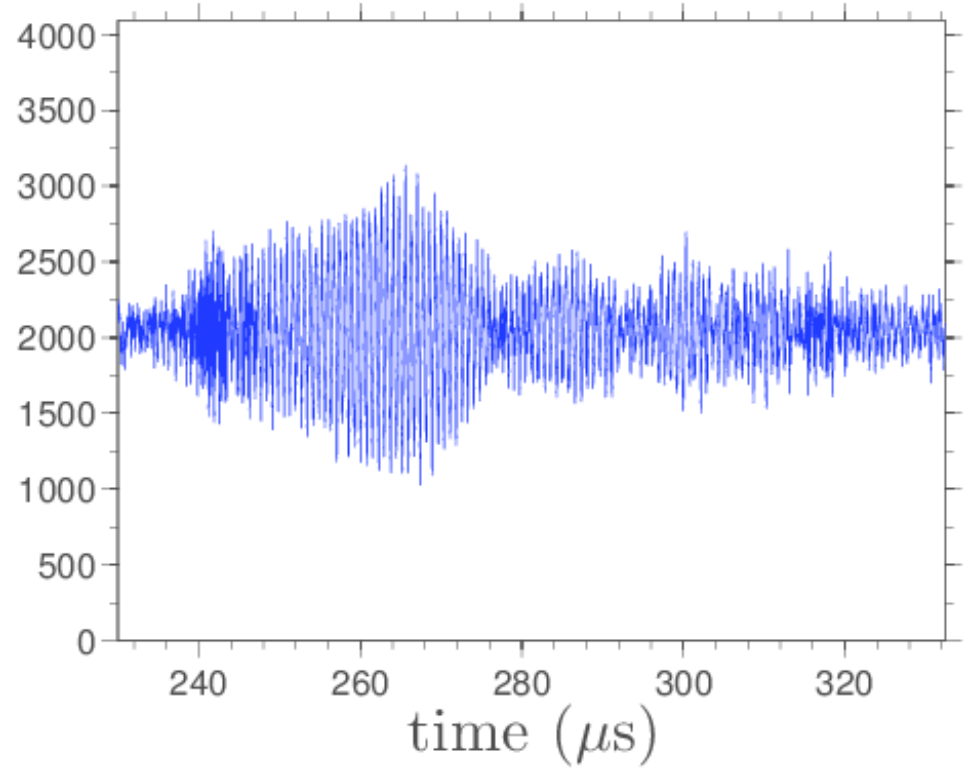

Figura 5.12: Sinal recebido na etapa (団) com ganho do receptor de $72 d B$ na janela de tempo de $230 \mu s$ a $332.4 \mu s$, com tração máxima aplicada à placa de $12.8 M P a$.

O eixo vertical representa o valor da tração aplicada, o eixo horizontal a frequência. Essa representação é feita para a magnitude do espectro e fase, corrigida para um valor entre $-180^{\circ}$ e $180^{\circ}$. Desse modo, valores em frequência que apresentam variação com a tração aplicada são facilmente observáveis.

São observadas 5 regiões de maior intensidade no espectro do sinal. De acordo com a figura 3.3.b essas regiões são de 1.23 a $1.45 \mathrm{M} \mathrm{Hz}$, o pico principal, e $0.45 \mathrm{MHz}$ a $0.94 \mathrm{MHz}, 3.04 \mathrm{MHz}$ a $3.94 \mathrm{MHz}, 4.00 \mathrm{MHz}$ a $4.80 \mathrm{MHz}$ e $4.92 \mathrm{MHz}$ a $5.30 \mathrm{MHz}$, os outros picos.

Observe-se que a magnitude do espectro sofre pouca variação. Pela escala de cores vê-se que o valor máximo da diferença é de 15 unidades, que ocorre na região em torno de $4.4 \mathrm{MHz}$. Há também variação na região em torno de $3.5 \mathrm{MHz}$, seguido pela região em torno de $0.7 \mathrm{MHz}$. Todas essas são faixas de frequências onde o módulo da função de transferência é reduzido comparado com o pico máximo em torno de $1.3 \mathrm{M} \mathrm{Hz}$, onda há pouca variação de amplitude.

Todavia, como visto na seção 1 uma diferença de fase faz com que não haja compensação de fase do sinal de inversão temporal recebido no instante $t_{0}+T$ e logo que esse não seja máximo nesse instante, além de causar a não simetria do sinal recebido sendo mais severa a degradação do sinal de inversão temporal.

A figura [.3.b mostra a diferença de fase das componentes em frequência de cada sinal recebido em relação ao sinal original, sem aplicação de tração. É 


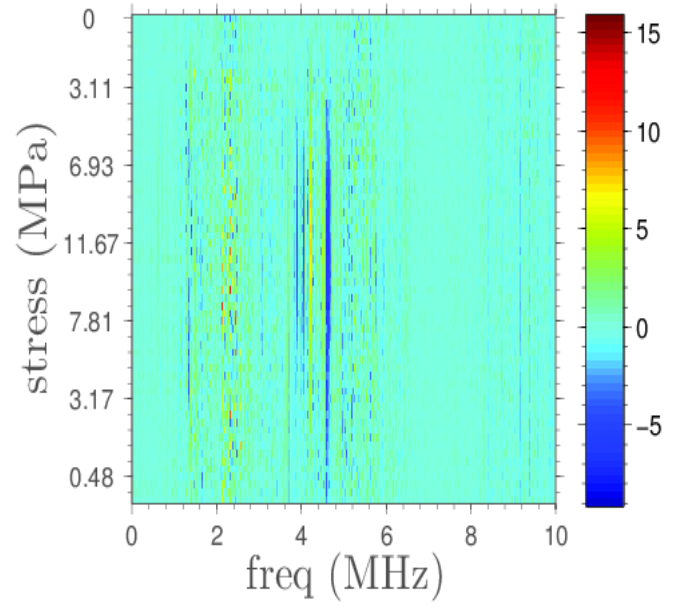

(a)

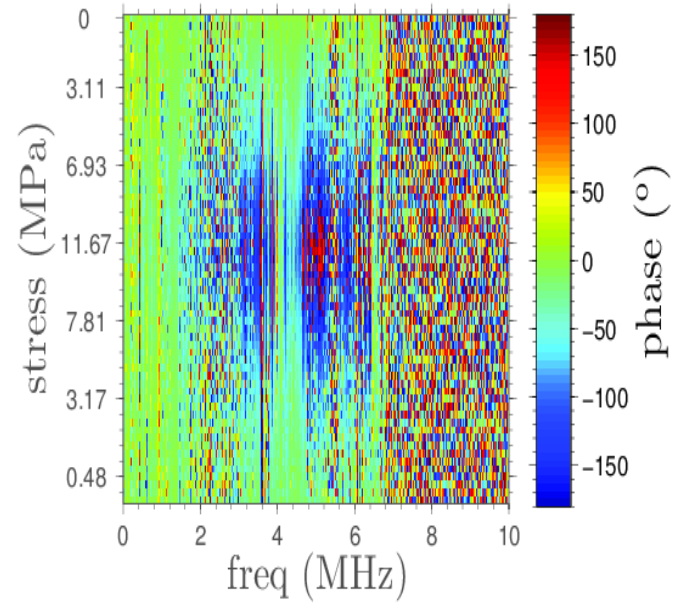

(b)

Figura 5.13: Diferença da função de transferêcia para cada valor de tração aplicado à placa. Módulo (a) e fase (b) para frequências positivas.

possível observar a existência de regiões de fase aleatória, onde as cores mudam violentamente entre medidas sucessivas. Essas representam zonas de frequência onde a amplitude é muito reduzida, o que pode ser comprovado observando o módulo do espectro do sinal original, figura 3.3.b. Uma componente exponencial complexa onde a amplitude seja zero, ou na prática muito baixa, tem fase desconhecida, o que explica a aleatoriedade nas medidas.

Ao observar a diferença na fase das componentes em frequência constatase que há mudança de fase altas, de até $\pm 180^{\circ}$ nas regiões em torno de $3.5 \mathrm{M} \mathrm{Hz}$, $4.4 M H z$ e $5.1 M H z$. Contudo essas regiões são pouco relevantes no sinal de inversão temporal por possuírem baixa amplitude. Assim sendo, perde-se a sensibilidade dessas regiões quando se faz o processo de inversão temporal. Por outro lado a região em torno da frequência cuja amplitude é máxima, 1.3M Hz, tem pouca variação de fase, a mudança máxima de fase é de $-40^{\circ}$. A figura [.14 mostras essas regiões em evidência, salienta-se que a escala da variação de fase da região em torno de $1.3 \mathrm{MHz}$ é reduzida para facilitar a visualização por ter menor variação de fase comparada com as demais faixas de frequência.

Conclui-se que se as componentes de frequências com maior sensibilidade à variação de tração forem usadas com maior peso no processo de inversão temporal espera-se obter um sinal, no domínio do tempo, com maior sensibilidade à tração. Uma maneira de se fazer isso é equalizar o espectro do sinal, alterando o módulo das componentes de frequência mais sensíveis, antes de transmiti-lo invertido no tempo. 


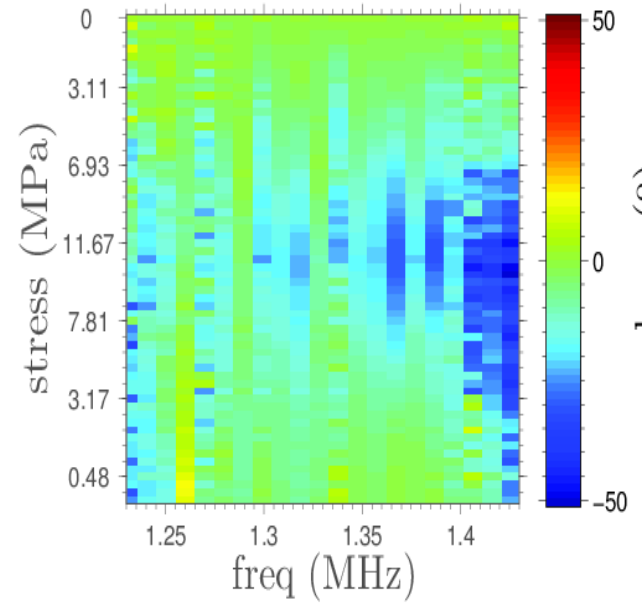

(a)

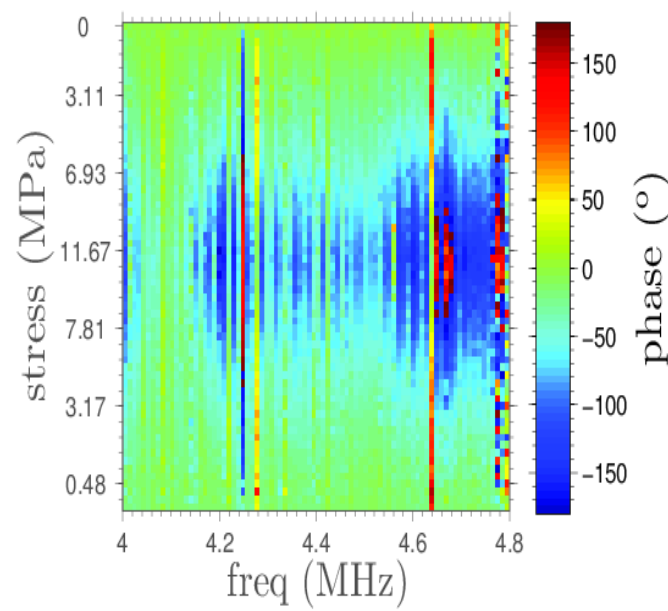

(c)

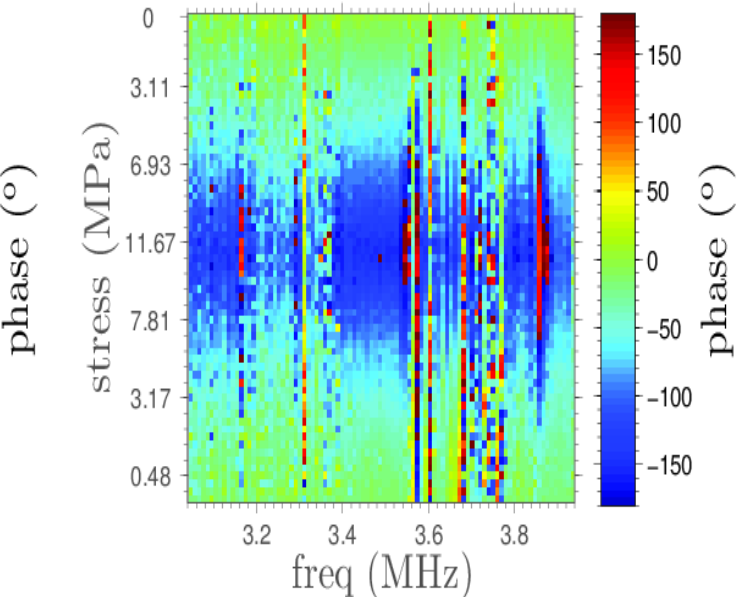

(b)

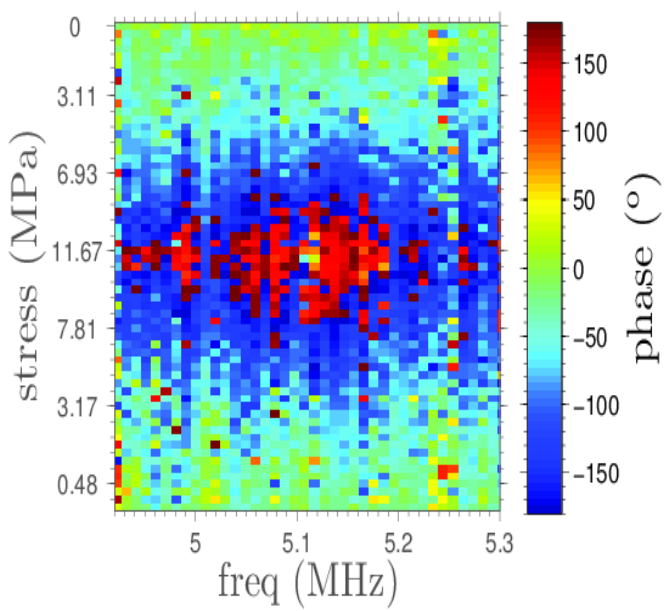

(d)

Figura 5.14: Diferença de fase da função de transferêcia para cada valor de tração aplicado à placa nas regiões de 1.23 a $1.43 \mathrm{MHz}$ (a), $3.04 \mathrm{MHz}$ a $3.94 \mathrm{MHz}$ (b), 4.00 a $4.80 \mathrm{MHz}$ (c), $4.92 \mathrm{MHz}$ a $5.30 \mathrm{MHz}$ (d). Observe-se que a escala de cores de (a) é reduzida para facilitar a visualização da variação de fase.

\section{3}

\section{Equalização de Faixas de Frequência}

Nessa seção é apresentado um experimento cujo objetivo é obter melhor focalização temporal e maior sensibilidade à tração no sinal de inversão temporal. A idéia é alterar o módulo dos picos de magnitude do espectro de modo que o espectro do sinal de inversão temporal seja mais equalizado, de modo semelhante técnica do filtro inverso exposta em 1.34, onde várias componentes em frequência são somadas com amplitudes iguais para construção do sinal no domínio do tempo.

Emprega-se então um filtro equalizador nas 5 regiões analisadas na seção 
anterior. Com isso impõe-se maior riqueza espectral ao sinal de inversão temporal. Além disso, como as faixas de frequência apresentam maior sensibilidade à tração, sobretudo manifestada em mudança de fase, espera-se que o sinal de inversão temporal recebido passe a ser mais sensível à variação de tração.

A aplicação do filtro equalizador procede da seguinte maneira. Ao receber o sinal na etapa (四) obtém-se sua transformada de Fourier. Utilizam-se as 5 faixas de frequência definidas na seção anterior, em cada uma dessas faixas aplicá-se um janelamento gaussiano de parâmetro $\alpha=1$ [‥5]. Esse janelamento é escolhido empiricamente para fornecer resposta espectral mais suave. O pico em frequência, $P_{i}$, de cada faixa, $i$, é registrado. Todas as componentes em frequência pertencentes a faixa $i$ são multiplicadas por $\frac{\max ^{2}\left(P_{i}\right)}{P_{i}^{2}}$, tal que $\max \left(P_{i}\right)$ é o valor máximo de todo o espectro e $\max ^{2}\left(P_{i}\right)=\left\{\max \left(P_{i}\right)\right\}^{2}$. O sinal é então re-convertido para o domínio do tempo usando a transformada inversa de Fourier, através do algoritmo IFFT [ [.5.] , e, em seguida, invertido no tempo. Salienta-se que, como já se tinha o sinal no domínio da frequência, poder-se-ia, ao invés de invertê-lo no tempo, usar o conjugado do sinal no domínio da frequência, e multiplicá-lo por fator de fase global de final de janela $e^{-j 2 \pi f\left(t_{0}+T\right)}$, de acordo com tull.

Objetiva-se com esse processamento transmitir um sinal $x_{1}(t)$ que gere um sinal na recepção, $y_{1}(t)$, que tenha os picos de cada uma das 5 faixas de frequência com mesmo valor. Isso é esperado porque o sinal ao ser transmitido na etapa (四) passa pelo sistema cuja função de transferência é igual aquela da primeira transmissão, $H(f)$, que age em cada um dos módulos dos picos em frequência $i$ multiplicando-os por $P_{i}$. Como o pulso inicial é considerado ideal, a resposta obtida na etapa (四) no domínio da frequência é equivalente a função de transferência do meio. Ao ser recebido o sinal $Y_{1}(f)$ os picos em frequência são multiplicados, pelo filtro, por $\frac{\max ^{2}\left(P_{i}\right)}{P_{i}^{2}}$ e, então, passam a assumir o valor $\frac{\max ^{2}\left(P_{i}\right)}{P_{i}}$ antes da transmissão na etapa (四). Ao ser transmitido, cada pico é novamente multiplicado idealmente por $P_{i}$, e, logo, o sinal recebido na etapa (四) tem cada um dos picos igual a $\max ^{2}\left(P_{i}\right)$.

Assim, o sinal de inversão temporal recebido é, não somente, mais rico espectralmente, como apresenta as faixas de frequência mais sensíveis à tração com mesmo módulo das demais. Espera-se, então, que o sinal de inversão temporal recebido seja mais sensível à tração.

A figura mostra o sinal recebido e filtrado, no domínio do tempo, obtido pela IFFT do sinal filtrado, e no domínio da frequência. Observe-se que as faixas de frequência originalmente com menor valor de pico são aquelas com a maior intensidade após passar pelo filtro, de tal modo a equilibrar o valor de 
todas as faixas no sinal de recebido na figura (四).

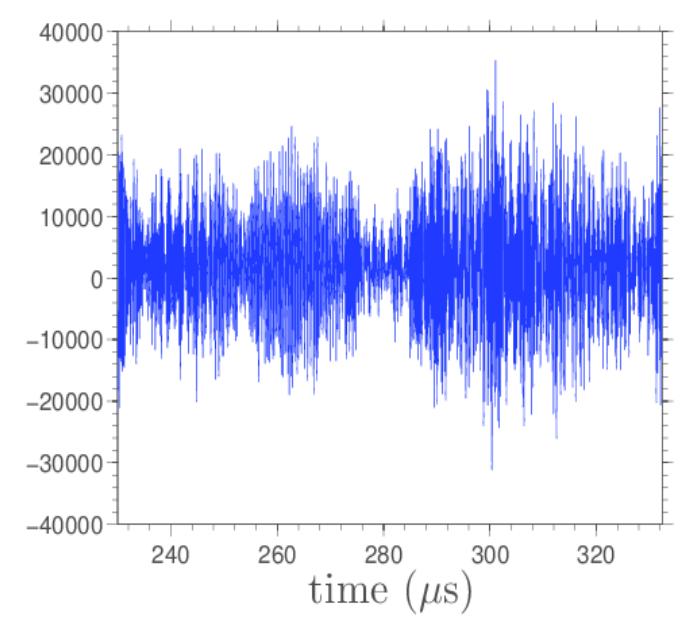

(a)

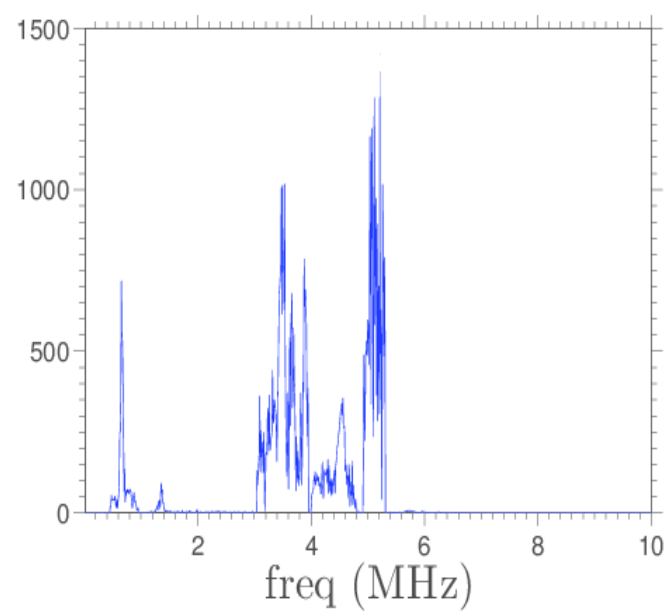

(b)

Figura 5.15: Sinal recebido na etapa (四) e filtrado com filtro equalizador de frequências,n o domínio do tempo (a) e módulo do espectro de frequências (b).

O sinal de inversão temporal obtido é mostrado na figura [ل Comprovase que os picos em frequência são equilibrados e o sinal no tempo torna-se mais estreito devido a maior riqueza espectral. A largura de $-6 d B$ do pico central que é igual $475 \mathrm{~ns}$.

A energia desse sinal é menor que a do sinal de inversão temporal sem aplicação de filtro, seção $50 d B$, maior que os apenas $40 d B$ necessários para a recepção com ausência de filtro. Calculando-se o ganho de recepção frente ao sinal inicial recebido tem-se o valor $28.20 d B$,

Outra característica do sinal recebido é a diminuição da simetria. O coeficiente de simetria do sinal recebido é de 0.850 . 


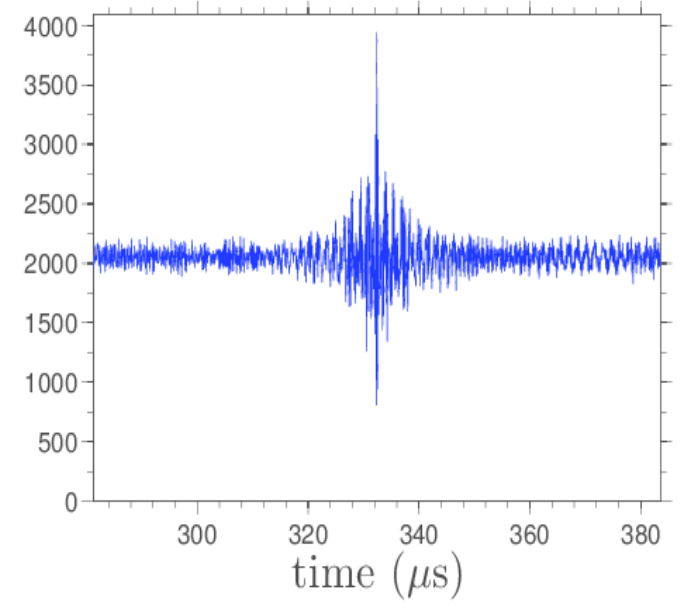

(a)

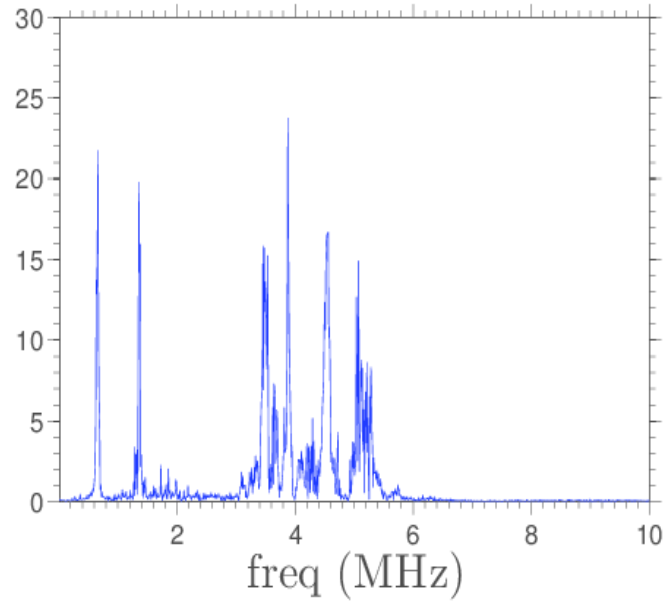

(b)

Figura 5.16: Sinal de inversão temporal recebido na etapa (四) usando filtro equalizador, no domínio do tempo (a) e módulo do espectro de frequências (b).

\subsection{1}

\section{Influência da Tração - tração inicial nula}

Do mesmo modo que na primeira experiência traciona-se a placa para vários valores de tração e repete-se as etapas (四) e (四) para cada um desse valores. Nessa experiência tracionou-se a placa até $10.8 M P a$.

\subsubsection{1 \\ Valor de Pico}

A figura 517 mostra a queda relativa dos valores de pico acima do valor médio em função da tração aplicada. Os ponto representados por • são as medições quando se aumenta a tração e os pontos representados por $\times$ as medições quando se diminui a tração após ter chegado no valor máximo.

É notável o incremento na sensibilidade do sinal à tração aplicada em relação a primeira experiência. Observe-se que para o valor de tração máxima, $10.8 \mathrm{MPa}$, o valor de pico chega a $73.1 \%$ do valor inicial, o que significa uma queda de $26.9 \%$ ou $-2.72 d B$. Se se considerar um caimento linear começando em torno a $5 M P a$ tem-se um queda de $3.7 \times 10^{-02}$ para cada $M P a$ de tração aplicada. O que equivale em um aumento de sensibilidade de 6.24 vezes, ou $15.9 d B$, comparado com a situação inicial.

Conclui-se que o estudo das faixas de frequências mais sensíveis à tração se mostra útil no projeto de um filtro equalizador capaz de fornecer um sinal de inversão temporal mais sensível à variação de tração aplicada na placa. 


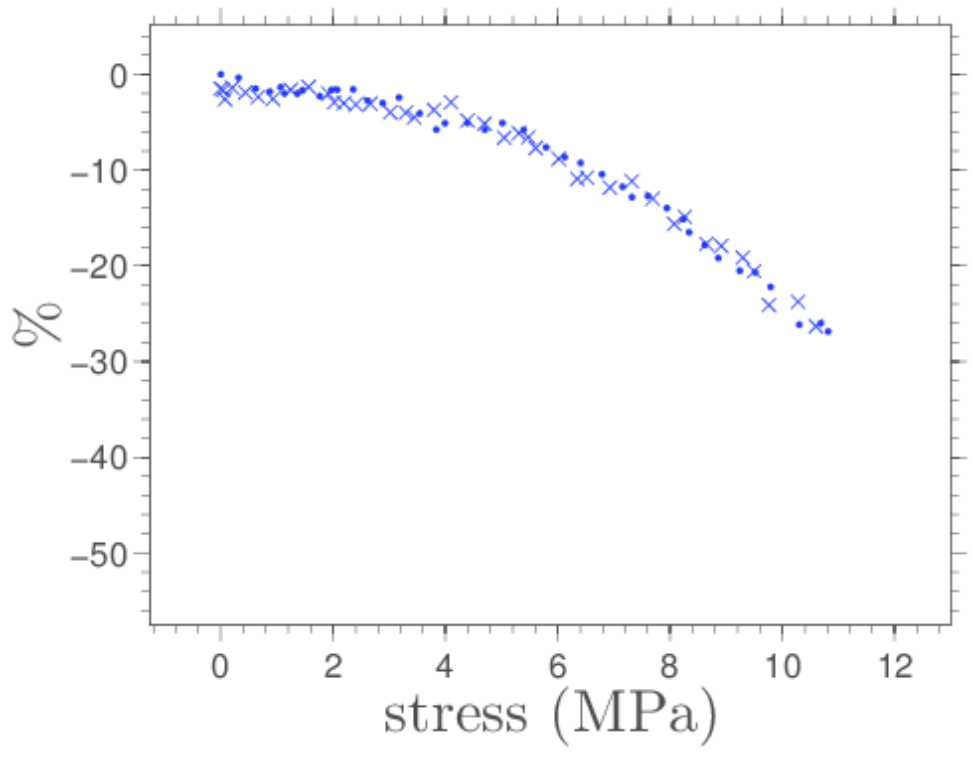

Figura 5.17: Valor de pico do sinal de inversão temporal utilizando o filtro equalizador, em função da tração aplicada para para sistema inicialmente livre de tração. Os símbolos • representam as medições de tração crescente e os símbolos $\times$ representam as medições de tração decrescente.

\subsubsection{2 \\ Instante de Pico}

A posição do tempo de máximo também é observada e como na primeira experiência é calculado o instante de pico através do modelo proposto em 4.4.I. O intervalo de velocidade de grupo para cada modo propagante em cada frequência é o mesmo da experiência inicial e dado pela equação

O espectro de amplitudes utilizado é o obtido na etapa (四) dada a transmissão do sinal invertido no tempo e filtrado na etapa (四), ou seja, aquele exibido pela figura

A figura mostra os instantes de pico medidos junto com os instantes de pico calculados para as diferentes trações aplicadas. Exibem-se os valores calculados para o instante de máximo utlizando os modelos elásticos e acustoelásticos representados no gráficos pelas linhas tracejada e contínua, respectivamente.

Os valores calculados levando-se em conta os efeitos acustoelásticos são mais próximos dos valores medidos que os valores calculados levando-se em consideração apenas o efeito elástico, o qual subestima o retardo causado pela aplicação da tração. O erro médio quadrático para os valores calculados com cada modelo são 10.41 ns e $17.12 n s$, respectivamente. 


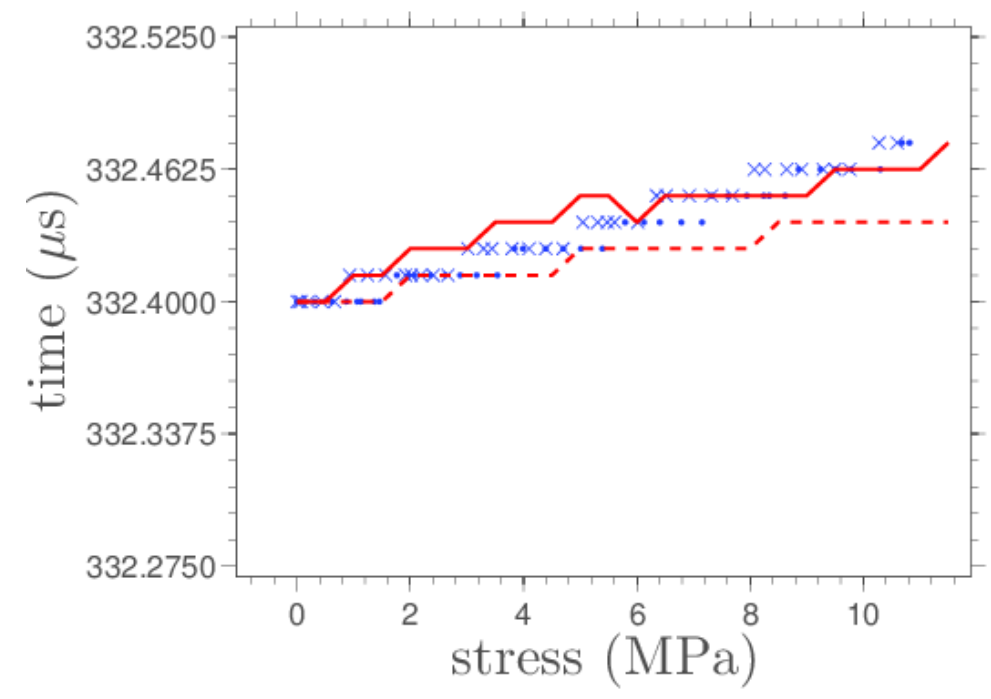

Figura 5.18: Instante de pico do sinal de inversão temporal utilizando o filtro equalizador, em função da tração aplicada para sistema inicialmente livre. Os símbolos • representam as medições de tração crescente e os símbolos $\times$ representam as medições de tração decrescente. A linha contínua representa os valores calculados pelo modelo acustoelástico e a linha tracejada pelo modelo elástico.

\subsection{2}

\section{Influência da Tração - sistema inicialmente tracionado}

Como no caso da primeira experiência repete-se a o procedimento para a placa inicialmente tracionada. As etapas (田) e (四) e a filtragem do sinal são feitas com a placa em tração máxima. A tração aplicada é diminuída e para cada valor repete-se as etapas (四) e (四) até a condição de tração nula, em seguida, retorna-se ao valor inicial, máxima.

Nessa experiência o valor inicial de tração imposto foi de $\tau_{\max }=$ 10.87MPa.

\subsubsection{1}

\section{Valor de Pico}

A figura 5 mostra a degeneração dos valores de pico acima do valor médio em função da tração encontrada.

Para a posição de tração nula a queda é de $25.6 \%$ ou $-2.56 d B$. Se se considerar um caimento linear a partir de uma diferença de $5 M P a$ do valor inicial de tração, i.e. para valores menores que aproximadamente $6 M P a$, há uma queda de $3.51 \times 10^{-02}$ para cada $M P a$ de variação de tração em relação ao valor inicial. 


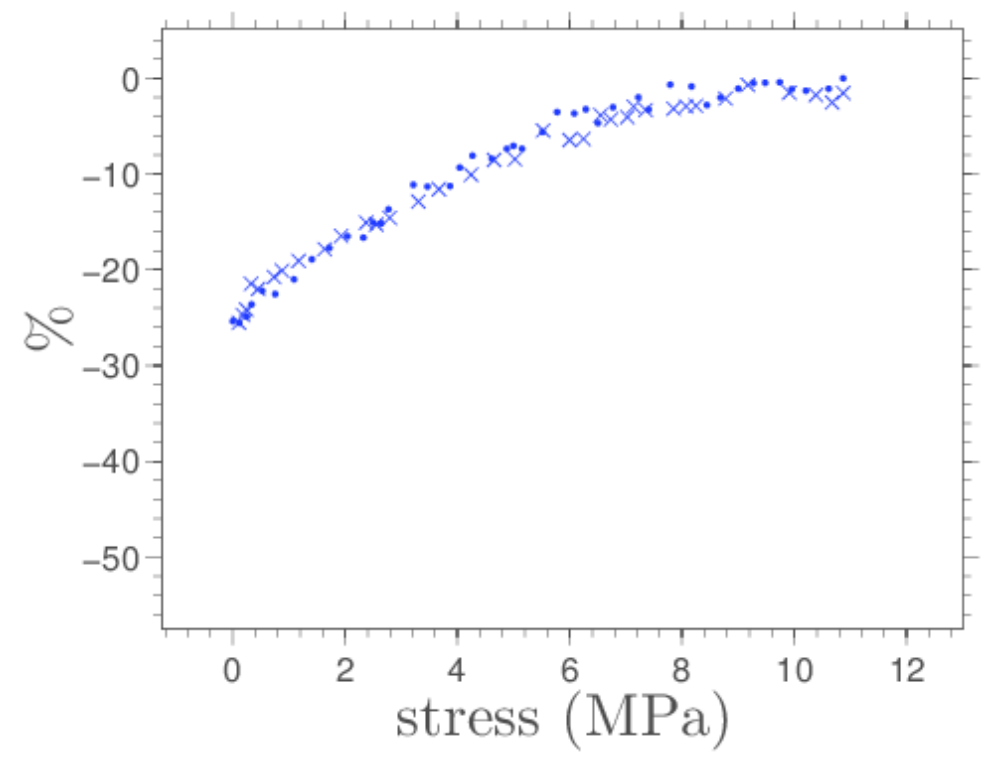

Figura 5.19: Valor de pico do sinal de inversão temporal utilizando o filtro equalizador, em função da tração aplicada para sistema inicialmente tracionado. Os símbolos • representam as medições de tração decrescente e os símbolos $\times$ representam as medições de tração crescente.

\subsubsection{2 \\ Instante de Pico}

A posição do tempo de máximo é mostrada na figura da tração imposta, junto com os valores calculados. Do mesmo modo que nos casos anteriores o intervalo de velocidade receptíveis é dado pela equação [-1. É usado como amplitude de cada componente em frequência a trasnformada do sinal de inversão temporal, etapa (四), da placa inicialmente tracionada.

Como no caso da tração crescente observa-se a maior relevância do modelo acustoelástico. O erro médio quadrático dos instantes de picos calculados em relação aos medidos foram de 19.02ns para o modelo elástico e $7.629 n s$ para o modelo acustoelástico. 


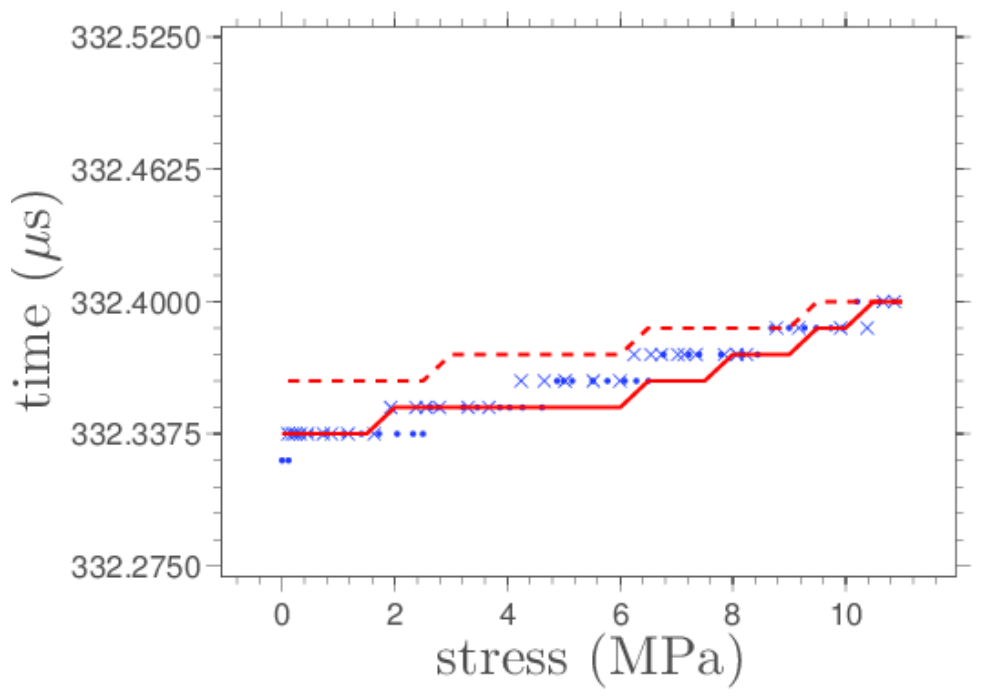

Figura 5.20: Instante de pico do sinal de inversão temporal utilizando o filtro equalizador, em função da tração aplicada para sistema inicialmente tracionado. Os símbolos • representam as medições de tração decrescente e os símbolos $\times$ representam as medições de tração crescente. A linha contínua representa os valores calculados pelo modelo acustoelástico e a linha tracejada pelo modelo elástico.

\section{4}

\section{Filtro Inverso}

Como mostrado na seção anterior consegue-se melhor sensibilidade do sinal de inversão temporal à tração aplicada quando as faixas de frequência mais sensíveis tem módulos iguais. Contudo a divisão do espectro em faixas de frequência requer uma análise criteriosa da sensibilidade espectral, como feito na seção [】, o que pode complicar o uso da técnica.

A teoria do filtro inverso é exposta na seção 1.3 .4 onde é mostrado que essa técnica fornece, em teoria, um sinal recebido cujo espectro possui todas as frequências com igual módulo. Assim, todas as componentes possuirão mesma contribuição na formação do sinal recebido, inclusive as mais sensíveis. Essa técnica não requer uma análise da função de transferência do sistema a fim de obter as componentes em frequência, ou faixas de frequência, mais aptas à inversão.

É, contudo, necessário estabelecer um limiar de inversão. Ou seja, um valor de amplitude a partir do qual o sinal passa a não ser considerado como ruído, sendo, então, invertido. No experimento feito esse limiar é encontrado empiricamente, o valor utilizado é $1 \%$ do valor do pico máximo de amplitude do espectro. Se o limiar é posto abaixo desse valor há muitas componentes de frequência ruidosas fazendo com que a forma característica do sinal de inversão 
temporal no domínio do tempo não seja presente.

Do mesmo modo como no filtro equalizador o sinal recebido na etapa (四) é filtrado no domínio da frequência. Assim é necessário a obtenção da transformada de Fourier do sinal para aplicar-se o filtro inverso, e, então, o sinal é reconvertido para o domínio do tempo pela transformada inversa de Fourier, onde o mesmo é invertido no tempo e transmitido, etapa (四).

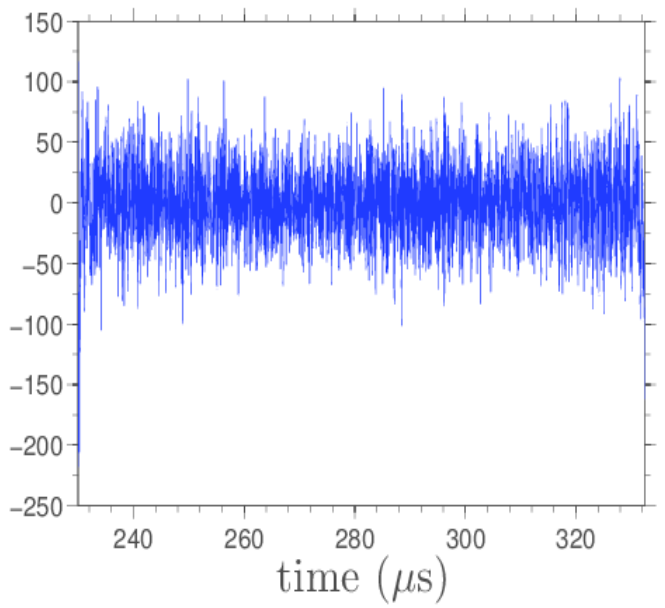

(a)

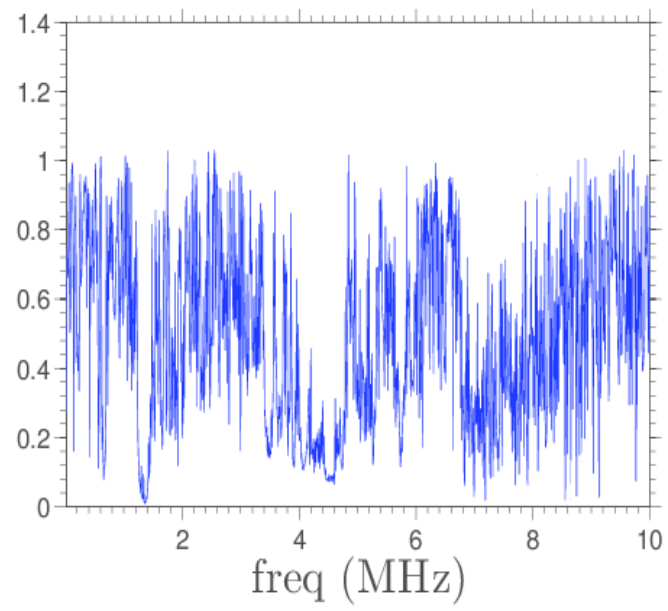

(b)

Figura 5.21: Sinal recebido na etapa (四) e filtrado pelo filtro inverso, no domínio do tempo (a) e módulo do espectro de frequências (b).

A figura filtrado no domínio da frequência possui as componentes invertidas com baixa amplitude, porque essas originalmente possuíam valor elevado mas ao serem invertidas passam a exibir os valores mais baixos do espectro.

O sinal filtrado é invertido no tempo, normalizado para limitar seu valor máximo e mínimo entre -1 e 1 e, então, pode ser transmitido. Recebe-se o sinal da figura $\mathbf{4}$ na etapa (目). Analisando-se o espectro de frequências comprovase que há mais equilibrio entre cada uma das componentes de frequências na faixa até $7 \mathrm{MHz}$, banda do pulso inicial aplicado, figura -b. A presença de componentes de frequência com intensidade mais elevadas se deve, além dos fatores experimentais, ao fato de, antes do sinal ser transmitido, ter algumas amostras iniciais e finais anuladas. De tal modo, o sinal é alterado e consequentemente seu espectro, fazendo com que a forma do sinal recebido não corresponda fielmente ao previsto pela teoria do filtro inverso.

Percebe-se que a focalização temporal do sinal é muito mais eficiente que nos casos anteriormente tratados. A figura 123 mostra a região central ao instante de pico do sinal ficalizado. A largura de $-6 d B$ do pico central desse sinal é de $80 \mathrm{~ns}$. 


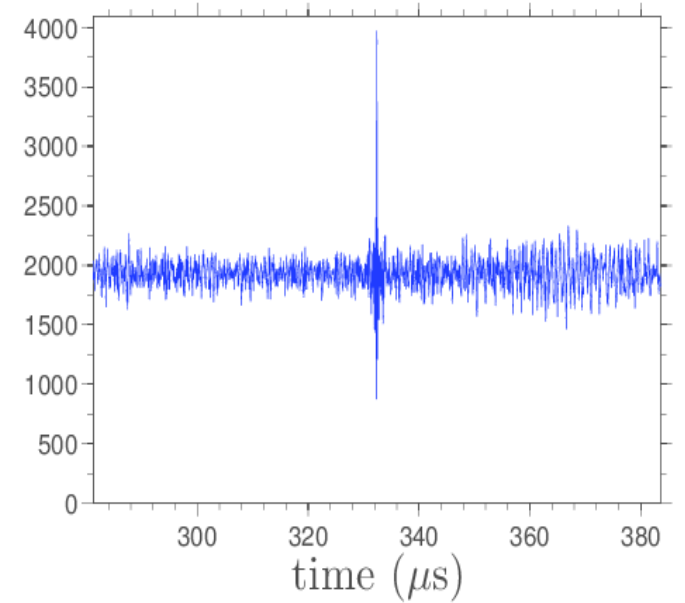

(a)

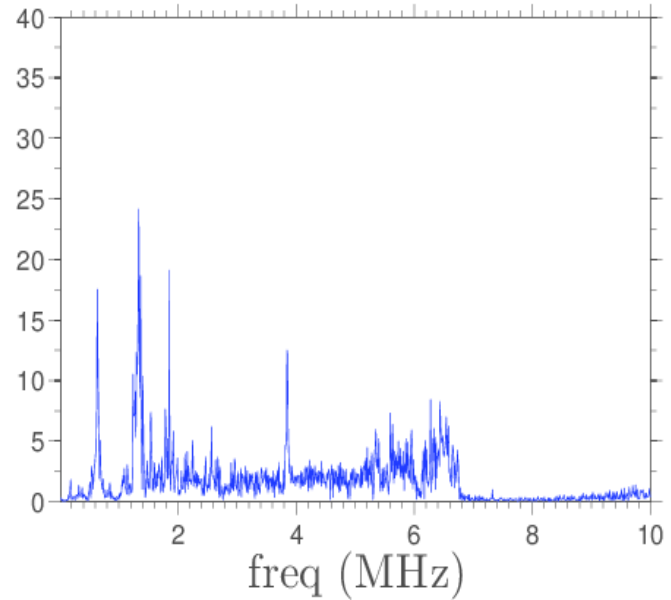

(b)

Figura 5.22: Sinal de inversão temporal recebido usando o filtro inverso com ganho do receptor de $58 \mathrm{~dB}$ na janela de tempo de $281.2 \mu \mathrm{s}$ a $383.6 \mu \mathrm{s}$, no domínio do tempo (a) e magnitude da transformada de Fourier (b) para frequências positivas.

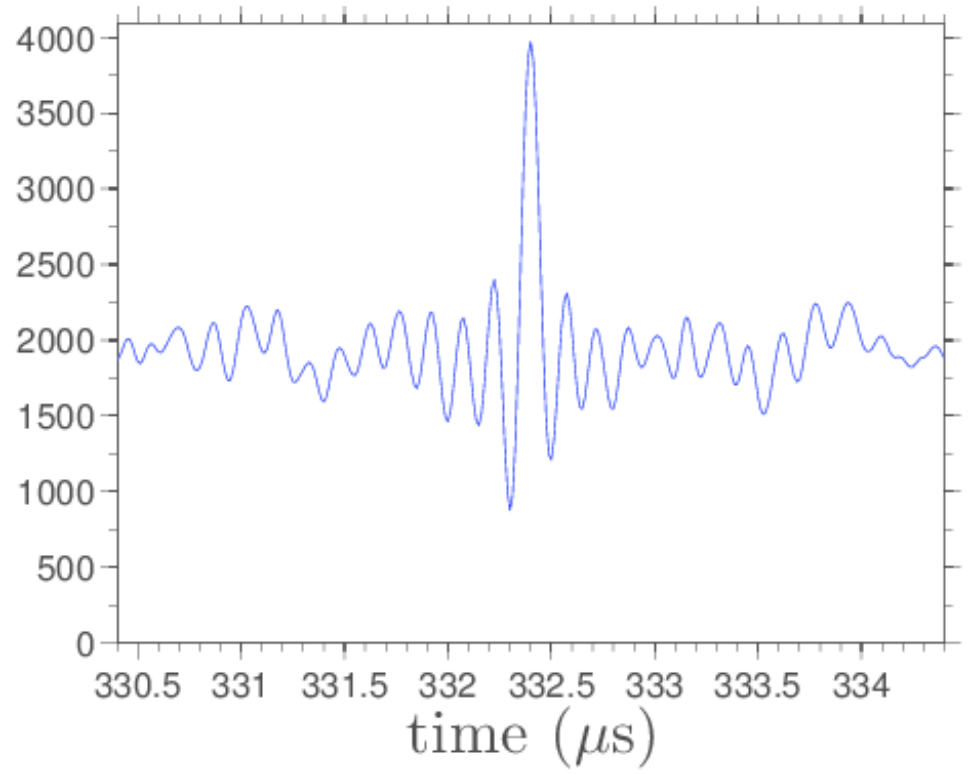

Figura 5.23: Detalhe do sinal de inversão temporal recebido usando o filtro inverso para o instante de focalização temporal.

Contudo a energia desse sinal é bastante reduzida comparada ao sinal

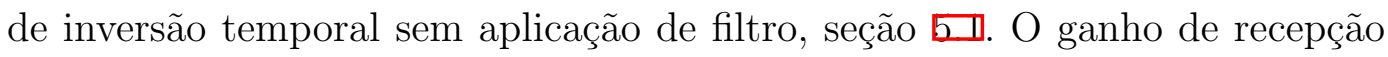
usado nessa experiência é de $58 d B$. Calculando-se o ganho de recepção frente ao sinal inicial recebido tem-se o valor $22.45 \mathrm{~dB}$. O coeficiente de simetria do sinal recebido é de 0.279 . 


\subsection{1}

\section{Influência da Tração - tração inicial nula}

O mesmo procedimento é aplicado nessa experiência. A tração é aplicada à placa através da barra roscada e o sinal da figura 5 é sucessivamente transmitido. Nessa experiência a condição de tração máxima aplicada é de 12.5MPa.

Adianta-se que, essa experiência fornece um sinal muito mais sensível a tração. Pode-se observar na figura [2] que a forma do sinal para a condição de tração máxima aplicada, $12.5 M P a$, é totalmente degenerada.

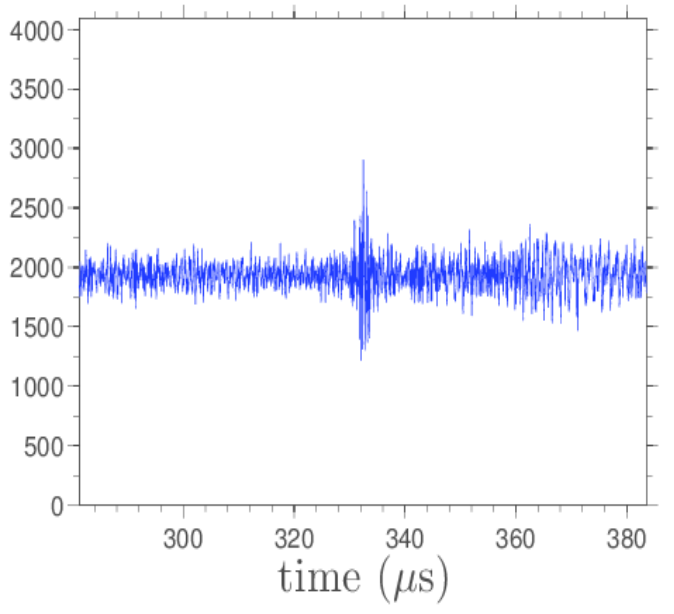

(a)

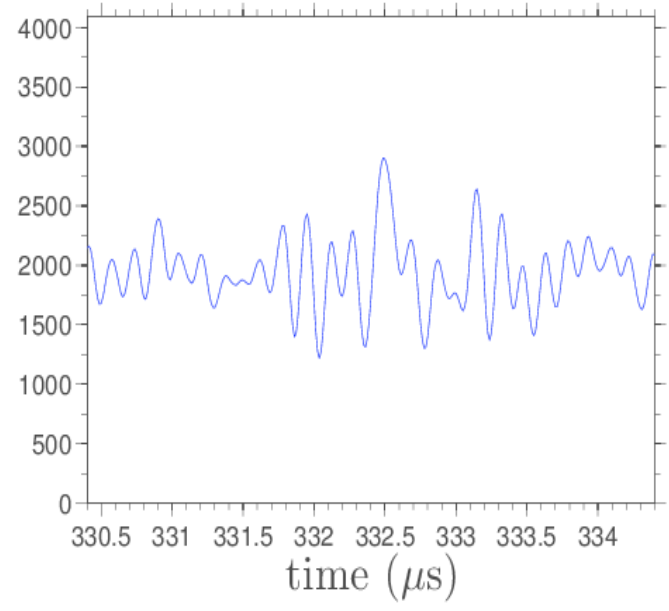

(b)

Figura 5.24: Sinal de inversão temporal recebido utilizando filtro inverso para a condição de tração máxima aplicada de $12.5 \mathrm{MPa}$, em toda a janela temporal (a) e detalhe do instante de focalização temporal (b).

\subsubsection{1 \\ Valor de Pico}

A figura mostra a queda percentual dos valores de pico acima do valor médio em função da tração. Os pontos representados pelo símbolo • são as medições quando se aumenta a tração e os pontos representados por $\times$ são as medições quando se diminui a tração após ter chegado no valor máximo.

Observe-se que o valor de pico diminui bastante quando comparado com a experiência inicial. $\mathrm{O}$ valor de pico no estado de tração máxima atinge o valor de $47.7 \%$ do valor inicial equivalente a uma queda de $52.3 \%$ ou $-6.43 d B$.

Do mesmo modo pode-se considerar um decaimento linear para trações maiores que $3 M P a$, e essa é de $5.1 \times 10^{-02}$ para cada $M P a$ de tração aplicada. O que equivale em um aumento de sensibilidade de 8.68 vezes, ou $18.77 d B$, comparado com a situação inicial. 


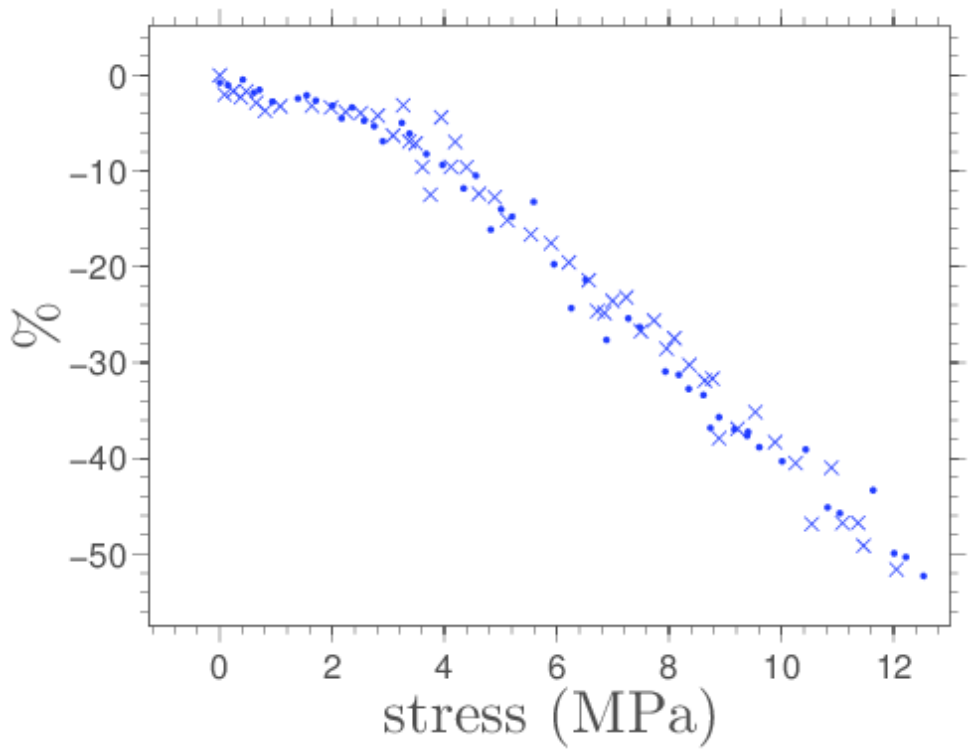

Figura 5.25: Valor de pico do sinal de inversão temporal utilizando o filtro inverso, em função da tração aplicada para sistema inicialmente livre de tração. Os símbolos • representam as medições de tração crescente e os símbolos $\times$ representam as medições de tração decrescente.

Comprova-se a melhoria no processo imposta pelo filtro inverso ao igualar os módulos das componentes de frequência não só na focalização temporal como na sensibilidade do sinal de inversão temporal à variação de tração.

\subsubsection{2}

\section{Instante de Pico}

A posição do tempo de máximo também é observado e, como nos casos anteriores é calculado o instante de pico através do modelo proposto em 1.4. 1 . O intervalo de velocidade de grupo para cada modo propagante em cada frequência é o mesmo, dado pela equação [-1. O espectro de amplitudes utilizado está exibido na figura

A figura 18 mostra os instantes de pico medidos junto com os instantes de pico calculados para as diferentes trações aplicadas, considerando ambos os modelos.

Observe-se que os valores medidos condizem com os valores obtidos considerando o efeito acustoelástico. Os valores calculados levando-se em consideração apenas o efeito da deformação subestimam o deslocamento temporal causado pela aplicação da tração.

O erro médio quadrático do modelo acustoelástico é de 6.611ns e do modelo elástico é de 20.01ns. Observa-se que para sinais com maior riqueza 


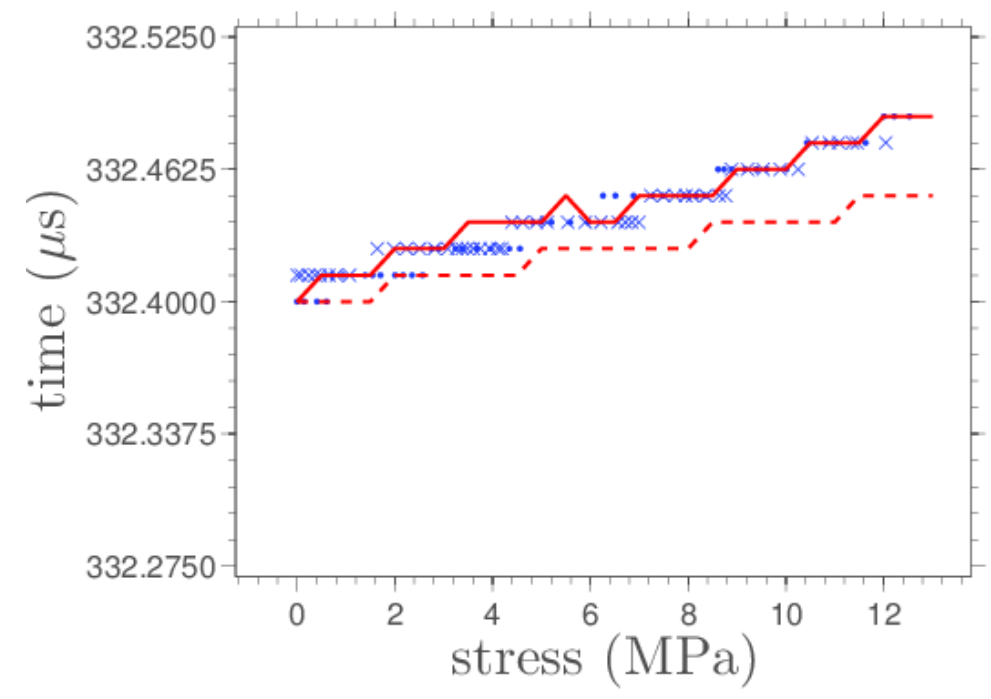

Figura 5.26: Instante de pico do sinal de inversão temporal utilizando o filtro inverso, em função da tração aplicada para sistema inicialmente livre de tração. Os símbolos • representam as medições de tração crescente e os símbolos $\times$ representam as medições de tração decrescente. A linha contínua representa os valores calculados pelo modelo acustoelástico e a linha tracejada pelo modelo elástico.

espectral o modelo que considera a mudança na velocidade das ondas guiadas devido aos efeitos acustoelásticos é mais adequado.

\section{4 .2}

\section{Influência da Tração - sistema inicialmente tracionado}

Como nos casos anteriores faz-se as medições para a placa inicialmente tracionada, nessa as etapas (i) e (四) e a aplicação do filtro inverso se procedem com a placa em tração máxima. A tração aplicada é diminuída e para cada valor repete-se as etapas (四) e (四) até a condição de tração nula, em seguida, retorna-se ao valor inicial, máxima.

Nessa experiência o valor inicial de tração imposto foi de $\tau_{\max }=$ 9.817MPa.

\subsubsection{1}

\section{Valor de Pico}

A figura 5 mostra a queda relativa dos valores de pico acima do valor médio em função da tração medidos.

Para a posição de tração nula a queda é de $23.5 \%$ ou $-2.33 d B$. Se se considerar um caimento linear a partir de uma diferença de $3 M P a$, i.e. para 


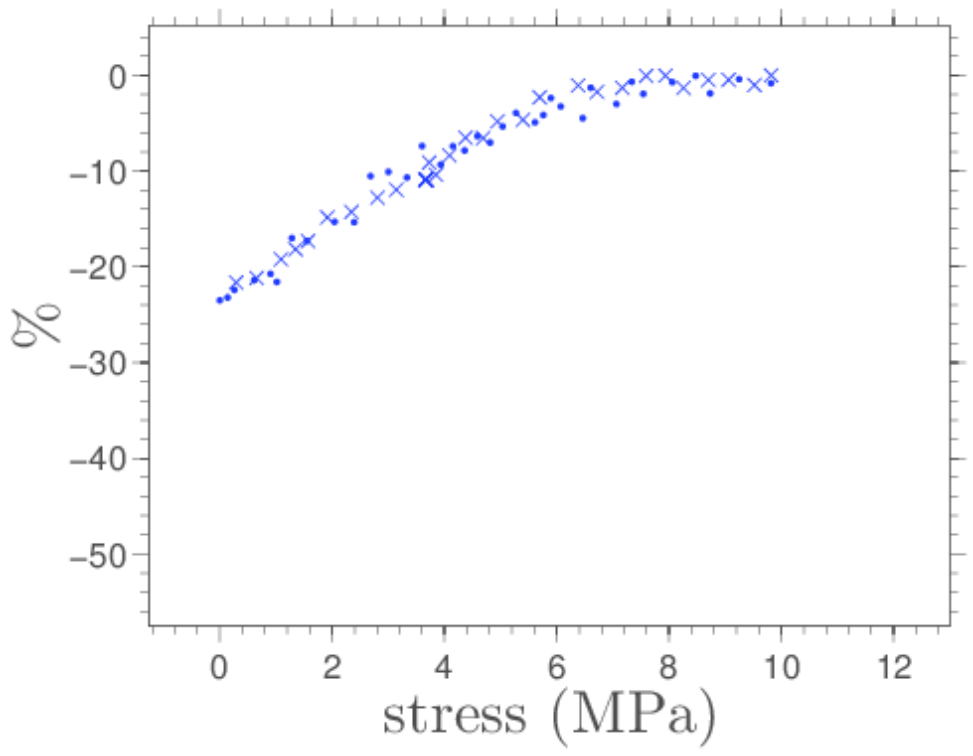

Figura 5.27: Valor de pico do sinal de inversão temporal utilizando o filtro inverso, em função da tração aplicada para sistema inicialmente tracionado. Os símbolos • representam as medições de tração decrescente e os símbolos $\times$ representam as medições de tração crescente.

valores menores que aproximandamente 7.0MPa, há uma queda de $3.35 \times 10^{-02}$ para cada $M P a$ de tração aplicada.

\subsubsection{2 \\ Instante de Pico}

A posição do tempo de máximo é mostrada na figura tração imposta.

Do mesmo modo que nos casos anteriores, o intervalo de velocidade receptíveis é dado pela equação [temporal da etapa (四) da placa inicialmente tracionada são usados na rotina de cálculo do instante de pico do sinal.

Como no caso da tração crescente observa-se a maior relevância do modelo acustoelástico. O erro médio quadrático dos instantes de picos calculados em relação aos medidos é de $21.648 n$ s para o modelo elástico e 8.326ns para o modelo acustoelástico. 


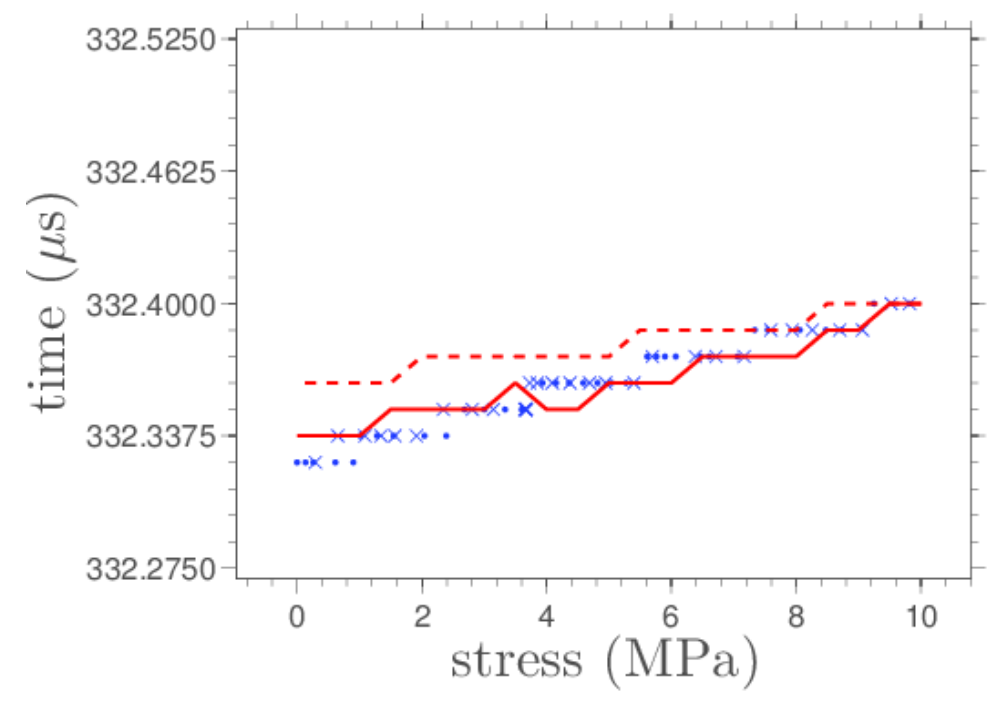

Figura 5.28: Instante de pico do sinal de inversão temporal utilizando o filtro inverso, em função da tração aplicada para sistema inicialmente tracionado. Os símbolos • representam as medições de tração decrescente e os símbolos $\times$ representam as medições de tração crescente. A linha contínua representa os valores calculados pelo modelo acustoelástico e a linha tracejada pelo modelo elástico.

\section{5 \\ Resumo dos Resultados Experimentais}

Essa seção traz o resumo dos resultados experimentais encontrados.

A tabela 1 mostra os valores de ganho em relação ao sinal originalmente recebido, o valor do coeficiente de simetria e a largura de $-6 d B$ do sinal de inversão temporal recebido, a fim de se caracterizar a qualidade da focalização temporal, para cada um dos experimentos.

Tabela 5.1: Características da focalização temporal em cada experiência.

\begin{tabular}{c|ccc}
\hline Experimento & Ganho & $\begin{array}{c}\text { Coeficiente } \\
\text { de Simetria }\end{array}$ & $\begin{array}{c}\text { Largura } \\
\text { de }-6 d B \\
n s\end{array}$ \\
\hline Inicial & 36.65 & 0.974 & 13300 \\
\hline Filtro Equalizador & 28.20 & 0.850 & 475 \\
\hline Filtro Inverso & 22.45 & 0.279 & 80 \\
\hline
\end{tabular}

Comprova-se que ao aumentar a riqueza espectral fazendo com que os módulos das componentes em frequência possuam intensidades próximas melhora-se o processo de focalização temporal, como indica a forte diminuição da largura do pico do sinal de inversão temporal. As formas desse sinais são encontrados nas figuras 5.6, 5.10 e 5.2. 
Em contrapartida à melhora da focalização temporal observa-se a diminuição do ganho do sinal de inversão temporal frente ao sinal recebido na etapa (四) e a diminuição da simetria do sinal.

A perda de energia do sinal recebido quando se usa os filtros, se deve a diminuição forçada da intensidade das componentes naturalmente mais fortes do sistema. Essas são identificáveis pelo espectro de amplitude da função de transferência do sistema mostrada na figura 5.3 . Ambos os experimentos de filtragem intensificam as componentes mais fracas do espectro em relação as mais fortes, fazendo com que a intensidade do sinal recebido seja menor que no experimento onde não se usa filtragem.

Já a diminuição da simetria se deve a maior suscepitibilidade dos sinais filtrados ao ruído imposta quando se aumenta a intensidade das componentes em frequência a fim de enriquecer o espectro. Assim, não apenas as componentes de sinal, mas também aquelas de ruído podem ser incrementadas. No caso do filtro equalizador todo o conteúdo das faixas é multiplicado pelo mesmo fator, inclusive as componentes mais influenciadas pelo ruído dentro de cada faixa. No caso do filtro inverso é escolhido um limiar empírico para efetuar-se a inversão, contudo mesmo assim componentes em frequência com ruído podem ser invertidas e, logo, terem alta contribuição no sinal recebido na etapa (四)

A tabela 2 mostra os valores de queda relativa do pico do sinal recebido na condição de tração máxima de cada experimento; caimento linear para as medidas de maior tração de cada experimento; e queda relativa dos valores de pico para o menor valor de tração máxima dentre todos os experimentos a fim de facilitar a comparação, para os experimentos onde a placa encontra-se inicialmente sem tração.

Tabela 5.2: Valores da sensibilidade para tração crescente.

\begin{tabular}{|c|c|c|c|}
\hline Experimento & $\begin{array}{c}\text { Queda em tração } \\
\text { máxima } \\
\%\end{array}$ & $\begin{array}{c}\text { Queda em } \\
10.80 M P a \\
\%\end{array}$ & $\begin{array}{c}\text { Queda Linear } \\
\% / M P a\end{array}$ \\
\hline Inicial & $6.00 @ 12.60 \mathrm{MPa}$ & 3.9 & 0.59 \\
\hline Filtro Equalizador & $26.9 @ 10.80 \mathrm{MPa}$ & 26.9 & 3.70 \\
\hline Filtro Inverso & $52.3 @ 12.50 M P a$ & 45.2 & 5.10 \\
\hline
\end{tabular}

A tabela 5.3 traz os mesmos valores para tracionamento decrescente na placa inicialmente tracionada. O valor da queda em tração nula é acompanhado da diferença de tração relativo à tração inicial. A fim de facilitar a comparação é marcado o valor de queda na condição de menor variação entre todos os experimentos. 
Tabela 5.3: Valores da sensibilidade para tração decrescente.

\begin{tabular}{c|ccc}
\hline Experimento & $\begin{array}{c}\text { Queda em } \\
\text { tração nula }\end{array}$ & $\begin{array}{c}\text { Queda com } \\
\text { diferença de } \\
9.82 \mathrm{MPa}\end{array}$ & Queda Linear \\
& $\%$ & 7 & $\% / M P a$ \\
\hline Inicial & $8.20 @ 11.55 \mathrm{MPa}$ & 7.0 & 1.07 \\
\hline Filtro Equalizador & $25.6 @ 10.87 \mathrm{MPa}$ & 20.0 & 3.51 \\
\hline Filtro Inverso & $23.5 @ 9.82 \mathrm{MPa}$ & 23.5 & 3.35 \\
\hline
\end{tabular}

Observa-se que a sensibilidade aumenta, tanto no processo de tração crescente quanto decrescente, quando se usa sinais com maior riqueza espectral. Seja por uma seleção das faixas de frequência com maior sensibilidade de fase, como feito no experimento do filtro equalizador, ou seja igualando todas as componentes em frequência acima de uma limiar, como no caso do filtro inverso.

A tabelas 5 e e 5 mostram os valores de erro dos modelos propostos para o instante de pico do sinal de inversão temporal recebido para o tracionamento crescente e decrescente da placa, respectivamente.

Tabela 5.4: Erro do modelo proposto em tração crescente.

\begin{tabular}{c|cc}
\hline Experimento & $\begin{array}{c}\text { Erro modelo } \\
\text { elástico } \\
n s\end{array}$ & $\begin{array}{c}\text { Erro modelo } \\
\text { acustoelástico } \\
n s\end{array}$ \\
\hline Inicial & 5.187 & 28.51 \\
\hline Filtro Equalizador & 17.12 & 10.41 \\
\hline Filtro Inverso & 20.01 & 6.611 \\
\hline
\end{tabular}

Tabela 5.5: Erro do modelo proposto em tração decrescente.

\begin{tabular}{c|cc}
\hline Experimento & $\begin{array}{c}\text { Erro modelo } \\
\text { elástico } \\
n s\end{array}$ & $\begin{array}{c}\text { Erro modelo } \\
\text { acustoelástico } \\
n s\end{array}$ \\
\hline Inicial & 4.884 & 29.52 \\
\hline Filtro Equalizador & 19.02 & 7.629 \\
\hline Filtro Inverso & 21.65 & 8.326 \\
\hline
\end{tabular}

Os modelos propostos comparados com os valores experimentais se mostram coerente. Obtem-se menor erro médio quadrático do modelo elástico para o experimento inicial, onde o sinal apresenta uma baixa faixa de frequência 
relevante. Para os demais experimentos o modelo acustoelástico é mais preciso, onde o sinal apresentava faixa mais larga de frequências.

O cálculo da variação de fase usada no modelo acustoelástico proposto é feito com a rotina computacional exposta na seção W. métodos númericos para encontrar raiz do determinante da matriz $M_{21}$ para uma varredura de frequência e número de onda. Está-se, então, sujeito a problemas de singularidades, condicionamento da matriz e determinação dos valores de tolerância. Havendo uma larga faixa espectral na amplitude do sinal efeitos dessa natureza são naturalmente compensados pela integral de cada componente em frequência e então o modelo acustoelástico representa uma melhor estimativa. 


\section{6 \\ Conclusões}

Esse trabalho estudou a teoria das ondas mecânicas, sobretudo das guiadas em placas de face paralelas, o processo de inversão temporal de campos acústicos e princípios da teoria da acustoelasticidade.

A técnica da inversão temporal em placas foi experimentalmente aplicada. Meios de aperfeiçoamento da qualidade da focalização temporal com base no equilíbrio da intensidade do espectro de amplitude foram propostos e suas capacidades avaliadas.

Destaca-se como resultado deste trabalho a comprovação da sensibilidade ao tracionamento axial do sinal de inversão temporal de ondas guiadas em placas de faces paralelas. Essa é observada pela redução do valor de pico do sinal de inversão temporal recebido e seu deslocamento temporal, dada a variação da intensidade da tração aplicada à placa. O tracionamento experimental se deu tanto no sentido crescente como decrescente da tração inicial. Em ambos os casos retornou-se ao valor de tração inicial e do mesmo modo se comportou a forma do sinal de inversão temporal recebido. Ou seja, o valor de pico retorna para o valor inicial indicando que o processo degenerativo imposto pelo tracionamento é mais relevante que variações externas nas condições do experimento, sendo a mais evidente delas a temperatura.

Propôs-se dois modelos para o sinal de inversão recebido com base na variação de fase causada pela velocidade de propagação de cada modo propagante de onda de Lamb. Ambos foram usadas para o cálculo do instante de pico do sinal de inversão temporal em função da tração aplicada à placa e seus valores confrontados aos experimentais em cada um dos cenários. Ambos mostraram-se coerentes, no sentido que os resultados obtidos são da mesma ordem de grandeza das medições, tanto para a placa inicialmente tracionada, como livre de tração. O modelo elástico se mostrou mais adequado no caso de sinais de inversão temporal de estreito espectro enquanto o acustoelástico melhor para sinais com mais componentes em frequência, apresentando erro médio quadrático médio menor que uma amostra temporal, usando a frequência de 
amostragem máxima fornecida pelo equipamento utilizado.

Esse resultado introduz um método que relaciona o instante do pico do sinal de inversão temporal à variação da tração aplicada à placa. $\mathrm{O}$ mesmo pode ser aplicado em um cenário onde se deseje obter o valor da variação da tração aplicada a uma placa.

Seu uso de forma quantitativa requer o cálculo computacional dos modos de propagação das ondas de guiadas para o caso experimental em questão e, para o uso do modelo acustoelástico, do cálculo desses para todo o âmbito de intensidades de tração aplicáveis.

Adicionalmente, há o detalhe da resolução temporal que pode associar diversos valores de tração ao mesmo instante de pico, como foi observado nos experimentos apresentados. A resolução temporal é dada pela frequência de amostragem do aparelho. Aumentar a distância entre transdutores pode fazer com que para a mesma intensidade de tração aplicada haja maior intensidade do deslocamento do instante de pico a ponto de ser melhor distinguível usando a mesma frequência de amostragem. Em contra partida, ao aumentar a distância ocorre a diminuição de amplitude do sinal observado, logo um compromisso entre ambas torna-se necessário. Outra alternativa é usar uma interpolação com filtro passa baixa no sinal recebido a fim de obter maior resolução temporal.

Todavia, o uso da presente técnica em um cenário qualitativo é mais simples. O deslocamento temporal do instante de pico e, também, a redução de seu valor podem ser utilizados como apontadores de variação da tração aplicado. Sendo, assim, aplicável em monitoramento da variação de tração.

Cuidados devem ser tomados no sentido de distinguir a variação aguda devido a uma diferença de tração de degenerações de longo prazo inerentes à física do problema. Nos experimentos feitos a variação predominante foi dada pelo tracionamento, o que é comprovado pela recuperação do sinal quando o estado de tração inicial é retomado. Contudo, para um monitoramento constante onde o tempo de medição seja prolongado variações de longo prazo podem influenciar o sinal observado. A fim de contornar isso, pode-se, por exemplo, re-adquirir o sinal inicial, o qual é invertido no tempo e transmitido, em intervalos predefinidos de tempo.

Durante o estudo observou-se os seguinte pontos que merecem ser analisados como possíveis formas de aprimoramento do processo.

- O uso da técnica de inversão temporal no domínio da frequência, onde a função de transferência é obtida diretamente para cada componente de frequência, pode fornecer uma resposta em frequência mais precisa. A técnica da inversão temporal requer a obtenção da resposta impulsional 
do sistema a fim de invertê-la e retransmití-la, ou, como feito no presente trabalho, executar alguma espécie de processamento digital no sinal recebido. Logo a obtenção da função transferência melhor caracterizada para cada componente de frequência pode implicar em focalização temporal mais estreita e sinais mais sensíveis à tração.

- A pesquisa de transdutores mais adequados ao experimento em questão, com melhor resposta em frequêcia e maior ganho. Dentro desse ponto caberia averiguar o uso de transdutores multielementos do tipo phased array ou uma combinação de transdutores espalhada pela placa, para a recepção do diversos sinais os quais seriam invertidos no tempo e transmitidos simultaneamente. Desse modo a sensibilidade do sinal de inversão de temporal à mudança de fase na propagação das onda guiadas seria afetado não somente pelo não casamento em frequência, como também por um possível não casamento dos sinais transmitidos em cada elemento quando a placa estivesse com o seu estado de tração alterado.

- Uso de um sistema de tracionamento mais robusto e automatizado. Durante o processo experimental foi algumas vezes necessário o reparo da ponte tracionadora. O uso de um sistema de tracionamento mais forte possibilitaria a aplicação do procedimento em uma maior variedade de placas e materias e, sobretudo, aplicação de limites de tração mais elevados. Para isso pode ser preciso o uso de sistema automatizado onde o tracionamento não se dê manualmente. 


\section{Referências Bibliográficas}

[1] SANTIN, J. L. Ultra-Som: técnica e aplicação. Optagraf Gráfica e Editora, Curitiba, 2003.

[2] DUBÉ, N. Introduction to Phased Array Ultrasonic Technology Applications: R/D Tech Guideline. Olympus NDT, 2007.

[3] ROSE, J. L. Ultrasonic waves in solid media. Cambridge University Press, 1999.

[4] FINK, M.; PRADA, C. Acoustic time-reversal mirrors. Inverse Problems, 17(1):R1, 2001.

[5] FINK, M. Time reversal of ultrasonic fields-part I: Basic principles. IEEE Transactions on Ultrasonics, Ferroelectrics, and Frequency Control, 39(5):555-566, Sept. 1992.

[6] ING, R. K.; FINK, M. Time-reversed lamb waves. IEEE Transactions on Ultrasonics, Ferroelectrics, and Frequency Control, 45(4):1032-1043, July 1998.

[7] PÉREZ, N. Inversión temporal de ondas ultrasónicas en cavidades acústicas. Tesis de Doctorado en Fisica, Universidad de La Republica, Uruguay, 2006.

[8] ACHENBACH, J. D. Wave propagation in elastic solids. NorthHolland. Amsterdam, 1975.

[9] Laboratory for active materials and smart structures, 2002. College of Engineering and Computing, Mechanical Engineering, University of South Carolina. Disponível no endereço eletrônico: http://wwW.me.sc . edu/Research/lamss/research/Waves/sld004.htm. Acessado em janeiro 2012.

[10] STOBBE, D. M. Acoustoelasticity in 7075-t651 aluminum and dependence of third order elastic constants on fatigue damage. Masters of Science Thesis, School of Mechanical Engineering, Georgia Institute of Technology, 2005.

[11] BRAGA, A. M. B.; HERMANN, G. Floquet waves in anisotropic periodically layerd composites. J. Acoust. Soc. Am., 91(3):1211-1227, Mar. 1992. 
[12] KIM, K. Y.; SACHSE, W. Acoustoelasticity of elastic solids in: Handbook of elastic properties of solids, liquids, and gases. Academic Press, 1:441-468, 2001.

[13] FREITAS, M. A. Monitoramento de tensão mecânica em risers flexíveis por eletromagnetismo. Tese de Doutorado, Departamento de Telecomunicações (CETUC), PUC-Rio, 2011.

[14] HUGHES, D.; KELLY, J. Second-order elastic deformation of solids. J. Appl. Phys Phys Rev, 92:1145, 1953.

[15] MURnaGHAN, F. D. Finite Deformation of an Elastic Solid. John Wiley \& Sons Inc., 1951.

[16] OGILVIE, G. Mathematical methods I, 2008. Natural Sciences Tripos, Part IB - Michaelmas Term, University of Cambridge Fellow of Clare College. Disponível no endereço eletrônico: http://www.damtp.cam.ac. uk/user/gio10/nst_notes.pdf . Acessado em junho 2012.

[17] LAMB, J. S.; ROBERTS, J. A. Time-reversal symmetry in dynamical systems: A survey. Physica D, 112:1-39, 1998.

[18] FINK, M.; MONTALDO, G. ; TANTER, M. Ultrasonic time reversal mirrors. In: AIP CONFERENCE PROCEEDINGS, HIGH FREQUENCY OCEAN ACOUSTICS: HIGH FREQUENCY OCEAN ACOUSTICS CONFERENCE, volume 728, p. 514-521, 2004.

[19] WU, F.; THOMAS, J.-L. ; FINK, M. Time reversal of ultrasonic fields-part II: Experimental results. IEEE Transactions on Ultrasonics, Ferroelectrics, and Frequency Control, 39(5):567-578, Sept. 1992.

[20] CASSEREAU, D.; FINK, M. Time-reversal of ultrasonic fields-part III: Theory of the closed time-reversal cavity. IEEE Transactions on Ultrasonics, Ferroelectrics, and Frequency Control, 39(5):579-592, Sept. 1992.

[21] CHAKRON, N.; FINK, M. ; WU, F. Time reversal processing in ultrasonic nondestructive testing. IEEE Transactions on Ultrasonics, Ferroelectrics, and Frequency Control, 42(6):1087-1098, Nov. 1995.

[22] PRADA, C.; KERBRAT, E.; CASSEREAU, D. ; FINK, M. Time reversal techniques in ultrasonic nondestructive testing of scattering media. Institute os Physics Publishing, Inverse Porblems, 18:1761-1773, 2002 .

[23] FINK, M.; PRADA, C.; CASSEREAU, D. ; KERBRAT, E. Time reversal techniques in non destructive testing. In: EUROPEAN CONGRESS OF ACOUSTICS, 2002.

[24] CHAMBER, D. H. Analysis of the time-reversal operator for scatterers of finite size. Journal of the Acoustical Society of America, 112(2):411-419, Aug. 2002. 
[25] PRADA, C.; WU, F. ; FINK, M. The iterative time reversal mirror: A solution to self-focusing in the pulse echo mode. Journal of the Acoustical Society of America, 90(2):1119-1129, Aug. 1991.

[26] PRADA, C.; FINK, M. Eigenmodes of the time reversal operator: a solution to selective focusing in multiple-target media. Wave Motion, 20:151-163, 1994.

[27] PRADA, C.; THOMAS, J.-L. ; FINK, M. The iterative time reversal process: Analysis of the convergence. Journal of the Acoustical Society of America, 97(1):62-71, Jan. 1995.

[28] PRADA, C.; FINK, M. Selective focusing through inhomogeneous media: The D.O.R.T. method. IEEE Ultrasonics Symposium, 1995.

[29] MinOnZIO, J.-G.; PRADA, C.; AUBRY, A. ; FINK, M. Multiple scattering between two elastic cylinders and invariants of the time-reversal operator: Theory and experiment. Journal of the Acoustical Society of America, 120(2):875-883, Aug. 2006.

[30] PRADA, C.; TANTER, M. ; FINK, M. Flaw detection in solid with the D.O.R.T. method. IEEE Ultrasonics Symposium, 1997.

[31] KERBRAT, E.; PRADA, C.; CASSEREAU, D. ; FINK, M. Detection and imaging in complex media with the D.O.R.T. method. IEEE Ultrasonics Symposium, 2000.

[32] KERBRAT, E.; PRADA, C.; CASSEREAU, D. ; FINK, M. Multiple scattering between two elastic cylinders and invariants of the time-reversal operator: Theory and experiment. Journal of the Acoustical Society of America, 113(3):1230-1240, Mar. 2003.

[33] DEVANEY, A. J. Super-resolution processing of multi-static data using time reversal and music. Manuscrito não publicado, Disponível no endereço eletrônico: http://www.ece.neu.edu/faculty/ devaney/preprints/. Acessado em janeiro 2012, 2002.

[34] Devaney, A. J.; MAREnGO, E. A. ; GRUBER, F. K. Time-reversalbased imaging and inverse scattering of multiply scattering point targets. The Journal of the Acoustical Society of America, 118(5):31293138, Nov. 2005.

[35] DRAEGER, C.; FINK, M. One-channel time-reversal in chaotic cavities: Theoretical limits. Journal of the Acoustical Society of America, 105(2):611-617, 1999.

[36] DRAEGER, C.; AIME, J.-C. ; FINK, M. One-channel time-reversal in chaotic cavities: Experimental results. Journal of the Acoustical Society of America, 105(2):618-625, 1999. 
[37] MONTALDO, G.; PÉREZ, N.; NEGREIRA, C. ; FINK, M. The spatial focusing of a leaky time reversal chaotic cavity. Waves in Random and Complex Media, 17(1):67-83, 2007.

[38] PÉREZ, N.; MONTALDO, G. ; NEGREIRA, C. Spatial focalization using temporal inversion in chaotic cavities: influence of surface roughness. In: ULTRASONICS SYMPOSSWEETHEARTIUM, 2005 IEEE, volume 4, p. 2255 - 2258, sept. 2005.

[39] ROUX, P.; ROMAN, B. ; FINK, M. A. Time-reversal in an ultrasonic waveguide. Applied Physics Letters, 70(April):1811-1813, 1997.

[40] ING, R. K.; FINK, M. Self-focusing and time recompression of lamb waves using a time reversal mirror. Ultrasonics, 36(1):179-186, 1998.

[41] KERBRAT, E.; ING, R. K.; PRADA, C.; CASSEREAU, D. ; FINK, M. The D.O.R.T. method applied to detection and imaging in plates using lamb waves. In: AIP CONFERENCE PROCEEDINGS,REVIEW OF PROGRESS IN QUANTITATIVE NONDESTRUCTIVE EVALUATION: VOLUME 20., volume 557, p. 934-940, 2001.

[42] WANG, C. H.; ROSE, J. T. ; CHANG, F.-K. A computerized timereversal method for structural health monitoring. In: PROCEEDINGS OF SPIE CONFERENCE ON SMART STRUCTURES AND NDE, SAN DIEGO, CA, USA, 2003.

[43] PARK, H. W.; SOHN, H.; LAW, K. H. ; FARRARD, C. R. Time reversal active sensing for health monitoring of a composite plate. Journal of Sound and Vibration, 302:50-66, 2007.

[44] PARK, H. W.; KIM, S. B. ; SOHN, H. Understanding a time reversal process in lamb wave propagation. Wave Motion, 46:451-497, 2009.

[45] ROSE, L. R. F.; WANG, C. H. Mindlin plate theory for damage detection: Source solutions. Journal of the Acoustical Society of America, 116:154-171, 2004.

[46] OPPENHEIM, A. V.; WILlSKY, A. S. ; HAMID, S. Signals and Systems. Pretice Haal, 1996.

[47] PÉREZ, N.; MELlO, P.; ADAMOWSKI; CEZAR, J. ; NEGREIRA, C. Frequency domain identification of time reversal process in acoustic cavities. In: INTERNATIONAL CONGRESS ON ULTRASONICS ICU 2009, SANTIAGO DE CHILE. PROCEEDINGS OF INTERNATIONAL CONGRESS ON ULTRASONICS ICU, 2009.

[48] BARNETT, A. H. Greens functions for the wave equation, 2006. Disponível no endereço eletrônico: http://www.math.dartmouth.edu/ $\sim$ ahb/notes/waveequation.pdf. Acessado em junho 2012. 
[49] ALlEYNE, D.; PIALUCHA, T. ; CAWLEY, P. A signal regeneration technique for long-range propagation of dispersive lamb waves. Ultrasonics, 31(3):201-204, 1993.

[50] TANTER, M.; THOMAS, J. L. ; FINK, M. Time reversal and the inverse filter. Journal of the Acoustical Society of America, 30(2):223$234,2000$.

[51] TANTER, M.; AUBRY, J. F.; GERBER, J.; THOMAS, J. L. ; FINK, M. Optimal focusing by spatio-temporal inverse filter. I. Basic principles. The Journal of the Acoustical Society of America, 110(1):3747, July 2001.

[52] AUBRY, J. F.; TANTER, M.; GERBER, J.; THOMAS, J. L. ; FINK, M. Optimal focusing by spatio-temporal inverse filter. II. Experiments. Application to focusing through absorbing and reverberating media. The Journal of the Acoustical Society of America, 110(1):48-58, July 2001.

[53] LECOEUR ELECTRONIQUE. Open system. Disponível no endereço eletrônico: http://www.lecoeur-electronique.com. Acessado em março 2012.

[54] LECOEUR ELECTRONIQUE. Open system - user guide for matlab interface, July 2007. Disponível no endereço eletrônico: http://www.lecoeur-electronique.net/cariboost_files/user_ 2/s_20gulde_20tor_20matlab_201ntertace_20r4.pdt. Acessado em março 2012.

[55] MATHWORKS. Mathworks r2012a documentation - matlab, 2012. Disponível no endereço eletrônico: http://www.mathworks.com/help/ techdoc/. Acessado em junho 2012.

[56] OLYMPUS NDT. Panametrics - ultrasonic transducers - wedges, cables, test blocks. Disponível no endereço eletrônico: http://www. olympus-ims.com/data/File/panametrics/panametrics-UT.en.pdf. Acessado em março 2012.

[57] CRAIG, J. Electrical resistance strain gage circuits, 2000. Georgia Tech, AE3145. Disponível no endereço eletrônico: http://soliton.ae.gatech.edu/people/jcraig/classes/ae3145/ Lab2/strain-gages.pdf. Acessado em junho 2012.

[58] ANALOG DEVICES. Analog devices AD620 - low cost low power instrumentation amplifier, 2011. Disponível no endereço eletrônico: http://wwW.analog.com/static/imported-files/ data_sheets/AD620.pdf. Acessado em junho 2012. 